\title{
EFEITOS DA ESTIMULAÇÃO ELÉTRICA NEUROMUSCULAR DO QUADRÍCEPS SOBRE AS VARIÁVEIS CARDIO-RESPIRATÓRIAS EM PORTADORES DE LESÃO MEDULAR
}

\section{Fernanda Rossi Paolillo}

Dissertação apresentada ao Programa de PósGraduação Interunidades em Bioengenharia - Escola de Engenharia de São Carlos / Faculdade de Medicina de Ribeirão Preto / Instituto de Química de São Carlos - da Universidade de São Paulo, para obtenção do Título de Mestre em Bioengenharia.

Orientador: Prof. Dr. Alberto Cliquet Jr. 


\section{FOLHA DE APROVAÇÃO}

Tese defendida e aprovada em

pela comissão julgadora:

(Assinatura)

(Nome/Instituição)

(Assinatura)

(Nome/Instituição)

(Assinatura)

(Nome/Instituição)

(Assinatura)

(Nome/Instituição)

(Assinatura)

(Nome/Instituição) 


\section{DEDICATÓRIA}

Ao meu filho Ricardo,

que este trabalho seja um exemplo em sua vida.

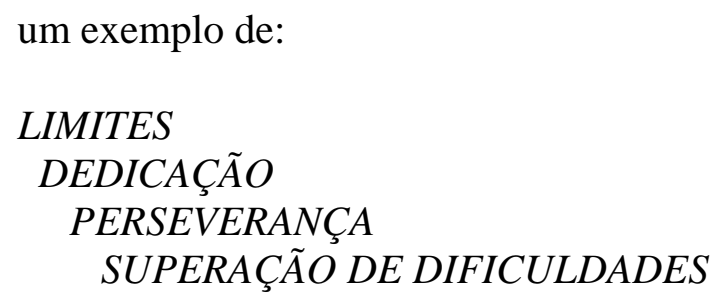

Em fim, de ALEGRIA E ESPERANÇA ... 


\section{AGRADECIMENTOS}

A TODA minha família, em especial aos meus pais, Marta e Nicola, pela minha vida, dedicação infinita e estímulos ao estudo.

Ao meu orientador Prof. Dr. Alberto Cliquet Jr. pela oportunidade e privilégio de ser sua aluna. Pelo exemplo de pessoa e profissional. Pela confiança e encaminhamento profissional.

Ao Prof. Dr. Luiz Eduardo Barreto Martins pela amizade, paciência e apoio científico durante toda a realização deste trabalho.

Ao Jarbas, pelo nosso filho Ricardo, pelo apoio, amizade, carinho e por entender meus momentos de ausência para conclusão deste trabalho.

A minha irmã, Alessandra, pelo acompanhamento em todo trabalho, inclusive nas longas e longas madrugadas, nas viagens e viagens para Campinas, ...

Pelos pacientes e seus familiares, o que sem eles não seria possível a realização deste trabalho. Além da lição de vida ...

Ao Programa Interunidades Bioengenharia e ao Departamento de Engenharia Elétrica da USP, São Carlos. Ao Prof. Dr. José Carlos Pereira, Janete e Melaine pela organização burocrática do mestrado. A todos os Professores e Técnicos de Laboratório pelo incentivo aos estudos. Pela amizade e apoio de Rosane, Xaraba, José Carlos, Marisa, Denise, Jussara, Cida, Áurea, Kely e em especial ao Valdir pelo desenvolvimento do projeto da mesa para o cicloergômetro de braço.

Ao Departamento de Ortopedia e Traumatologia da FCM/UNICAMP.

Aos amigos do Departamento de Educação Física da UFSCar pelo estímulo para realização deste trabalho, em especial a Prof ${ }^{\mathrm{a}}$. Dr ${ }^{\mathrm{a}}$. Paula Hentschel Lobo da Costa, Prof ${ }^{\mathrm{a}}$. Ms. Selva Barreto, Prof ${ }^{\mathrm{a}}$. Dr ${ }^{\mathrm{a}}$. Ana Cláudia Duarte e Prof $^{\mathrm{a}}$. Dr ${ }^{\mathrm{a}}$. Ana Damaso pela amizade e longas conversas nos momentos difíceis.

A todos, todos, sem exceção, a todos os meus amigos do LABCIBER (USPSão Carlos) e do Laboratório de Biomecânica e Reabilitação do Aparelho Locomotor (UNICAMP), pela amizade, colaboração e grandes momentos de convivência.

A amiga Marcela Sene por todo suporte ! financeiro.

A FAPESP (Processo $n^{\circ}$ 96/12198-2) e CAPES pelo apoio e suporte 


\section{RESUMO}

O objetivo desta pesquisa foi investigar as variáveis cardio-respiratórias (Pa, FC, $\mathrm{VO}_{2}, \mathrm{VCO}_{2}$ e $\mathrm{Ve}$ ) durante a Estimulação Elétrica Neuromuscular (EENM) do quadríceps em portadores de lesão medular. Participaram da pesquisa dez pacientes (cinco paraplégicos e cinco tetraplégicos) e um sujeito saudável voluntário padrão. O protocolo do teste consistiu em 10 minutos de repouso, 20 minutos de EENM dos quadríceps e 10 minutos de recuperação. O sujeito saudável realizou o mesmo procedimento, entretanto, os movimentos de flexão/extensão dos joelhos foram realizadas de maneira voluntária. Durante a EENM foram constatados baixos valores de $\mathrm{VO}_{2}$ e $\mathrm{VCO}_{2}$, lenta cinética dos gases e valores alterados de $\mathrm{Po}_{2}$ e $\mathrm{Pco}_{2}$, em outros casos foi constatada a rápida cinética dos gases. Houve o aumento da Pa sistólica e da FC, entretanto em alguns pacientes observaram-se limitações na resposta da FC. Portanto, os pacientes apresentaram algumas limitações nas respostas cardiorespiratórias, indicando realização de exercício exaustivo, mas apresentaram capacidade de realização de exercício induzido artificialmente, possivelmente devido aos benefícios da EENM. 


\begin{abstract}
The objective of this research was to evaluate cardiorespiratory responses (Heart Rate, Blood Pressure, $\mathrm{VO}_{2}, \mathrm{VCO}_{2}$ e Ve) to Neuromuscular Electrical Stimulation (NMES) of the quadriceps in patients with spinal cord injury. Ten patients (five paraplegics and five tetraplegics) and one healthy subject participated in this study. The protocol of the test consisted of ten minutes of rest, twenty minutes of NMES of the quadriceps and ten minutes of recovery. However, the healthy subject performed the voluntary movement of knee flexion and extension. The findings in this study indicated that patients during NMES demostrated low values of $\mathrm{VO}_{2}$ e $\mathrm{VCO}_{2}$, slow gas kinetics and altered values of $\mathrm{Po}_{2}$ and $\mathrm{Pco}_{2}$, on the others cases, the fast kinetics of the gas was verified. Moreover, there were increases in blood pressure and heart rate. Nevertheless, for some patients, heart rate response limitations were observed. Therefore, the patients presented some limitations in the cardiorespiratory responses, indicating performance of exhaustive exercise, but the use of NMES can elicit improvements in exercise tolerance due to its benefits.
\end{abstract}




\section{LISTA DE FIGURAS}

FIGURA 1 - Diagnóstico de siringomielia por imagem de ressonância magnética..20 FIGURA 2 - Organização anatômica das vias na medula espinhal............................25 FIGURA 3 - Paraplégico realizando o treinamento da marcha através de EENM (a) e utilizando o sistema híbrido - EENM e KAFO (b) .39

FIGURA 4 - Procedimento experimental em pacientes com paraplegia (a) e tetraplegia (b).

FIGURA 5 - Variáveis cardio-respiratórias do paciente 1 durante o repouso, EENM e recuperação: cinética dos gases (a); $\mathrm{Po}_{2}$ e $\mathrm{Pco}_{2}$ (b); resposta da FC (c).

FIGURA 6 - Variáveis cardio-respiratórias do paciente 2 durante o repouso, EENM e recuperação: cinética dos gases (a); $\mathrm{Po}_{2}$ e $\mathrm{Pco}_{2}$ (b); resposta da FC (c).

FIGURA 7 - Variáveis cardio-respiratórias do paciente 3 durante o repouso, EENM e recuperação: cinética dos gases (a); $\mathrm{Po}_{2}$ e $\mathrm{Pco}_{2}$ (b); resposta da FC (c).

FIGURA 8 - Variáveis cardio-respiratórias do paciente 4 durante o repouso, EENM e recuperação: cinética dos gases (a); $\mathrm{Po}_{2}$ e $\mathrm{Pco}_{2}$ (b); resposta da $\mathrm{FC} \mathrm{(c)..................66}$ FIGURA 9 - Variáveis cardio-respiratórias do paciente 5 durante o repouso, EENM e recuperação: cinética dos gases (a); $\mathrm{Po}_{2}$ e $\mathrm{Pco}_{2}$ (b); resposta da $\mathrm{FC} \mathrm{(c).}$

FIGURA 10 - Variáveis cardio-respiratórias do paciente 6 durante o repouso, EENM e recuperação: cinética dos gases (a); $\mathrm{Po}_{2}$ e $\mathrm{Pco}_{2}$ (b); resposta da $\mathrm{FC} \mathrm{(c).}$ 68 FIGURA 11 - Variáveis cardio-respiratórias do paciente 7 durante o repouso, EENM e recuperação: cinética dos gases (a); $\mathrm{Po}_{2}$ e $\mathrm{Pco}_{2}$ (b); resposta da $\mathrm{FC} \mathrm{(c)...}$

FIGURA 12 - Variáveis cardio-respiratórias do paciente 8 durante o repouso, EENM e recuperação: cinética dos gases (a); $\mathrm{Po}_{2}$ e $\mathrm{Pco}_{2}$ (b); resposta da $\mathrm{FC} \mathrm{(c).....}$ 70 FIGURA 13 - Variáveis cardio-respiratórias do paciente 9 durante o repouso, EENM e recuperação: cinética dos gases (a); $\mathrm{Po}_{2}$ e $\mathrm{Pco}_{2}$ (b); resposta da $\mathrm{FC} \mathrm{(c)...................71}$ FIGURA 14 - Variáveis cardio-respiratórias do paciente 10 durante o repouso, EENM e recuperação: cinética dos gases (a); $\mathrm{Po}_{2}$ e $\mathrm{Pco}_{2}$ (b); resposta da FC (c)......72 FIGURA 15 - Procedimento experimental com o Polar (a) e ECG (b)...................100 FIGURA 16 - Cinética dos gases - pacientes 2 (a), 5 (b), 7 (c) e 10 (d) que utilizaram o Polar. 103 
FIGURA 17 - Cinética dos gases - pacientes 3 (a), 4 (b) e 6 (c), que utilizaram o Eletrocardiógrafo

FIGURA 18 - Respostas da FC com o Polar (a) e ruídos presentes nos resultados da FC (b). 108

FIGURA 19 - Sinais do ECG durante o repouso (a) e EENM (b)..........................109

FIGURA 20 - Resposta da FC, por Polar, durante a Marcha com EENM. 114

FIGURA 21 - Respostas cardio-respiratórias durante a postura ereta e marcha: cinética dos gases (a); pressão parcial de $\mathrm{O}_{2}$ e $\mathrm{CO}_{2}$ (b); resposta da FC por ECG (c)

FIGURA 22 - Respostas cardio-respiratórias durante a EENM do quadríceps: cinética dos gases (a); pressão parcial de $\mathrm{O}_{2}$ e $\mathrm{CO}_{2}$ (b); resposta da FC por ECG (c). 116

FIGURA 23 - Procedimento experimental com o sujeito saudável. 118

FIGURA 24 - Variáveis cardio-respiratórias do sujeito saudável durante o repouso, flexão e extensão do joelho e recuperação: cinética dos gases (a); $\mathrm{Po}_{2}$ e $\mathrm{Pco}_{2}$ (b); resposta da FC (c)

FIGURA 25 - Procedimento experimental em neurofisiologia (a) e atividade muscular do grupo flexor do punho direito do paciente 10 sem e com a EENM (b). 


\section{LISTA DE TABELAS}

TABELA 1 - Perfil dos portadores de lesão medular participantes da pesquisa........50

TABELA 2 - Altura e massa corpórea dos pacientes...............................................51

TABELA 3 - Média e desvio padrão das variáveis cardio-respiratórias durante o repouso, EENM e recuperação em paraplegia..............................................................73

TABELA 4 - Média e desvio padrão das variáveis cardio-respiratórias durante o repouso, EENM e recuperação em tetraplegia.........................................................74 TABELA 5 - Média e desvio padrão das varáveis cardio-respiratórias durante o repouso, regime permanente e recuperação, com FC monitorada por Polar..... .105 TABELA 6 - Média e desvio padrão das variáveis cardio-respiratórias durante o repouso e recuperação. Valores iniciais e de pico do aumento linear durante a EENM e FC monitorada por Polar. 106

TABELA 7 - Média e desvio padrão das variáveis cardio-respiratórias durante o repouso e recuperação. Valores iniciais e de pico do aumento linear durante a EENM e FC registrada por ECG.

TABELA 8 - Valores de pico da FC obtidos por paraplégicos e tetraplégicos durante a marcha com EENM 111

TABELA 9 - Média e desvio padrão das variáveis cardio-respiratórias durante o repouso, exercício de flexão/extensão de joelhos e recuperação - sujeito saudável..... 119 


\section{ABREVIAÇÕES E SIGLAS}

Além das abreviações e siglas, também são apresentadas algumas expressões técnicas utilizadas.

- ACTH: Adrenocorticotrofina

- ASIA: Escala de Deficiência da American Spinal Injury Association

- ATP: Adenosina Trifosfato

- BTPS: Temperatura Corporal, Pressão (760 mmHg) e Saturação no Vapor d’água

- $\quad$ Burst: trens de pulso

- COI: Comitê Olímpico Internacional

- CPG: Central Pattern Generator (Gerador de Padrão Central)

- DHEA: Deidrospiandrosterona

- DS: Sulfato Deidrospiandrosterona

- ECG: Eletricardiograma

- EENM: Estimulação Elétrica Neuromuscular

- EPOC: Excesso Post-Exercise Oxygen Consuption

- FC: Freqüência Cardíaca

- Feed-Forward: sistema de controle, alimentação.

- Feedback positivo/negativo: sistemas de controle, retroalimentação negativa/positiva

- Fibra muscular tipo I: fibra vermelha, com característica oxidativa, de contração lenta e baixa fadigabilidade.

- Fibra muscular tipo II: fibra branca, com característica glicolítica, de contração rápida e alta fadigabilidade.

- Fibra Muscular tipo IIa e IIax: fibras mistas, com características glicolíticas e oxidativas.

- FIM: Functional Independence Measure, índice de independência funcional

- GLUT 4: proteína transportadora de glicose

- HKAFO: Hip- Knee-Ankle-Foot

- HGO: Hip Guindance Orthoses

- H-Reflexo: Reflexo de Hoffmann 
- Input: sinal de entrada

- ISMGF: International Stoke Mandeville Games Federation

- ISMWSF: International Stoke Mandeville Wheelchair Sports Federation

- Intervalo BxB (Breath-Breath): registros de respiração à respiração

- Intervalo R-R (Rate-Rate): registros de freqüência à frenqüência cardíaca

- KAFO: Knee-Ankle-Foot

- NMDA: N-Methyl-D-Aspartate

- OTG: Órgão Tendinoso de Golgi

- Pa: Pressão Arterial

- $\quad \mathrm{PCO}_{2}$ : Pressão Parcial de Dióxido de Carbono

- PCr: fosfocreatina

- $\quad \mathrm{Po}_{2}$ : Pressão Parcial de Oxigênio

- PRL: Prolactina

- RNAm: expressões dos genes de proteínas

- SNC: Sistema Nervoso Central

- Steady-State: regime permanente

- STPD: Temperatura Padrão, Pressão $(760$ mmHg) e Sem Saturação no vapor d’água

- TN-C: Sítio de Ligação da Troponina com o Cálcio

- $\quad \mathrm{VCO}_{2}$ : Produção de Dióxido de Carbono

- Ve: Ventilação Minuto

- $\quad \mathrm{VO}_{2}$ : Consumo de Oxigênio

- UCP, UCP2 e UCP: uncoupling proteins

- 4 AP: Amino Piridina, bloqueador de $\mathrm{K}^{+}$

- 5-HT: Serotonina 


\section{SUMÁRIO}

\section{PREFÁCIO}

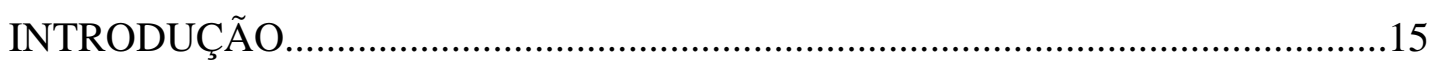

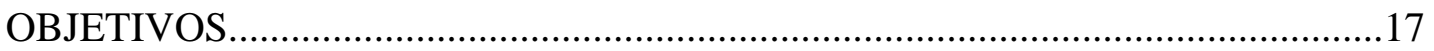

CAPÍTULO 1 .18

1.0 ASPECTOS FISIOLÓGICOS DOS PORTADORES DE LESÃO MEDULAR.18

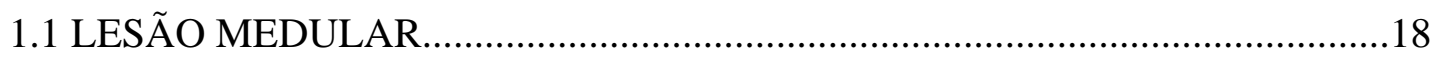

1.2 SEQÜELAS DA LESÃO MEDULAR E SUAS IMPLICAÇÕES NA ATIVIDADE MOTORA

1.2.1 DISFUNÇÕES DECORRENTES DA AUSÊNCIA DE CARGA

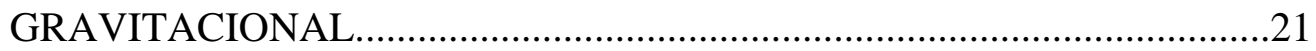

1.2.2 DISFUNÇÃO HORMONAL E METABÓLICA....................................22

1.2.3 DISFUNÇÃO CARDIO-RESPIRATÓRIA..........................................23

1.2.4 DISFUNÇÃO AUTONÔMICA...........................................................24

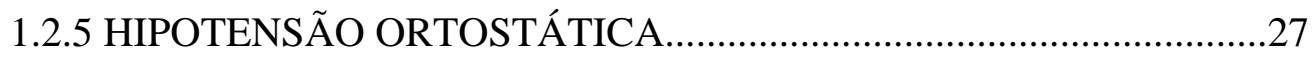

1.2.6 HIPOTENSÃO DURANTE O EXERCÍCIO.........................................28

1.2.7 TERMORREGULAÇÃO..................................................................29

1.2.8 DISREFLEXIA AUTONÔMICA...............................................................

1.3 ATIVIDADE FÍSICA, RECREAÇÃO E ESPORTE COMPETITIVO..................32

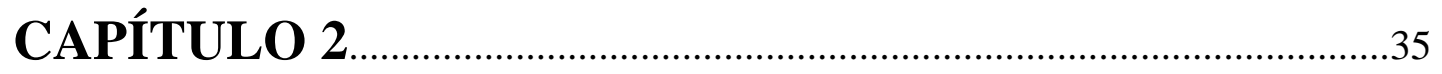

2.0 ESTIMULAÇÃO ELÉTRICA NEUROMUSCULAR..........................................35

2.1 INTERFACE HOMEM-MÁQUINA..................................................................36

2.1.2 EXERCÍCIO INDUZIDO POR ESTIMULAÇÃO ELÉTRICA NEUROMUSCULAR 
2.1.3 PADRÕES RÍTMICOS LOCOMOTORES E PLASTICIDADE NEURAL EM PORTADORES DE LESÃO MEDULAR............................44 2.2 ADAPTAÇÕES FISIOLÓGICAS AO TREINAMENTO ATRAVÉS DE ESTIMULAÇÃO ELÉTRICA NEUROMUSCULAR 43

CAPÍTULO 3 .47

3.0 FISIOLOGIA DO EXERCÍCIO: ASPECTOS BIOENERGÉTICOS. .47

CAPÍTULO 4 .49

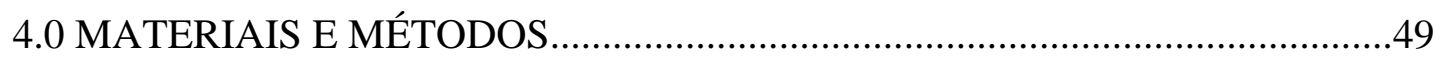

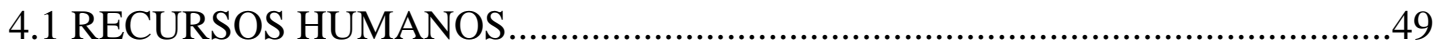

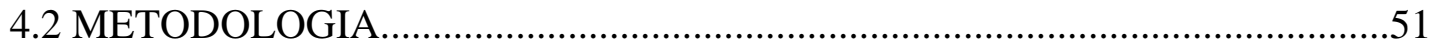

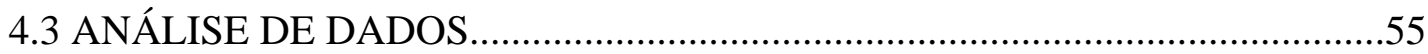

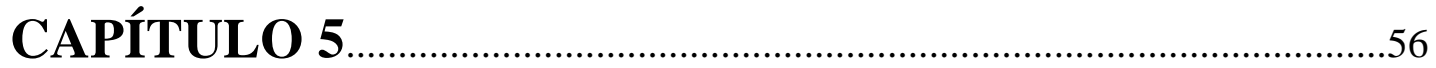

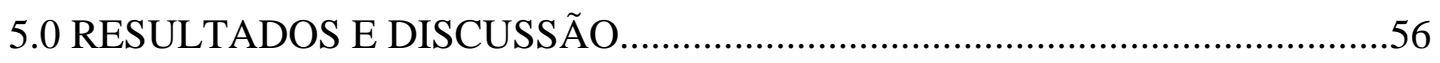

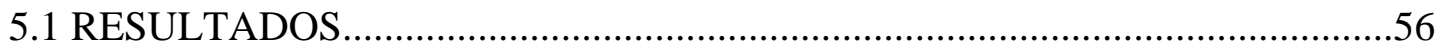

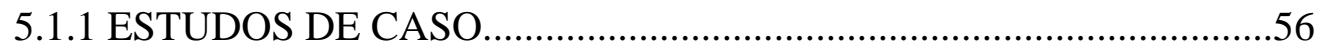

5.1.2_RESULTADOS COM OS VALORES BRUTOS DOS PACIENTES PARAPLÉGICOS E TETRAPLÉGICOS.............................................................63

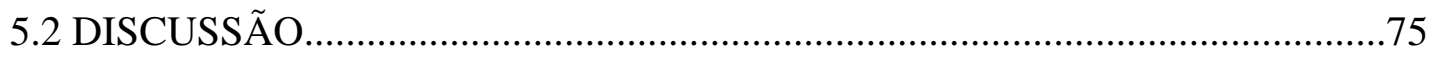

5.2.1 RESPOSTAS CARDIO-RESPIRATÓRIAS À ESTIMULAÇÃO ELÉTRICA NEUROMUSCULAR DO QUADRICEPS. 
APÊNDICE A - O ESTUDO PILOTO: POLAR OU ECG? UMA QUESTÃO METODOLÓGICA

APÊNDICE B - INFORMAÇÕES COMPLEMENTARES REFERENTES AOS ESTUSDOS DE CASO

APÊNDICE C - REsultados do Sujeito SAudÁVEL

APÊNDICE D - REFLEXOS INTERMEMBROS EM TETRAPLEGIA

ANEXO A - TERMO DE CONSENTIMENTO PÓS - INFORMAÇÃO

ANEXO B - PROTOCOLOS ASIA E FIM 


\section{INTRODUÇÃO}

Durante a execução de um exercício, os sistemas fisiológicos que estão mais diretamente envolvidos são os Sistemas Muscular, Cardiovascular e Respiratório. A imposição de uma atividade física controlada permite quantificar a funcionalidade destes sistemas. A quantificação da capacidade de realização de atividade física evidencia, de forma indireta, a reserva funcional dos sistemas cardio-respiratório, muscular e metabólico, em especial pelo consumo de oxigênio e produção de ácido lático muscular durante o exercício físico. Portanto, as avaliações funcionais são utilizadas para quantificar a performance, ou seja, o desempenho do sistema fisiológico diante do estresse de um esforço físico pré-estabelecido.

Estas avaliações são de grande importância para diversas populações, como para portadores de patologias respiratórias (SHERMAN, MATITYAHU \& CAMPBELL, 1996) e cardíacas (MEYER et al., 1996), sendo relevantes para o diagnóstico e acompanhamento durante o período de reestabelecimento. Para os atletas viabiliza o controle do treinamento e os resultados do desempenho (MEYER, GABRIEL \& KINDERMANN, 1999).

As avaliações fisiológicas também são imprescindíveis para os portadores de lesão medular, pois possibilitam o diagnóstico, evolução e controle do processo de reabilitação para favorecer sua saúde e seu estado funcional, fornecem ainda dados para o desenvolvimento e aperfeiçoamento de instrumentação biomédica para reabilitação.

Além da disfunção física e sensorial, várias são as seqüelas da lesão medular, por exemplo, atrofia do sistema músculo-esquelético, espasticidade, hiperreflexia ou 
hiporreflexia do Sistema Nervoso Autônomo (HANDA, 1997), mudanças metabólicas, hormonais e neuromusculares (EDGERTON et al., 2000), redução da capacidade respiratória, da circulação sangüínea e das dimensões das estruturas cardíacas, que juntamente com o estado sedentário podem conduzir a doenças cardiovasculares e respiratórias (SMITH et al., 2001); (HUONKER et al., 1998). Estas alterações limitam as respostas fisiológicas à atividade motora, podendo ocorrer a rápida instalação da fadiga (DALLMEIJER et al., 1999).

Ainda, as respostas fisiológicas basais e durante a atividade motora dependem, por exemplo, do nível/tempo de lesão medular e tipo de reabilitação realizada, necessitando-se de maiores investigações.

Pesquisadores têm otimizado várias técnicas de reabilitação que podem prevenir/minimizar/reverter algumas seqüelas decorrentes da lesão medular, como a Estimulação Elétrica Neuromuscular (EENM), o uso de ergômetros de braço (BROWN et al., 2001) e o Sistema de Suspensão Corpórea (KOJIMA, NAKAZAWA \& YANO, 1999).

A Estimulação Elétrica Neuromuscular é uma técnica alternativa para a restauração e/ou recuperação das funções motoras perdidas através da ativação artificial dos músculos esqueléticos (HANDA, 1997); (TEPAVAC \& SCHWIRTLICH, 1997). O exercício induzido artificialmente no quadríceps, em portadores de lesão medular, é realizado na fase inicial do Programa de Reabilitação da Marcha através de EENM, pois o músculo quadríceps é o principal atuador durante a postura ereta e o andar. Assim, é importante avaliar os efeitos da EENM do quadríceps sobre as variáveis cardio-respiratórias em paraplégicos e tetraplégicos.

Desta forma, a Bioengenharia, mais especificamente a Engenharia de Reabilitação, desenvolve estratégias para otimizar a interface homem-máquina, através de equipes multidisciplinares, convergindo para a melhora da qualidade de vida dos portadores de deficiência sensório-motora. 


\section{OBJETIVO GERAL}

Investigar as variáveis cardio-respiratórias - Pressão Arterial (Pa), Freqüência Cardíaca (FC), Consumo de Oxigênio $\left(\mathrm{VO}_{2}\right)$, Produção de Dióxido de Carbono $\left(\mathrm{VCO}_{2}\right)$, Ventilação Minuto (Ve), Pressão Parcial de Oxigênio $\left(\mathrm{Po}_{2}\right)$, Pressão Parcial de Dióxido de Carbono $\left(\mathrm{PcO}_{2}\right)$ - durante a EENM do quadríceps em portadores de lesão medular.

\section{OBJETIVOS ESPECÍFICOS}

1. Verificar se os portadores de lesão medular apresentam limitações às respostas cardio-respiratórias durante a EENM do quadríceps.

2. Avaliar a capacidade de realização de exercício durante a EENM do quadríceps. 


\section{CAPÍtULO 1}

\subsection{ASPECTOS FISIOLÓgICOS DOS PORTADORES DE LESÃO MEDULAR}

Após a lesão medular as respostas fisiológicas basais e durante a atividade motora estão relacionadas com a etiologia/tipo/nível/tempo de lesão, faixa etária, sexo, tipo de reabilitação realizada e nível de atividade física.

\subsection{LESÃO MEDULAR}

A lesão medular, caracterizada por disfunção física e sensorial, inclui várias classificações do estado neurológico do paciente, ou seja, o termo tetraplegia é definido como a redução ou perda da função motora e/ou sensorial dos segmentos cervicais da medula espinhal, o termo paraplegia refere-se a redução ou perda da função motora e/ou sensorial dos segmentos torácicos, lombares ou sacrais da medula espinhal. Lesão incompleta é um termo usado para descrever a preservação parcial da função motora ou sensorial abaixo do nível neurológico. Lesão completa refere-se a perda total da função motora e sensorial no segmento sacral mais baixo. "Zona de preservação parcial” só se refere aos pacientes com lesão completa, nos quais os dermátomos e miotómos distais ao nível neurológico permanecem parcialmente inervados (BARROS FILHO et al., 1994). 
Várias são as causas da lesão medular, ou seja, por diversas patologias, como tumores, má formação congênita, hérnia de disco, acidentes vasculares, infecções causadas por vírus ou bactéria; por acidentes envolvendo automóveis, bicicletas, atropelamento e quedas; em conseqüência da violência através de armas de fogo ou armas brancas e, outros decorrentes de acidentes no trabalho, nos esportes ou atividades de lazer, como equitação, hóquei, mergulho, surf, esqui, futebol, vôo de para-quedas, salto de asa-delta e vários outros esportes radicais de extrema velocidade na terra e no ar (BELANGER \& LEVI, 2000); (SEKHON \& FEHLINGS, 2001); (www.sarah.br).

A lesão primária é definida como o mecanismo inicial da lesão. Ocorre imediatamente após o acidente e pode resultar em contusão, hemorragia, rompimento e laceração da medula (BELANGER \& LEVI, 2000); (SEKHON \& FEHLINGS, 2001).

A lesão secundária é caracterizada por processos celulares e bioquímicos em cascata, que são iniciados pelo mecanismo primário e podem causar contínuo dano e morte celular, resultando em efeitos sistêmicos (alterações na freqüência cardíaca, pressão arterial, termorregulação), mudança vascular local (perda da autorregulação da microcirculação, hemorragia, trombose), mudanças bioquímicas (acúmulo de neurotransmissor, produção de radicais livres, peroxidação lipídica, redução do metabolismo energético), mudanças eletrolíticas (redução na concentração celular de sódio, potássio e cálcio), edema, apoptose, entre outros (SEKHON \& FEHLINGS, 2001).

\subsection{SEQÜELAS DA LESÃO MEDULAR E SUAS IMPLICAÇÕES NA ATIVIDADE MOTORA}

As seqüelas após a lesão medular são fatores limitantes durante a atividade motora. Entretanto, o treinamento físico pode gerar benefícios aos portadores de lesão medular, prevenindo, minimizando e até revertendo algumas seqüelas. 
A siringomielia (FIGURA 1) é caracterizada pela concentração local anormal de fluído céfalo-raquidiano na medula espinhal, o fator inicial pode ser um aumento na resistência local deste fluxo, causada por fibrose, deformidade espinhal e compressão dural (BELANGER \& LEVY, 2000). Esta patologia restringe ainda mais a atividade motora, pois o esforço físico também pode gerar aumento da resistência deste fluído, aumentando o nível de lesão (ASANO et al., 1996).

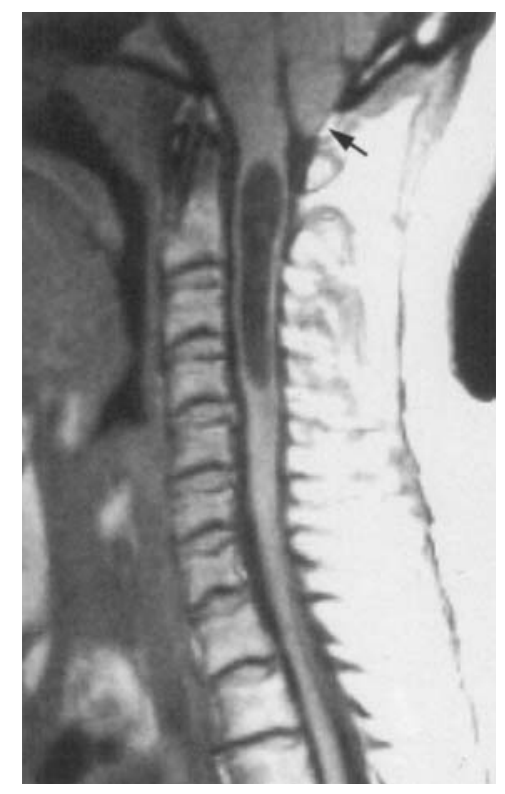

FIGURA 1 - Diagnóstico de siringomielia por imagem de ressonância magnética.

A espasticidade é uma desordem motora caracterizada pelo aumento dependente da velocidade do tônus muscular (hiperatividade do reflexo de estiramento tônico) em indivíduos que apresentam lesão no neurônio motor superior. O termo também inclui características associadas ao reflexo tendíneo exagerado, clônus e espasmo flexor, podendo resultar em dor, distúrbios posturais e contraturas permanentes (BELANGER \& LEVI, 2000); (DUNE, HEYE \& DUNE, 1995). Portanto, pode interferir no controle do movimento durante a atividade motora (ROGERS, 2002). 
Outro fator que acomete o sistema fisiológico dos portadores de lesão medular é a ausência de carga gravitacional.

\subsubsection{DISFUNÇÕES DECORRENTES DA AUSÊNCIA DE CARGA GRAVITACIONAL}

A Engenharia Espacial estuda os princípios da ausência de carga, enfatizando as pesquisas sobre a interação dos portadores de lesão medular com a biologia gravitacional, além do desenvolvimento de novas técnicas de instrumentação biomédica, avaliações fisiológicas e biomecânicas (EDGERTON et al., 2000).

Recentes descobertas relacionadas ao prolongado período de permanência na cama ou cadeira de rodas e em vôo espacial, implicam em diversas seqüelas, como a osteopenia/osteoporose decorrente da ausência de cargas gravitacionais. Ainda, o balanço negativo de cálcio gerado por alterações no seu metabolismo (perda de cálcio pela urina/fezes e diminuição de sua absorção) causam redução na densidade mineral óssea e aumento dos marcadores bioquímicos de reabsorção, que juntamente com a diminuição da força e da atividade muscular tornam o osso suscetível a fraturas (BLOOMFIELD, 1997); (DEC, SPARROW \& McKEAG, 2000). Então, para que haja o remodelamento ósseo, a presença de cargas no sistema músculoesquelético, principalmente nos membros inferiores, é essencial para a prevenção e tratamento da osteoporose por desuso (CARVALHO, CARVALHO \& CLIQUET Jr., 2001).

Também ocorrem mudanças estruturais e bioquímicas no músculo esquelético, que geram redução da massa, volume e força muscular, que juntamente com o reduzido transporte e utilização de oxigênio, aumentam a fadigabilidade. Tais alterações são caracterizadas pela redução de enzimas oxidativas (desidrogenase succinate), no fenotipo da miosina com predominância de fibras rápidas (tipo II) em comparação com as lentas (tipo I) e perda de mionúcleos (EDGERTON et al., 2000).

Embora, os portadores de lesão medular apresentem essas alterações musculares desde a fase aguda da lesão (CASTRO et al., 1999), a plasticidade 
muscular pode ocorrer, por exemplo a transformação do tipo de fibra II para I, e são mais evidentes naqueles que realizam treinamento sistematizado (HARTKOPP et al., 1999); (HUONKER et al., 1998); (SCHANTZ et al., 1997).

Além de alterações estruturais e bioquímicas no sistema músculo-esquelético, também podem ocorrer mudanças neuromusculares, como alterações no recrutamento de unidades motoras mediado por vias supraespinhais e sensóriasmotoras, bem como mudanças na modulação neural da função endócrina, o que explica a relação entre ausência de carga e resposta atrófica, pois não há ativação dos proprioceptores musculares, por exemplo o fuso muscular e os Órgãos Tendinoso de Golgi (OTG), responsáveis por estimular a liberação do hormônio do crescimento da glândula pituitária (EDGERTON et al., 2000).

Além do comprometimento na liberação do hormônio do crescimento, outras alterações hormonais e metabólicas podem ocorrer.

\subsubsection{DISFUNÇÃO HORMONAL E METABÓLICA}

O sistema neuroendócrino é um grande regulador das reações imune/inflamatória. Portadores de lesão medular podem apresentar padrões hormonais alterados dependendo do nível de lesão.

Os hormônios adrenais, como o sulfato deidrospiandrosterona (DS) e seu metabólito ativo, deidrospiandrosterona (DHEA) mantêm o sistema imune íntegro, além da importante contribuição do cortisol na imunidade celular. A glândula adrenal é controlada pela pituitária, cujos produtos adrenocorticotrofina (ACTH) e a prolactina (PRL) podem apresentar efeitos diretos na imunidade. Ao investigar a função da pituitária e adrenal em portadores de lesão medular, constatou-se que o ACTH, PRL e cortisol não apresentaram alterações significativas. Entretanto, o DHEA e o DS foram elevados nos tetraplégicos comparados aos paraplégicos e ao grupo controle. Este aumento nos níveis hormonais pode ser decorrente da resposta neuro-hormonal compensatória decorrente da baixa imunidade. Estes dados são importantes para intervenção e prevenção de morte por infecção (CAMPAGNOLO et al., 1999). 
Ainda pode ser observado em indivíduos com lesão medular, o desequilíbrio da taxa metabólica e mudanças na composição corporal, com redução da massa muscular e aumento do percentual de gordura, que juntamente com o estado sedentário podem resultar em obesidade, diabetes mellitus (tipo II) e doenças respiratórias e cardiovasculares. A cardiopatia que ocorre com maior incidência são as doenças coronarianas (HJELTNES et al., 1999); (JEAN et al., 2003); (MOHR et al., 2001).

\subsubsection{DISFUNÇÃO CARDIO-RESPIRATÓRIA}

Os portadores de lesão medular podem apresentar atrofia do miocárdio e diminuição da função cardíaca, que é gerada pela redução do débito cardíaco e do volume sistólico devido a reduzida carga crônica de pressão ventricular, segundo a lei de Frank Starling (ROGERS, 2002).

Portadores de lesão medular podem apresentar redução das dimensões cardíacas em comparação com indivíduos saudáveis e não treinados, devido a redução da massa muscular ativa, função vascular alterada, disfunção autonômica e redução drástica da atividade física (SCHMID et al, 1998 a).

Entretanto, atletas paraplégicas de elite (jogadoras de basquetebol em cadeira de rodas) apresentaram aumento total e relativo no volume cardíaco em comparação com as portadoras de lesão medular sedentárias, apresentando dimensões cardíacas semelhantes aos sujeitos saudáveis e não treinados (SCHMID et al, 1998 a).

Os atletas paraplégicos de basquetebol em cadeira de rodas apresentaram diâmetro ventricular esquerdo no final da diástole e volume sistólico ventricular esquerdo semelhantes aos indivíduos saudáveis e não treinados, enquanto os valores foram superiores quando comparados aos paraplégicos sedentários (HUONKER et al., 1998).

Constatou-se também, o aumento de massa e volume ventricular esquerdo em paraplégicos fundistas comparado ao grupo de indivíduos saudáveis e não praticantes de atividade física regular, mas não houve aumento semelhante como nos atletas corredores, embora a dimensão da câmera cardíaca e a espessura da parede do 
miocárdio não diferiram-se entre os grupos (PRICE, DAVIDOFF \& BALADY, 2000).

Ainda, observou-se o aumento na dimensão interna da artéria subclávia de paraplégicos atletas, comparados aos paraplégicos sedentários e sujeitos saudáveis sedentários, respectivamente. Entretanto, constatou-se hipotrofia da artéria femoral comum decorrente da paralisia dos membros inferiores (HUONKER et al., 1998).

Outro fator que acomete a resposta cardio-respiratória de pacientes com lesão medular é a paralisia dos músculos diafragma, intercostais e assessórios que conduzem a redução da capacidade inspiratória e a hipoventilação crônica. O acometimento da musculatura abdominal resulta na redução da expiração forçada (ROGERS, 2002).

A capacidade respiratória é diretamente proporcional à quantidade de músculos inspiratórios e expiratórios envolvidos. Portanto, indivíduos com alto nível de lesão medular apresentam valores inferiores de volumes e capacidades pulmonares, comparados aqueles com menor nível de lesão (BAYDUR, ADKINS \& MILIC-EMILI, 2001).

Portanto, pronunciadas desordens cardiovasculares, pulmonares e metabólicas em portadores de lesão medular estão intimamente relacionadas à disfunção autonômica.

\subsubsection{DISFUNÇÃO AUTONÔMICA}

O Sistema Nervoso é dividido em Central e Periférico. O Sistema Nervoso Central (SNC) é constituído pelo encéfalo e medula espinhal. O Sistema Nervoso Periférico é subdividido em aferente (conduz a informação dos receptores periféricos para o SNC) e eferente, que conduz a informação central para os músculos esqueléticos (Sistema Nervoso Somático) e para as glândulas, músculos liso e cardíaco (Sistema Nervoso Autônomo).

O Sistema Nervoso Autônomo é dividido em Sistema Nervoso Simpático e Parassimpático, seu controle ocorre por circuitos do reflexo simpático espinhal e por mecanismos mais complexos, que envolvem o tronco cerebral e a medula espinhal. 
Este sistema é regulado por informações dos receptores no organismo e modulados por centros cerebrais superiores, em especial o hipotálamo, conduzindo aos ajustes fisiológicos necessários (SCHMID et al., 1998 b). Sua atuação é essencial para a funcionalidade de vários sistemas fisiológicos durante o repouso, mudança postural e em especial durante o exercício físico. Assim, o Sistema Nervoso Simpático tem alta influência sobre a função cardiovascular, pulmonar e processos metabólicos, como a freqüência cardíaca, volume sistólico, pressão arterial, glicogenólise, glicólise e lipólise (LEGRAMANTE et al, 2001); (SCHMID et al., 1998 a).

A origem das fibras do Sistema Nervoso ocorre em diferentes níveis da medula espinhal.

Em relação ao Sistema Nervoso Autônomo, o controle parassimpático tem origem crânio-sacral, no qual o tronco cerebral e medula espinhal atuam sobre o sistema cardíaco e o gastrointestinal, além das fibras que são originárias da região sacral (L5-S5) que atuam sobre o sistema reprodutivo e urinário. O controle simpático tem origem tóraco-lombar (T1-L5), atuando sobre os sistemas cardiovascular, pulmonar, gastrointestinal, renal e glândulas sudoríparas (GLASER, 2002).

O Sistema Nervoso Somático apresenta sua raiz motora para o diafragma entre C3-C5, para o membro superior entre C4-T1, para os músculos torácicos e intercostais entre T8-T12, para os músculos abdominais entre T7-T12 e para os membros inferiores entre L1-S2 (GLASER, 2002).

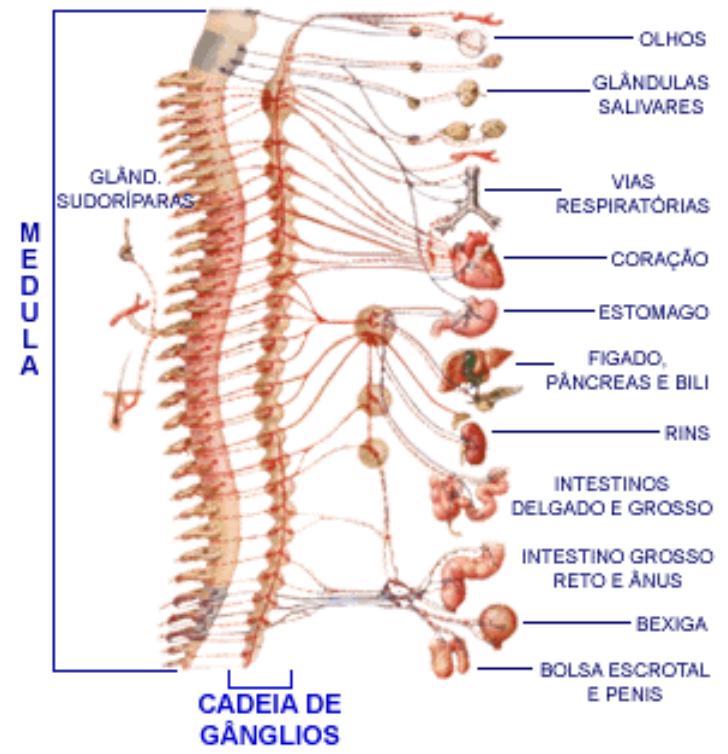

FIGURA 2 - Organização anatômica das inervações na medula espinhal. 
A lesão medular gera a interrupção das vias do Sistema Nervoso Central para o Sistema Nervoso Periférico - perda da transmissão de informação aferente e eferente - que resultam em mudanças patológicas na inervação simpática (STEINBERG et al., 2000), dependendo da organização anatômica das vias na medula espinhal, como mostra a Figura 2.

A origem das fibras simpáticas para o coração, medula adrenal e resposta vasomotora são apresentadas de forma variada por diversos autores (GLASER, 2002); (ROGERS, 2002); (SCHIMID et al., 1998 a); (STEMBERG et al., 2000); (THEISEN et al., 2001); (YOO et al., 2001), devido a descrição da maior porção de inervação simpática (corpos celulares dos neurônios originários das células intermediolaterais da coluna). O controle simpático para o coração tem a sua origem entre T1-T4 com maior porção entre T3-T5, para medula adrenal entre T3-L3 com maior porção entre T6-T10 e para a resposta vasomotora acima de T6 ou L1, ou ainda, apresenta alterações independentes do nível de lesão medular. Então, os autores referem-se à pronunciada disfunção simpática para o coração, medula adrenal e resposta vasomotora quando a lesão medular ocorre acima da $6^{a}$ vértebra torácica (T6). Entretanto, o nervo cardíaco vagal e a via aferente do reflexo baroceptor pelo nervo vago e glossofaríngeo geralmente são intactos.

A capacidade funcional nos portadores de lesão medular é inversamente relatada para o nível de lesão e se esta é completa ou não. Entretanto, a capacidade remanescente motora e sensorial pode ser facilmente detectada (por exemplo, pelo Protocolo ASIA), mas a função residual e mecanismos de controle redundante para as estruturas dos órgãos são mais difíceis para serem determinados.

A perda total ou parcial do controle simpático para o coração ocorre geralmente em indivíduos com nível de lesão medular acima de T6. Com isso, a cardioaceleração torna-se dependente da saída do tônus vagal e durante o exercício físico o aumento de carga não necessariamente resulta no aumento equivalente da freqüência cardíaca (ROGERS, 2002). Então, a cardioaceleração pode não ocorrer no 
exercício, primariamente, devido ao controle do tônus parassimpático vagal para o nódulo S-A (GLASER, 2002).

Desta forma, a resposta da freqüência cardíaca durante o exercício físico pode ser um indicativo da integridade do Sistema Nervoso Simpático. Outro método de avaliação é a mensuração dos níveis de catecolaminas (adrenalina e noradrenalina) no plasma sangüíneo, pois estes neurotransmissores ajudam os indivíduos a responderem ao estresse do exercício físico.

A finalidade da adrenalina é acelerar a lipólise nos tecidos adiposos, a glicogenólise muscular e a glicogenólise hepática. Entretanto, em portadores de lesão medular acima de T6, o controle simpático para medula adrenal pode ser ausente ou parcial. Isto pode resultar em liberação anormal de catecolaminas durante a atividade física (ROGERS, 2002); (SCHMID et al., 1998 b); (STEINBERG et al., 2000).

O Sistema Nervoso Simpático também controla as respostas vasomotoras. Entretanto, a lesão medular pode resultar na perda total ou parcial da resposta vasocontritora a baixo do nível de lesão (membros inferiores, área esplânica e abdominal), que juntamente com a ausência da bomba muscular esquelética e respiratória, resultam em stasis venoso, retorno venoso dificultado, redução do volume sistólico e do débito cardíaco, gerando hipotenção ortostática e durante o exercício (HOPMAN et al., 1998); (ROGERS, 2002); (THEISEN et al., 2001).

\subsubsection{HIPOTENSÃO ORTOSTÁTICA}

A hipotensão ortostática é a queda súbita da pressão sangüínea durante a postura ereta (passivamente) e quando se permanece nesta posição ou durante a postura sentada. Esta resposta fisiológica ocorre geralmente em pacientes com lesão medular acima de T6, devido a interrupção das vias simpáticas eferentes espinhais, caracterizada pela perda do controle do reflexo dos vasos sangüíneos via sinus baroceptores carotídeos e pela presença do reflexo que controla a freqüência cardíaca via nervo vago (ROGERS, 2002). 
O coração é regulado por sistemas de feedback que incluem o nódulo sinusal, baroceptores e quimiorreceptores. A estimulação dos receptores distribuídos no coração e grandes vasos pode causar reflexo cardiovascular, incluindo bradicardia e hipotensão mediada por aferentes vagal e um reflexo excitatório caracterizado por hipertensão e taquicardia mediada por aferentes da via simpática. Neste contexto, as variações de pressão arterial e freqüência cardíaca são neuralmente modulados por circuitos integrados de feedback positivo, ausência de seqüências barorreflexoras, e negativo, ocorrência de seqüências barorreflexoras. Perda parcial desta complexa regulação, como durante o estresse ortostático, pode ocorrer em portadores de lesão medular, pois os reflexos espinhais inibem os centros supraespinhais tornando o feedback positivo mais ativo (LEGRAMANTE et al., 2001).

Entretanto, o treinamento ortostático possibilita adaptações de FC e Pa, pois Legramante et al. (2001) sugerem que a regulação cardiovascular ocorre por um mecanismo integrado - feedback positivo que interage dinamicamente com o feedback negativo - mediado neuralmente e tipo feed-forward de curto tempo.

\subsubsection{HIPOTENSÃO DURANTE O EXERCÍCIO}

Durante o exercício em indivíduos saudáveis, ocorre vasodilatação nos músculos ativos, enquanto há vasoconstrição nos músculos inativos. Isto pode não ocorrer em indivíduos com lesão medular, ou seja, a vasodilatação ocorre nos membros superiores ativos, mas pode não ser compensada pela vasoconstrição nos membros inferiores, não gerando o aumento da pressão sistólica com o aumento da intensidade do exercício. Então, a resposta vasomotora tem efeitos diretos sobre o desempenho cardíaco, podendo causar hipotensão durante o exercício com os membros superiores (HOPMAN et al., 1998); (THEISEN et al., 2001).

Theisen et al. (2001) constataram que durante o exercício com o cicloergômetro de braço, a vasoconstrição não ocorreu nos membros inferiores de portadores de lesão medular e não está relacionada com o nível de lesão. 
Entretanto, a resposta circulatória deficitária durante a postura ortostática e exercitando-se com os membros superiores, pode ser minimizada adotando-se estratégias que favoreçam o retorno venoso e a eficiência cardíaca, evitando a hipotensão.

Os resultados obtidos por Hopman et al. (1998) mostram que a posição supina e o anti-G suit, as meias elásticas, a cinta abdominal e a Estimulação Elétrica Neuromuscular na posição sentada promovem benefício hemodinâmico central para os portadores de lesão medular durante o exercício submáximo com cicloergômetro de braço.

Ainda, outra disfunção do Sistema Nervoso Autônomo é a perda da termorregulação.

\subsubsection{TERMORREGULAÇÃO}

Em indivíduos portadores de lesão medular, a habilidade para termorregulação é comprometida devido (DEC, SPARROW \& McKEAG, 2000):

- redução da resposta termorregulatória para o centro de temperatura (possível redução do input para o centro termorregulatório hipotalâmico);

- perda do controle simpático para as respostas vasomotoras e sudomotoras nas áreas de insensibilidade na pele (abaixo do nível de lesão);

- perda da bomba muscular-esquelética nos membros paralisados.

Durante o exercício físico há aumento da energia metabólica nos músculos exercitados e parte da energia excedente é liberada na forma de calor para manter a homeostase, evitando por exemplo a hipertermia, desidratação e exaustão. Em portadores de lesão medular a dissipação de calor ocorre acima do nível de lesão, via suor, geralmente na cabeça e braços (BHAMBHANI, 2002).

A ausência da resposta termorregulatória do suor e da vasoconstrição ou vasodilatação abaixo do nível de lesão, gera a influência da temperatura do meio externo sobre a temperatura corporal, reduzindo a habilidade dos tetraplégicos e paraplégicos em tolerar extremas temperaturas (no calor pode gerar hipertermia e no 
frio, hipotermia). O que pode influenciar no desempenho durante a atividade motora (ROGERS, 2002).

Portanto, os portadores de lesão medular podem apresentar alterações nos mecanismos centrais e no feedback neural periférico - por exemplo, estimulação de volumeceptores e baroceptores, temperatura, lactato, potássio, $\mathrm{pH}$, catecolaminas que são responsáveis pelo controle/regulação da freqüência cardíaca, pressão arterial e ventilação durante o exercício físico (FREY et al., 1997). Ainda, estes pacientes apresentam disfunções nos sistemas gastrointestinal, urinário e reprodutivo, que podem estar relacionados aos episódios de disreflexia autonômica.

\subsubsection{DISREFLEXIA AUTONÔMICA}

Em lesões medulares acima da $6^{\mathrm{a}}$ vértebra torácica podem ocorrer episódios de hiperreflexia do Sistema Nervoso Simpático, isto é, disreflexia autonômica, desencadeada por estimulo nóxio ou viceral abaixo do nível de lesão, causando vasoconstrição e vascularização deficitária abaixo do nível de lesão, bradicardia, hipertensão, piloereção, suor acima do nível de lesão e enxaqueca (KARLSSON et al., 1998); (LEMAN, BERNET \& SEQUEIRA, 2000).

A hipertensão paroximal é resultante da estimulação dos boroceptores vasculares que ativam o Sistema Nervoso Parasimpático, causando vasodilatação acima do nível de lesão e reflexo bradicárdico (LEMAN, BERNET \& SEQUEIRA, 2000); (ROGERS, 2002). O súbito aumento da pressão sistólica ocorre a mais de 40 mmHg do valor basal e pode atingir $220 \mathrm{mmHg}$, caracterizando uma situação de risco (ROGERS, 2002).

Esta ativação do arco reflexo espinhal em resposta a uma exagerada atividade simpática e seus mecanismos específicos são desconhecidos. Portanto, muitos estudos investigam a relação dos substratos que mediam a disreflexia autonômica, como a adrenalina e noradrenalina.

Níveis de catecolaminas no plasma de ratos lesados medulares foram mensurados durante a disreflexia autonômica através da estimulação viceral 
(distensão colo-retal). Os resultados mostraram que os níveis de adrenalina e noradrenalina aumentaram significativamente, sugerindo que os dois hormônios causam mudanças cardiovasculares durante a disreflexia autonômica. O aumento significativo dos níveis de adrenalina no plasma indica que a exagerada atividade reflexa simpática envolve os neurônios pré-ganglionares simpáticos adrenais que estimulam a liberação de adrenalina da medula adrenal e consequentemente a liberação de noradrenalina nos terminais dos nervos simpáticos (LEMAN, BERNET \& SEQUEIRA, 2000).

Outro estudo avaliou a habilidade do estímulo simpatoexitatório mediado centralmente por estresse mental (5 minutos de teste aritmético) e durante a estimulação aferente periférica (5-6 minutos de percussão da bexiga) em indivíduos com alto nível de lesão medular (C7-T4). Durante a ativação central (mental) foi constatado exagerada resposta simpática acima do nível de lesão, com aumento da freqüência cardíaca, pressão arterial e no nível de noradrenalina no braço. Enquanto, a estimulação periférica (bexiga) indicou inervação simpática intacta, ativada por arco reflexo, devido ao aumento dos níveis de noradrenalina abaixo do nível de lesão, freqüência cardíaca inalterada e aumento da pressão arterial média. Ainda, foram constatados mecanismos normais de remoção de noradrenalina e ação de mecanismos compensatórios da perda de ativação central (KARLSSON et al., 1998).

A dor, as úlceras de pressão e a ossificação heterotópica ocorrem em portadores de lesão medular. Estas seqüelas podem desencadear a disreflexia autonômica. O controle intestinal e urinário são importantes para evitar infecção urinária e constipação, estratégias de controle e planejamento são fatores importantes para a execução de atividade física, principalmente para evitar a disreflexia autonômica (DEC, SPARROW \& McKEAG, 2000).

Um fator relevante em competição esportiva é o dopping em atletas com lesão medular. A disreflexia autonômica é desencadeada, por exemplo, através da distensão vesical ou por estímulo doloroso causado pela colocação de objetos pontiagudos na cadeira de rodas, gerando o aumento do aporte de oxigênio e melhor desempenho, porém gera hipertensão - fator de risco. Este dopping é proibido em 
competições esportivas (BHAMBHANI, 2002); (DEC, SPARROW \& McKEAG, 2000).

\subsection{ATIVIDADE FÍSICA, RECREAÇÃO E ESPORTE COMPETITIVO}

Portadores de deficiência física podem participar de quase todas as atividades físicas, sendo que alguns requerem equipamentos adaptados e outros não.

Durante o final da II Guerra Mundial, no Canadian Military Hospital na Inglaterra (Canadian Depatment of Veterans Affairs), o neurocirurgião Dr. Harry Botterell iniciou o processo de reabilitação para portadores de lesão medular. Uma das metas era a realização de atividade motora com o uso de cadeira de rodas, bem como de muletas “Canadenses” para marcha em pacientes que possuíam maior força nos membros superiores. Entretanto, estes veteranos davam poucos passos com alto gasto energético e com risco de queda, então a cadeira de rodas era mais utilizada para maior independência (TREMBLAY, 1996).

O esporte com cadeira de rodas surgiu após a II Guerra Mundial, foi implantado por Ludwing Guttmam e sua equipe, sendo um instrumento de reabilitação do Hospital Stoke Mandeville (Inglaterra), promovendo atividade física e de lazer aos indivíduos feridos na guerra (COOPER, 1995).

A $1^{\text {a }}$ competição esportiva de cadeiras de rodas foi em 1952. Os atletas eram dos Países Baixos, da República Federal da Alemanha, Suécia, Noruega e Israel. Neste evento foi formado o ISMGF (International Stoke Mandeville Games Federation) para promover competições esportivas com cadeiras de rodas. Para ampliar os números de eventos uniu-se ao COI (Comitê Olímpico Internacional) e se reorganizou em ISMWSF (International Stoke Mandeville Wheelchair Sports Federation). A introdução dos esportes de cadeira de rodas nas Olimpíadas iniciou-se no ano de 1960, em Roma (Itália) e foi denominado Paraolimpíadas durante o ano de 1964 em Tokyo (COOPER, 1995).

Vários são os esportes que os portadores de lesão medular praticam em cadeira de rodas, como a corrida, arremesso de disco, arremesso de peso, lançamento de dardo, tiro ao alvo, arco e flecha, bilhar, boliche, basquetebol, handbol, rugby, voleibol, tênis e tênis de mesa (GREEN, 2002). Esportes aquáticos como a natação, 
iatismo, remo, esqui aquático e os esportes de inverno, como o esqui na neve, não necessitam de cadeira de rodas durante a prática esportiva. Também, há várias atividades de lazer que podem ser realizadas com variedades de triciclos e bicicletas adaptadas para passear, como ativas nos membros superiores e passivas nos membros inferiores, de dois lugares e até cadeira de rodas adaptadas para fazer trilha (COOPER, 1995).

Entretanto, estas atividades físicas devem ser praticadas com vestuário apropriado, considerando a temperatura climática (COOPER, 1995), e se houver treinamento visando competições deve-se considerar as lesões esportivas (por uma força de grande magnitude ou por esforço repetitivo), com grande incidência, respectivamente, nas articulações do ombro, cotovelo e punho, além das tendinites, tenosinovitis e neuropatias (APPLE, CODY \& ALLEN, 2002); (DEC, SPARROW \& McKEAG, 2000), fazendo-se um balanço entre risco e benefício.

Para prevenir lesões e aumentar a eficiência mecânica durante a atividade motora, os alongamentos passivo e ativo são essenciais (GREEN, 2002); (DEC, SPARROW \& McKEAG, 2000).

O treinamento aeróbico juntamente com treinamento de força (musculação), em portadores de lesão medular, são importantes para realização de atividades de vida diária e como estratégia de condicionamento físico, aumentando a capacidade cardio-respiratória e a força muscular nos membros superiores (JACOBS et al., 2001).

Outras formas de se exercitar são, utilizando-se as esteiras para cadeira de rodas, ergômetros de cadeira de rodas, cicloergômetro de braço e cicloergômetro com Estimulação Elétrica nos membros inferiores (MORRISON, 2002).

Estes ergômetros são amplamente utilizados para realização de testes fisiológicos, com protocolos contínuo ou descontínuo. Embora, os testes realizados com cadeira de rodas e ergômetros de braço apresentem vantagens e desvantagens, o cicloergômetro de braço é mais vantajoso devido a alta eficiência mecânica, baixo custo, uso facilitado, portabilidade, entre outros, a grande desvantagem é não oferecer informações úteis referentes à capacidade de trabalho físico na atividade diária da deambulação com cadeira de rodas (DAVIS, 1993). 
A grande vantagem do cicloergômetro com Estimulação Elétrica nos membros inferiores comparado aos outros ergômetros de membros superiores é a ativação de grandes grupos musculares paralisados e a geração de pressão positiva nos membros inferiores que favorece a circulação sangüínea (GLASER et al., 2002). Entretanto, uma desvantagem é o risco de fraturas com o aumento de carga (FRANCO et al., 1999).

A vantagem do cicloergometro de braço e do cicloergômetro com Estimulação Elétrica nos membros inferiores são os movimentos sincrônicos que estimulam os reflexos espinhais, H-reflexo (BROOKE et al., 1995).

Entretanto, estratégias são utilizadas em ergômetro de cadeira de rodas para aumentar a performance durante um exercício, por exemplo, controlar um jogo de video game com a propulsão da cadeira de rodas, resultando em grande motivação, exercitando-se em altos níveis cardio-respiratórios e mantendo alta intensidade de exercício por longo período (O’CONNOR et al., 2001), resultados semelhantes foram encontrados com a utilização do cicloergômetro de braço para propulsão da cadeira de rodas (MUKHERJEE \& SAMANTA, 2001); (van der WOUDE et al., 2000).

Os portadores de lesão medular não se exercitam somente com os membros superiores e/ou sentados, também podem se exercitar caminhando através de métodos alternativos de treinamento da marcha, como o Sistema de Suspensão Corpórea e a Estimulação Elétrica Neuromuscular, considerados meios de reabilitação promissores. 


\section{CAPÍtulo 2}

\subsection{ESTIMULAÇÃO ELÉTRICA NEUROMUSCULAR}

A Estimulação Elétrica Neuromuscular é uma alternativa para a restauração e/ou recuperação das funções motoras perdidas através da ativação artificial dos músculos esqueléticos (HANDA, 1997); (TEPAVAC \& SCHWIRTLICH, 1996). Consideradas neuropróteses, promovem movimentos de membros superiores e inferiores.

Liberson, durante a década de 60, foi o primeiro a utilizar a Estimulação Elétrica para o tratamento do pé em gota em portadores de hemiplegia, o eletrodo era posicionado no nervo fibular para evocar o reflexo de retirada, com controle por chave na sola do sapato. Posteriormente, Kantrowitz utilizou a Estimulação Elétrica para restaurar a postura ereta de paraplégicos. Vodovinick, Hralj e Bajd iniciaram o desenvolvimento de estimuladores multicanais (KRALJ \& BAJD, 1989).

Atualmente, em diversas partes do mundo este sistema se encontra em diferentes fases de evolução, pois os estimuladores não foram comercialmente aceitos, por não executarem diferentes tarefas funcionais e pela rápida instalação da fadiga muscular. Então, cada grupo de pesquisadores passou a desenvolver o seu próprio estimulador, na tentativa de solucionar as limitações (KELLER et al., 2002); (MUNIH \& ICHIE, 2001). 
Além de eletrodos de superfície, foram incorporados os percutâneos e implantáveis. O estimulador passa a ter controle tanto de malha aberta como fechada e podem ser miniaturizados para implante. Estudos de neurofisiologia, biomecânica e fisiologia do exercício também estão em desenvolvimento para otimizarem a interface homem-máquina.

\subsection{INTERFACE HOMEM-MÁQUINA}

O músculo privado de contração voluntária representa a unidade contrátil isolada e independente de fatores motivacionais e da condução do Sistema Nervoso Central em modificar a produção de força (RABISCHONG \& CHAVET, 1997). Entretanto, a excitação muscular controlada por microprocessador pode ser satisfatoriamente coordenada gerando a função locomotora (MIZRAHI, 1997).

A Estimulação Elétrica Neuromuscular consiste em formas de pulsos aplicados ao nervo motor dos músculos. A força gerada pelo músculo estimulado pode ser modulado por duas maneiras, variando a quantidade de estímulos individuais de pulsos ou alternando seus números na unidade de tempo. Um dos métodos é caracterizado pelo recrutamento de axônios e consequentemente, modifica o recrutamento das unidades motoras, resultando na mudança da somação espacial da força. O outro, consiste na maneira em que estas unidades motoras são excitadas, resultando na mudança da somação temporal da força em cada unidade motora. A restauração da função deambulatória por Estimulação Elétrica, necessita de contração tetânica suave que produz altos valores de força e reduz a fadiga. Para se obter uma contração tetânica suave é necessária uma freqüência de estimulação relativamente alta, sendo de $25 \mathrm{~Hz}$ ou mais. A rápida instalação da fadiga muscular está relacionada com a freqüência de estimulação, por isso é importante a utilização de freqüências constantes durante a Estimulação Elétrica (MOURSELAS \& GRANAT, 1998).

Então, os parâmetros relevantes do sinal de estimulação são: freqüência e amplitude da estimulação, duração do pulso e forma de onda. Estes parâmetros são 
ajustados a fim de realizar contração tetânica suave, garantir o torque muscular necessário para a realização dos movimentos e minimizar a fadiga muscular.

O mecanismo de geração de força pelo recrutamento das unidades motoras e a força muscular decae com o tempo como resultado da fadiga muscular, estes são dois aspectos relevantes que relacionam a Estimulação Elétrica e o músculo (MIZRAHI, 1997).

O declínio na geração de força muscular durante a Estimulação Elétrica Neuromuscular pode ser resultante de alterações na propagação neuromuscular, no acoplamento excitação-contração e também, de mudanças metabólicas (TEPAVAC \& SCHWIRTLICH, 1996).

Portanto, a compreensão dos processos envolvidos na fadiga e no seu restabelecimento são essenciais, já que na paralisia decorrente da lesão medular a fadiga pode ser predominantemente periférica. Nessa perspectiva, o problema é significativo, uma vez que o feedback sensorial do músculo que indica o desenvolvimento da fadiga e previne a falência está ausente (MIZRAHI et al., 1997).

Então, a intervenção no processo da fadiga muscular ocorre por meio de protocolos de Estimulação, pela sua interação com períodos de recuperação, além dos diferentes métodos de controle (MIZRAHI, 1997).

\subsubsection{EXERCÍCIO INDUZIDO POR ESTIMULAÇÃO ELÉTRICA} NEUROMUSCULAR

O quadríceps é o responsável pela extensão do joelho durante a marcha e também representa o principal atuador no ato de ficar em pé e manter-se nesta postura (RABISCHONG \& CHAVET, 1997); (RIENER \& QUINTERN, 1997).

As características do músculo quadríceps estimulado artificialmente são amplamente pesquisadas por modelos biomecânicos-fisiológicos (RIENER \& QUINTERN, 1997); (LEVIN, MIZRAHI \& IZAKOV, 2000), pois visam explicar a relação entre Estimulação artificial, fadiga e patologia individual. Assim, os estudos da dinâmica muscular durante a fadiga podem capacitar o desenvolvimento de 
técnicas para efetiva ativação artificial dos músculos em portadores de lesão medular.

O exercício induzido por Estimulação Elétrica nos membros inferiores pode ser combinado com o uso de ergômetros de braço. Esta combinação é denominada Exercício Híbrido.

O híbrido estático é a combinação do cicloergômetro de braço com a Estimulação Elétrica simultânea nos músculos anteriores e posteriores dos membros inferiores com co-contrações isométricas e estímulos alternados na coxa e perna (quadríceps/bíceps femoral e gastrocnêmio/tibial anterior). O híbrido dinâmico é a combinação do cicloergômetro de braço com a Estimulação Elétrica dos músculos glúteo máximo, quadriceps e bíceps femoral para produzirem o ato de pedalar em cicloergômetro (BROWN et al., 2001).

O exercício induzido por Estimulação Elétrica e os exercícios híbridos, também são amplamente utilizados visando maximizar o desempenho dos sistemas cardiovascular, respiratório e muscular dos portadores de lesão medular (BARSTOW et al., 1996); (BROWN et al., 2001); (FRANKEN et al., 1997).

Portanto, a Estimulação Elétrica Neuromuscular é uma forma de exercitar-se semelhantemente a uma atividade esportiva, além de ser uma alternativa de locomoção para cadeira de rodas (MUNIH \& ICHIE, 2001).

\subsubsection{TREINAMENTO DA MARCHA}

Os portadores de lesão no neurônio motor superior deambulam com estímulo artificial e auxílio de andadores ou muletas (MUNYH \& ICHIE, 2001). O estímulo é disparado com as mãos em uma chave (controle por malha aberta) ou a marcha é automática (controle por malha fechada), no qual os parâmetros fisiológicos e biomecânicos são detectados por sensores artificiais (strain gages, eletrogoniômetros e acelerômetros) ou por sensores naturais (eletromiografia e eletroencefalograma) que enviam os sinais para o estimulador e através de complexos algorítimos (por exemplo, as redes neurais artificiais) produzem ajustes dos parâmetros de 
estimulação em tempo real, disparando o estímulo artificial, através de cabos e eletrodos colocados no ponto motor do músculo e/ou nervo, até mesmo com dispositivos implantáveis (SCOTT \& HAUGLAND, 2001).

O padrão de estimulação simples inclui dois canais para o músculo quadríceps, promovendo a extensão dos joelhos para ficar em pé, mais dois canais são adicionados para estimular o nervo fibular, desencadeando o reflexo de flexão para iniciar a fase de balanço da marcha, e mais canais são adicionados para melhorar a função locomotora. Em pacientes com lesão no motoneurônio inferior ou com lesões mais altas, os dispositivos mecânicos podem auxiliar a locomoção, por exemplo, as órteses "knee-ankle-foot” (KAFO), "hip-knee-ankle-foot” (HKAFO), “hip guidance orthoses” (HGO). A combinação destes dispositivos e a Estimulação Elétrica Neuromuscular são denominados Sistemas Híbridos.

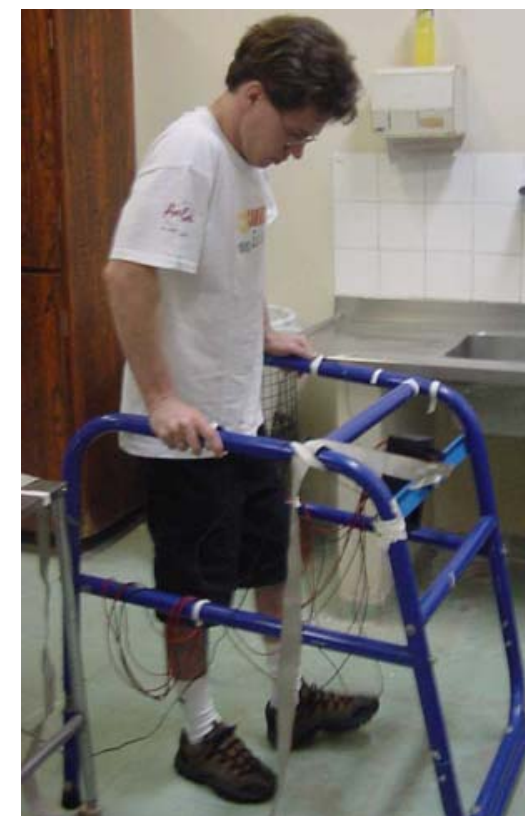

(a)

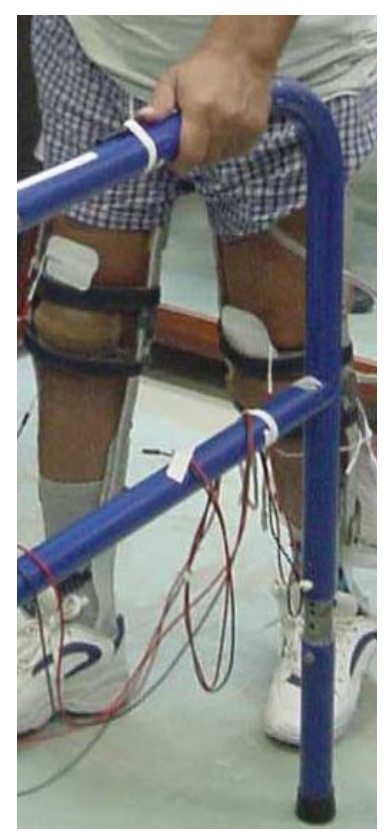

(b)

FIGURA 3 - Paraplégico realizando o treinamento da marcha através de EENM (a) e utilizando o sistema híbrido - EENM e KAFO (b). 
Cliquet Jr., Baxendale \& Andrews (1989) mensuraram o gasto energético em portadores de lesão medular durante a deambulação com Estimulação Elétrica, com órteses mecânicas e utilizando o sistema híbrido. Os resultados mostraram que a marcha assistida por HKAFO apresentou maior eficiência mecânica, devido ao suporte adequado de quadril e tronco que propiciaram a estabilidade e manutenção do equilíbrio. Enquanto que com o uso da Estimulação Elétrica obteve-se alto consumo de oxigênio resultante da fase de flexão/extensão do joelho e reequilíbrio postural.

Então, a redução da rápida instalação da fadiga e do gasto energético durante a Estimulação Elétrica podem ser obtidos pelo uso de órteses mecânicas, bem como, pelo sistema de marcha automática.

Fisekovic \& Popovic (2001) desenvolveram e avaliaram um controle para marcha automática em tempo real, utilizando redes neurais artificiais, acelerômetros nas articulações coxo-femorais, goniômetros nas articulações dos joelhos e coxofemorais e palmilhas com sensores de força (FSR). As marchas com e sem controle automático foram avaliadas mensurando a velocidade, o consumo de oxigênio e a freqüência cardíaca. Os resultados mostraram que a marcha com o controle automático foi mais rápida e com menor esforço fisiológico comparada ao controle manual.

Outra forma promissora de controle em tempo real é o sinal mioelétrico da atividade muscular voluntária (acima do nível de lesão), então diversos estudos de tratamento de sinais vêm sendo realizados para efetividade do sistema (FRIGO et al., 2000); (HINES et al., 1996). Atualmente, a grande meta para os pesquisadores é o controle por sinal obtido do eletroencefalograma (SCOTT \& HAUGLAND, 2001).

A Estimulação de superfície é vantajosa, pois não é um método invasivo, não requer muito tempo para aplicação e é removível a qualquer momento (BIJAK et al., 1999), além de ser cosmeticamente aceita (MUCCIO, ANDREWS \& MARSOLAIS, 1989). Com o sistema percutâneo, os pacientes podem apresentar dificuldade com a colocação dos eletrodos, além da provável deterioração do equipamento e riscos de 
infecção. Os sistemas implantáveis apresentam possíveis riscos cirúrgicos e complicações decorrentes dos implantes crônicos, outro aspecto relevante é a reversibilidade do sistema, caso no futuro ocorra a recuperação sensório-motora (KILGORE et al., 2001)

Os sistemas implantáveis constituem-se em estimulador implantável com circuitos eletrônicos (microcontrolador), baterias, transmissão por telemetria, controle por malha aberta e/ou fechada, cabos e eletrodos feitos de materiais resistentes à corrosão. O microprocessador não é implantável e apresenta interface para o computador (BHADRA, KILGORE \& PECKHAM, 2001); (MAYR et al., 2001); (SALMONS et al., 2001). O aperfeiçoamento deste sistema vem sendo realizado por meio de vários estudos sobre a arquitetura dos estimuladores, miniaturização de eletrodos e sensores, encapsulação dos dispositivos implantáveis por silicone ou outros biomateriais, colocação anatômica e técnicas cirúrgicas (DAVIS, 2002); (MAYR et al., 2001); (SALMONS et al., 2001); (TROYK \& DONALDSON, 2001).

O IRS-8, estimulador implantável de 8 canais, foi comercializado para restaurar as funções dos membros superiores de tetraplégicos e posteriormente utilizado em laboratório para restauração dos movimentos de membros inferiores (BHADRA, KILGORE \& PECKHAM, 2001). Também foi recentemente desenvolvido um estimulador implantável de 20 canais para restaurar o ato de ficar em pé e caminhar (MAYR et al., 2001). Em testes com ovelhas, durante 26 semanas, este sistema demonstrou critérios biológicos para aplicação clínica em portadores de lesão medular (BIJAK et al., 2001).

Além da EENM, outra técnica não convencional de reabilitação da marcha é o Sistema de Suspensão Corpórea, bem como sua combinação com a EENM e/ou esteira ergométrica, que promovem Padrões Rítmicos Locomotores. 


\subsubsection{PADRÕES RÍTMICOS LOCOMOTORES E PLASTICIDADE NEURAL EM PORTADORES DE LESÃO MEDULAR}

Após a lesão medular, o treinamento da marcha possibilita Padrões Rítmicos Locomotores, através da ativação do CPG (Central Pattern Generator - Gerador de Padrão Central), resultando em recuperação da função medular.

Experimentos evidenciam a ativação do CPG por drogas noradrenérgicas, mecanismos de modulação reflexa e coordenação subcortical.

Neurotransmissores e neuromoduladores, como a Serotonina (5-HT), Nmethyl-D-aspartato (NMDA), Glutamato, estão envolvidos nas propriedades rítimicas locomotoras, comprovadas com a aplicação destes agentes farmacológicos na medula de ratos (SCHIMIDT \& JORDAN, 2000); (WALWYN et al., 1999); (WHELAN, 1996).

Os reflexos de Hoffmann (H-reflex) são os reflexos evocados dos extensores do tornozelo, através de modulação sensorial (estímulo mecânico ou elétrico). A Estimulação Elétrica cutânea aferente das áreas que inervam o tornozelo e a região plantar desencadeiam o reflexo de flexão através das fibras aferentes Ia e Ib (fibras primárias), com o aumento do estímulo é gerada a atividade ipslateral do tornozelo, joelho e quadril, ativando as fibras aferentes II (fibras secundárias) e evocando um intenso reflexo de flexão, porém limita a ação dos músculos anti-gravitacionais (BARBEAU et al., 1999); (BROOKE et al., 1996); (TRIMBLE, KUKULKA, BHERMAN, 1998).

Os Órgãos Tendinosos de Golgi possuem função anti-gravitacional, representando o mecanismo de recepção de carga, responsável pelo controle do centro de massa do corpo durante a postura ereta e o andar. Assim, os Órgãos Tendinosos de Golgi (aferentes proprioceptivas) dos músculos extensores dos membros inferiores interagem com o CPG, favorecendo o Padrão Rítmico Locomotor, sem o auxílio do reflexo de flexão (BARBEAU et al., 1999); (DIETZ, 1996); (DIETZ, GOLLHOFER \& TRIPPEL, 1992); (KOJIMA, NAKAZAWA \& YANO, 1999).

Com estes estímulos há uma reorganização dos reflexos e o aumento da excitabilidade de motoneurônios, seguido de feedback das fibras aferentes I do grupo 
extensor, favorecendo a extensão do membro inferior durante a locomoção (BARBEAU et al., 1999). Com o treinamento da marcha, os movimentos passam a ser espontâneos (FOUAD et al., 2000); (WICKELGREN, 1998), há mudanças no padrão do sinal mioelétrico do grupo extensor dos membros inferiores, que se tornam próximos aos padrões normais, indicando recuperação da função medular (DIETZ et al., 1998); (ERNI \& COLOMBO, 1998); (KOJIMA, NAKAZAWA \& YANO, 1999) (LEROUX, FUNG \& BARBEAU, 1999).

Ainda, os circuitos espinhais apresentam flexibilidade, ou seja, avaliam perturbações do meio ambiente - por exemplo, o aumento do ângulo ou velocidade da esteira ergométrica - resultando em resposta apropriada durante a marcha (GUADAGNOLI, ETNYRE \& RODRIGUE, 2000); (LEROUX, FUNG \& BARBEAU, 1999).

Outro aspecto relevante é a ativação cortical constatada durante a Estimulação Elétrica nos membros inferiores de paraplégicos (IOANNIDES et al., 2002).

Portanto, a plasticidade neural em portadores de lesão medular possivelmente indica o motivo pelo qual ocorre o retorno de sensibilidade, movimentação voluntária e locomoção de forma não-assistida, como no caso de pacientes que fazem/fizeram parte do Programa de Estimulação Elétrica Neuromuscular da FCM/UNICAMP e USP/São Carlos (CLIQUET, 1994); (PAOLILLO, PAOLILLO \& CLIQUET, 2002).

Outras técnicas que podem resultar em recuperação neurológica, favorecendo o aumento da função e a atividade neural são o implante de células, a aplicação de drogas e de campos elétricos (GRILL et al., 2001).

\subsection{ADAPTAÇÕES FISIOLÓGICAS AO TREINAMENTO ATRAVÉS DE ESTIMULAÇÃO ELÉTRICA NEUROMUSCULAR}

Além da recuperação sensória-motora em portadores de lesão medular, várias são as respostas ao treinamento através de Estimulação Elétrica, por exemplo, em relação a espasticidade. 
A Estimulação Elétrica Neuromuscular gera atividade aferente pela estimulação direta das fibras aferentes (por exemplo, aferente Ia) e pelos sinais sensoriais do fuso muscular e tendão (proprioceptores) do músculo em contração. Estes sinais aferentes podem causar reflexos em indivíduos saudáveis e contração espástica nos portadores de lesão medular. Entretanto, os estudos constatam redução da espasticidade (DALY et al, 1996).

Os efeitos da Estimulação Elétrica sobre a reação espástica em lesados medulares foram investigados através da estimulação dos músculos dorsiflexores em diferentes freqüências, mensurando o momento da articulação do tornozelo em condições isométricas. Foi observada a redução da atividade espástica num pequeno período de contração, com o aumento da freqüência e de um "burst” ao outro (MELA, VELTINK \& HUIJING, 2001).

As adaptações fisiológicas ao treinamento através de Estimulação Elétrica estão relacionadas a mudanças adaptativas no músculo e são importantes para capacidade de endurance, sensibilidade à insulina e aumento da resistência à fadiga, como observado nas pesquisas a seguir.

O remodelamento muscular ocorre através do balanço entre degradação e síntese de proteína intracelular e de componentes da matrix extracelular. Os resultados de biópsia muscular em portadores de lesão medular mostraram aumento de colágeno no vasto lateral comparado aos sujeitos saudáveis. Entretanto, após dezoito meses de treinamento através de Estimulação Elétrica, a quantidade total de colágeno tipo IV não alterou, sugerindo acelerada ressintese, o que indica processo de remodelamento de colágeno intramuscular (KOSKINEN et al., 2000).

Os portadores de lesão medular podem apresentar aumento da resistência à insulina e desenvolvimento do diabetes mellitus (tipo II), principalmente devido a inatividade física, atrofia muscular e alterações no metabolismo de glicose. Mohr et al. (2000) avaliaram a ação da insulina em tetraplégicos e paraplégicos que realizaram o treinamento em cicloergômetro através do ato de pedalar induzido artificialmente. Seus resultados mostraram aumento da sensibilidade à insulina, o que pode prevenir o diabetes. Este efeito benéfico pode estar associado com o aumento da massa muscular, predominância do tipo de fibras musculares com características 
mais oxidativas (tipo IIa) e pelo aumento da proteína transportadora de glicose (GLUT 4).

As proteínas mitocondriais (UCP) são encontradas nos tecidos adiposos e nos músculos esqueléticos. Sua função é transformar os substratos energéticos em calor através da fosfosrilação oxidativa e da síntese de ATP (Adenosina Trifosfato). Alterações nas expressões do gene (RNAm) destas proteínas (UCP2 e UCP3) no músculo esquelético estão associadas a desordens no metabolismo dos carboidratos e lipídios, como a obesidade e resistência à insulina, além de serem mediadores termogênicos. Os valores destes parâmetros foram elevados em portadores de tetraplegia sedentários, entretanto após serem submetidos ao treinamento em cicloergômetro através de Estimulação Elétrica, constatou-se a redução destes valores, conduzindo à normalização do UCP 2 RNAm (HJELTNES et al., 1999).

Quanto à plasticidade muscular, em seis meses de exercício induzido por Estimulação Elétrica houve aumento de 10\% no volume muscular dos membros inferiores de tetraplégicos (SKÖLD et al., 2002) e em 8 meses de treinamento, houve o aumento de 59\% no diâmetro das fibras musculares (hipertrofia) do quadríceps em paraplégicos, sendo 65\% no diâmetro das fibras tipo I e 37\% no diâmetro das fibras tipo II, além do aumento de 53\% na concentração de enzimas aeróbicas e anaeróbicas, 30\% na área muscular e 45.7\% na força isométrica máxima (KERN, 1997). Em um sitema implantável de estimulação em animal detectou-se o aumento na proporção do tipo de fibra I e redução do tipo II, também houve o aumento significativo na força durante o movimento de extensão das articulações do joelho e coxo-femoral comparado ao movimento de flexão (BIJAK et al., 2001).

Peixoto e Cliquet Jr. (1996) investigaram a resistência à fadiga em duas técnicas de controle de estimulação do músculo quadríceps. A primeira, utilizando um canal para o músculo quadríceps e a outra, com o Estimulador Multicanal Sequencial, utilizando três canais para o vasto lateral, vasto medial e reto femoral. Os resultados mostraram aumento da resistência à fadiga, entretanto ao comparar as técnicas, a Estimulação Multicanal Sequencial mostrou melhora na linearidade do tempo da resistência à fadiga no decorrer do programa. 
Efeitos hemodinâmicos também são constatados com o exercício induzido artificialmente, como a melhora da circulação sangüínea, da microcirculação e das trocas transcapilares (DALY et al., 1996).

A prevenção das úlceras de decúbido ocorre pelo aumento, imediato e por longo período da perfusão sangüínea no músculo e na pele (KERN, 1997).

As mudanças cardiovasculares abruptas observadas durante a postura ereta, sentada e exercitando-se com os membros superiores podem ser minimizadas com o uso da Estimulação Elétrica nos membros inferiores devido a ativação da bomba muscular esquelética (ELOKDA, NIELSEN \& SHIELDS, 2000); (HOPMAN, 1998); (GLASER et al., 2002).

Benefícios funcionais cardiovasculares e respiratórios em portadores de lesão medular foram observados durante o treinamento através de Estimulação Elétrica nos membros inferiores (BARSTOW et al., 1996). Resultados semelhantes foram obtidos em cardiopatas e portadores de doença pulmonar crônica obstrutiva que realizaram EENM (BOURJEILY-HABR et al., 2002).

O treinamento da marcha também propicia outros efeitos benéficos para o sistema fisiológico dos portadores de lesão medular devido a sustentação de peso e atividade muscular, com conseqüente aumento do estímulo mecânico - efeito piezoelétrico - para o crescimento e remodelamento ósseo, o que previne/reduz/reverte a osteoporose por desuso (CARVALHO, CARVALHO \& CLIQUET Jr., 2001); (CLIQUET Jr., 2003). Além de prevenir as contraturas articulares, infecções no trato urinário e possibilitar a diminuição do tempo de trânsito intestinal (THOUMIE et al., 1995) e o alívio de pressão (MUCCIO, ANDREWS \& MARSOLAIS, 1989).

Diversos são os aspectos benéficos da reabilitação através de Estimulação Elétrica Neuromuscular. Nesta perspectiva, os princípios da fisiologia do exercício são fundamentais para viabilizar o aumento do desempenho durante o exercício induzido artificialmente. 


\section{Capítulo 3}

\subsection{FISIOLOGIA DO EXERCÍCIO: ASPECTOS BIOENERGÉTICOS}

Os fundamentos da fisiologia do exercício utilizados como base nesta pesquisa são apresentados por diversos autores, por exemplo, Powers \& Howley (1994); Wilmore \& Costill (1994); Mcardle, Katch \& Katch (1994); Mcardle, Katch \& Katch (1991).

Os sistemas bioenergéticos utilizados durante a atividade física são as vias anaeróbica e aeróbica. Quando se inicia um exercício a produção de ATP ocorre primeiramente através da fosfocreatina ( $\mathrm{PCr}$ ) e posteriormente pela glicólise anaeróbica, até atingir o "steady-state" (regime permanente), momento em que ocorre o processo de oxidação celular.

A célula muscular durante o repouso ou exercício de baixa a moderada intensidade produz ATP pelas vias oxidativas, ou seja, os nutrientes glicose e ácidos graxos livres são degradados por vias específicas (glicólise e beta oxidação respectivamente) até a formação de acetil CoA, que difunde-se do citoplasma celular para as cristas mitocondriais onde, num conjunto de reações químicas denominado de ciclo dos ácidos tricarboxílicos ou Ciclo de Krebs, ocorre formação de pares de hidrogênio. O elétron de hidrogênio percorre os citocromos da cadeia transportadora de elétrons e através de um mecanismo em cascata há liberação de energia (reações exoergônicas) a qual é utilizada para a biossíntese de ATP. O produto final desta reação, os prótons, tendem a provocar uma alteração importante no pH celular, a acidose. Assim, o oxigênio inspirado e transportado até as mitocôndrias tamponam 
os prótons, com a formação de uma molécula de água e ATP. Quão maior for a oferta de oxigênio às mitocôndrias (na dependência direta dos sistemas pulmonar e cardiovascular-sanguíneo), tão maior a produção de ATP e, como conseqüência uma atividade física mais intensa e duradoura.

No entanto, a partir de uma intensidade de esforço físico moderado à intenso, ocorre uma deficiência relativa de oxigênio às células musculares, iniciando uma alteração metabólica, onde a via oxidativa é desviada para glicólise anaeróbica, onde não há necessidade de oxigênio e a molécula de glicose tem como produto final a molécula de ácido lático.

A elevada concentração de ácido lático muscular altera o processo de contração muscular, pois seus íons $\mathrm{H}^{+}$competem com o $\mathrm{Ca}^{++}$no sítio $\mathrm{TN}-\mathrm{C}$ da tropomina, impedindo o processo contrátil e causando interrupção abrupta do exercício. O ácido lático quando difundido para o plasma causa acidez metabólica e se não tamponada o indivíduo não conseguirá manter o exercício. Então, é necessário manter o equilíbrio ácido-base, através dos tampões plasmáticos, bem como pelos sistemas respiratório e renal.

A presença de ácido lático na circulação sangüínea faz com que o tampão bicarbonato de sódio plasmático reaja com o ácido lático, formando um sal (lactato de sódio) e ácido carbônico que, rapidamente, dissocia-se em água e $\mathrm{CO}_{2}$. O controle da $\mathrm{Pco}_{2}$ é realizado pelo sistema respiratório, graças a existência de quimiorreceptores centrais e periféricos e sensíveis ao $\mathrm{CO}_{2}$ e também aos íons hidrogênio e, em menor sensibilidade, ${\mathrm{a} \mathrm{Po}_{2}}_{2}$.

Durante o exercício físico há uma tendência de instalar-se uma hipercapnia e hiperhidria que são prontamente ajustadas pelas correções respiratórias, ou seja, uma hiperventilação compensatória.

Portanto, o conhecimento da fisiologia do exercício é essencial para implementação de estratégias que viabilizem o ótimo desempenho físico dos lesados medulares, devido à disfunção do Sistema Nervoso Somático e Simpático. 


\section{CAPÍtUlO 4}

\subsection{MATERIAIS E MÉTODOS}

\subsection{RECURSOS HUMANOS}

Esta pesquisa foi aprovada pelo Comitê de Ética Local da Universidade Estadual de Campinas (UNICAMP).

Os indivíduos portadores de lesão medular que apresentaram doenças metabólicas, inflamatórias, cardiopatias e osteoporose intensa foram excluídos da pesquisa.

A seleção dos pacientes foi realizada a partir dos prontuários médicos do Hospital das Clínicas/UNICAMP, levando em consideração os seguintes fatores:

- Pacientes com lesão do neurônio motor superior, entre os níveis T12 e C4;

- Pacientes com o tempo de lesão acima de 1 ano;

- Sexo masculino;

- Idade entre 20 e 40 anos;

- Pacientes que fazem parte do Programa de Estimulação Elétrica Neuromuscular.

Após a seleção, os pacientes foram devidamente informados sobre o projeto de pesquisa e assinaram o Termo de Consentimento Pós-Informação (ANEXO A). 
Participaram desta pesquisa 10 pacientes com lesão medular do sexo masculino (5 paraplégicos e 5 tetraplégicos) que foram classificados de acordo com o Protocolo ASIA (escala de deficiência da American Spinal Injury Association) em lesão completa (A) e lesão incompleta (B).

Também foi avaliado, em cada paciente, o índice de independência funcional por meio do Protocolo FIM (Functional Independence Measure). Os protocolos ASIA e FIM são encontrados no Anexo B.

O perfil dos portadores de lesão medular são mostrados na Tabela 1.

TABELA 1 - Perfil dos portadores de lesão medular participantes da pesquisa.

\begin{tabular}{|c|c|c|c|c|c|c|c|c|}
\hline Pacientes & $\begin{array}{l}\text { Idade } \\
\text { (anos) }\end{array}$ & $\begin{array}{c}\text { Nível } \\
\text { de } \\
\text { Lesão }\end{array}$ & ASIA & FIM* & Causa da Lesão & $\begin{array}{c}\text { Tempo } \\
\text { de Lesão } \\
\text { (anos) }\end{array}$ & $\begin{array}{l}\text { Data de } \\
\text { Início da } \\
\text { EENM }\end{array}$ & $\begin{array}{c}\text { Fase de } \\
\text { Treinamento } \\
\text { Atual no } \\
\text { Programa de } \\
\text { EENM } \\
\end{array}$ \\
\hline 1 & 33 & T9-T10 & A & 116 & $\begin{array}{l}\text { Ferimento por } \\
\text { Arma de Fogo }\end{array}$ & 4 & Ago/2002 & Marcha \\
\hline 2 & 28 & T9 & A & 116 & $\begin{array}{l}\text { Ferimento por } \\
\text { Arma de Fogo }\end{array}$ & 4 & Jan/2002 & Marcha \\
\hline 3 & 36 & T6-T7 & B & 116 & $\begin{array}{c}\text { Acidente } \\
\text { Automobilístico }\end{array}$ & 4 & Fev/2000 & Marcha \\
\hline 4 & 40 & T6 & A & 114 & $\begin{array}{l}\text { Ferimento por } \\
\text { Arma de Fogo }\end{array}$ & 9 & Fev/2000 & Marcha \\
\hline 5 & 31 & $\mathrm{~T} 5$ & B & 113 & $\begin{array}{c}\text { Acidente } \\
\text { Automobilístico }\end{array}$ & 16 & Set/1999 & Marcha \\
\hline 6 & 35 & $\mathrm{C} 7$ & A & 71 & $\begin{array}{l}\text { Ferimento por } \\
\text { Arma de Fogo }\end{array}$ & 8 & Jun/2002 & Condicionamento \\
\hline 7 & 31 & C6-C7 & B & 88 & $\begin{array}{c}\text { Acidente } \\
\text { Automobilístico }\end{array}$ & 12 & Mar/1999 & Condicionamento \\
\hline 8 & 25 & C5-C6 & A & 65 & Mergulho & 10 & Fev/2003 & Condicionamento \\
\hline 9 & 26 & $\mathrm{C} 5$ & A & 74 & Mergulho & 2 & Fev/2001 & Condicionamento \\
\hline 10 & 28 & C4-C5 & A & 55 & Mergulho & 14 & Mar/1999 & Condicionamento \\
\hline
\end{tabular}

\footnotetext{
* Índice máximo:126
} 
Os valores de média e desvio padrão obtidos da altura (cm) e massa $(\mathrm{Kg})$ corpórea dos pacientes paraplégicos são respectivamente, $177 \pm$ 7,8 e 84,6 \pm 14,1. Para os pacientes tetraplégicos os valores obtidos são respectivamente, 177,2 \pm 6,94 e $62,4 \pm 5,02$.

TABELA 2 - Altura e massa corpórea dos pacientes.

\begin{tabular}{ccc}
\hline Pacientes & Altura Corpórea (cm) & Massa corpórea (Kg) \\
\hline 1 & 185 & 73 \\
2 & 182 & 86 \\
3 & 172 & 89 \\
4 & 166 & 70 \\
5 & 180 & 105 \\
6 & 167 & 67 \\
7 & 182 & 62 \\
8 & 185 & 68 \\
9 & 177 & 57 \\
10 & 175 & 58 \\
\hline
\end{tabular}

Participou também desta pesquisa um sujeito saudável (APÊNDICE C), voluntário padrão, que realiza atividade física uma vez por semana, do sexo masculino, com 25 anos de idade, cujos valores de altura e massa corpórea são respectivamente, $179 \mathrm{~cm}$ e $84 \mathrm{Kg}$.

\subsection{METODOLOGIA}

A presente pesquisa foi realizada no Laboratório de Biomecânica e Reabilitação do Aparelho Locomotor (Departamento de Ortopedia e Traumatologia / Hospital das Clínicas da UNICAMP).

O sistema de reabilitação de portadores de lesão medular através de Estimulação Elétrica Neuromuscular consiste na colocação de eletrodos autoadesivos na superfície da pele, sobre o ponto motor dos músculos e/ou diretamente nos nervos periféricos, de acordo com os movimentos desejados. O Programa é dividido em 3 etapas: 
A fase de condicionamento é realizada com os indivíduos sentados na própria cadeira de rodas, uma vez por semana, com duração de 20 minutos de estimulação do músculo quadríceps, gerando extensão do joelho direito e esquerdo alternadamente, seguidos por 15 minutos de estimulação do nervo fibular, evocando por reflexo a dorsiflexão do pé direito e esquerdo, também alternadamente. Em relação aos tetraplégicos, acrescenta-se 20 minutos de Estimulação de membros superiores.

Quando é observada a manutenção da extensão do joelho, inicia-se o treinamento do apoio bípede com auxílio de andador e estimulação concomitante do músculo quadríceps direito e esquerdo.

Com o aumento da resistência à fadiga, inicia-se o treinamento da marcha com auxílio de andador e estimulação dos músculos quadríceps e dos nervos fibulares.

O treinamento do apoio bípede e da marcha são realizados uma vez por semana e o tempo das sessões varia com o desempenho individual, aproximadamente 45 minutos.

As avaliações cardio-respiratórias ( $\mathrm{Pa}, \mathrm{FC}, \mathrm{VO}_{2}, \mathrm{VCO}_{2}$, Ve, $\mathrm{Po}_{2}$ e $\mathrm{Pco}_{2}$ ) foram realizadas no período diurno e os pacientes foram instruídos a seguir as seguintes recomendações (FREY et al., 1997); (HOPMAN et al., 1998); (STEMBERG et al., 2000):

1) Não poderá realizar atividade física intensa 3 dias antes dos testes.

2) 24 horas antes do teste, não poderá consumir cafeína, bebida alcóolica e nicotina.

3) Os medicamentos deverão ser suspensos 24 horas antes dos testes.

4) O esvaziamento do intestino deverá ser realizado na noite anterior ou de manhã e o esvaziamento da bexiga, imediatamente antes do teste ou utilizar a cateterização, para evitar a disreflexia autonômica.

5) Deverá realizar uma dieta controlada (30 minutos antes do teste), por exemplo, podendo comer $50 \mathrm{~g}$ de pão, $10 \mathrm{~g}$ de queijo, $10 \mathrm{~g}$ de presunto e $200 \mathrm{ml}$ de suco de laranja ou uma fruta, para evitar a hipoglicemia durante o exercício. 
O protocolo do teste consistiu em 10 minutos de repouso, 20 minutos de estimulação dos músculos quadríceps direito/esquerdo (contração isotônica concêntrica) e 10 minutos de recuperação em repouso.

Cada participante da pesquisa realizou várias vezes o teste, no mínimo 3 e no máximo 5 vezes.

Foi utilizado um estimulador portátil, desenvolvido pelo Prof. Dr. Alberto Cliquet Jr. (Departamento de Ortopedia e Traumatologia - FCM/UNICAMP e Departamento de Engenharia Elétrica - USP/ São Carlos).

Os parâmetros de estimulação utilizados foram: tipo de onda monofásica bipolar, ciclo de trabalho 4/12, freqüência de $25 \mathrm{~Hz}$, duração de pulso de $300 \mu$ s e amplitude de 0 a $150 \mathrm{~V}$, ajustável de acordo com cada paciente para manter a extensão máxima dos joelhos durante a estimulação dos quadríceps.

A pressão arterial foi mensurada pelo método do Esfigmomanômetro, durante o $5^{\circ}, 25^{\circ}$ e $35^{\circ}$ minuto de execução do teste. A FC foi monitorada por Eletrocardiograma (ECG), registrando os dados freqüência à freqüência (intervalo R$\mathrm{R}$, Rate-Rate) e para avaliação do $\mathrm{VO}_{2}, \mathrm{VCO}_{2}, \mathrm{Ve}, \mathrm{Po}_{2}$ e $\mathrm{Pco}_{2}$ foi utilizado o analisador de gases Sensormedics Vmax 29C, obtendo os registros de respiração à respiração (B-B, Breath-Breath).

A monitoração da FC por ECG foi escolhida para o desenvolvimento da pesquisa por permitir mais possibilidades quanto a definição das derivações para evitar o ruído e por apresentar filtro de $60 \mathrm{~Hz}$, pois no estudo piloto (APÊNDICE A) também foi utilizado o Polar e constatou-se a presença de ruído, o que resultou em leitura desordenada da FC.

O analisador de gases foi precisamente calibrado antes dos testes e os equipamentos foram devidamente esterilizados após cada teste, a temperatura climática limite para interromper o teste foi de $26^{\circ} \mathrm{C}$. A temperatura climática foi controlada por ar condicionado, mantendo a temperatura entre $23^{\circ}$ e $25^{\circ} \mathrm{C}$. 


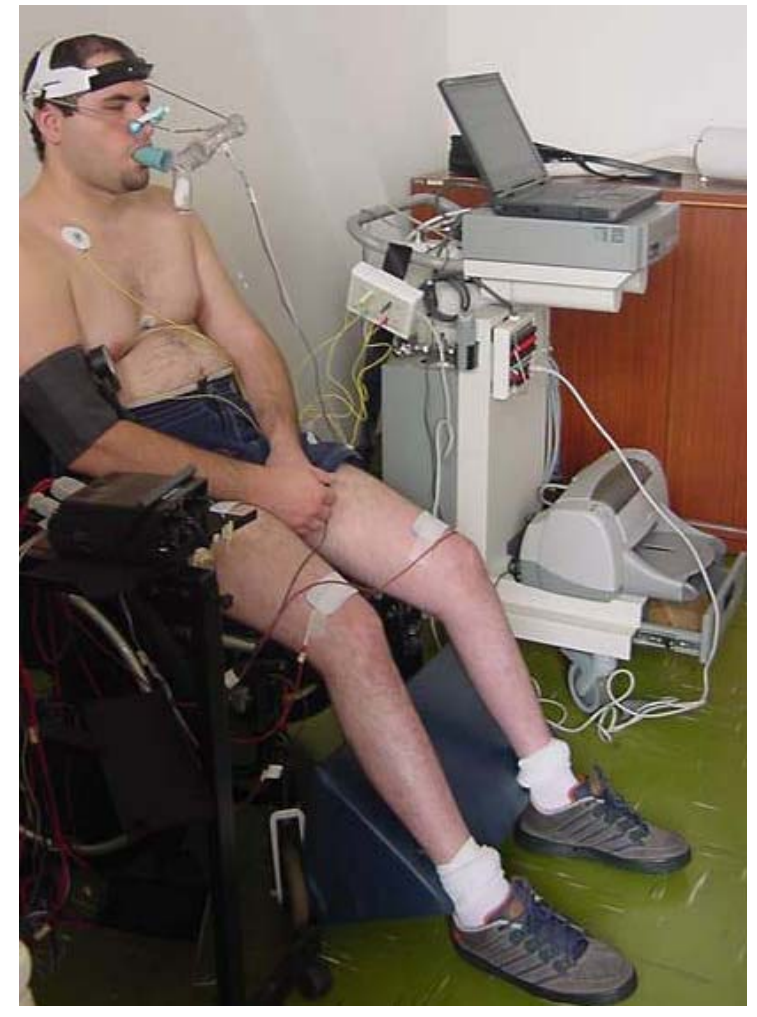

(a)

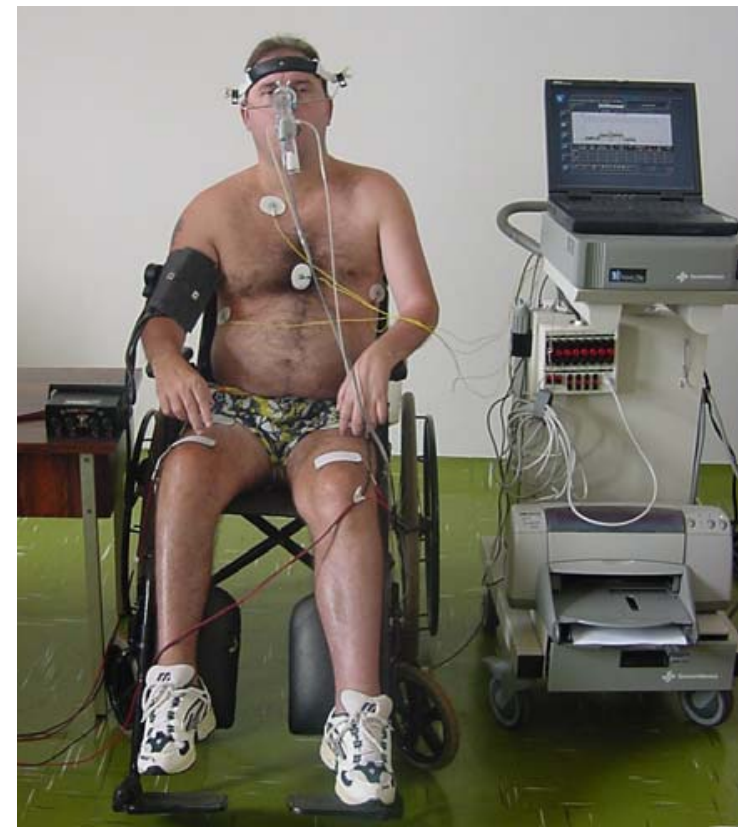

(b)

FIGURA 4 - Procedimento experimental em pacientes com paraplegia (a) e tetraplegia (b). 


\subsection{ANÁLISE DOS DADOS}

Os gráficos das variáveis cardio-respiratórios foram plotados utilizando o Vmax Software (a cada freqüência para a $\mathrm{FC}$ e a cada respiração para o $\mathrm{VO}_{2}, \mathrm{VCO}_{2}$, Ve, $\mathrm{Po}_{2}$ e $\mathrm{PCO}_{2}$ ).

Foi realizada a inspeção visual dos gráficos e a descrição dos resultados obtidos, posteriormente foram obtidos a média e desvio padrão dos valores das variáveis cardio-respiratórias durante os últimos dois minutos em cada fase de transição do teste (repouso, EENM e recuperação). Os dados desta pesquisa foram analisados por meio de estudos de caso devido à variabilidade intersujeitos. 


\section{Capítulo 5}

\subsection{RESULTADOS E DISCUSSÃO}

\subsection{RESULTADOS}

Os resultados abaixo mostram a descrição do comportamento das variáveis cardio-respiratórias dos dez pacientes com lesão medular por meio de estudos de caso.

\subsubsection{ESTUDOS DE CASO}

\section{ESTUDO DE CASO 1}

O paciente 1, com lesão medular completa entre T9 e T10, durante o repouso apresentou FC elevada, enquanto os valores de Pa foram similares aos obtidos pelo sujeito saudável (APÊNDICE C).

Ainda, apresentou valores de $\mathrm{VO}_{2}$ e $\mathrm{VCO}_{2}$ inferiores comparados ao sujeito saudável (APÊNDICE C) durante o repouso e EENM.

Também foi observado durante a EENM, que a cinética dos gases $\left(\mathrm{VO}_{2}\right.$, $\mathrm{VCO}_{2}$ e $\mathrm{Ve}$ ) mostrou que o regime permanente foi atingido rapidamente nos primeiros três minutos (FIGURA 5-a). A FC apresentou ruído (FIGURA 5-c). É importante ressaltar que este paciente apresenta três balas alojadas no corpo, ou seja, na medula espinhal, no lado esquerdo do pescoço e no músculo peitoral maior 
esquerdo. $\mathrm{A} \mathrm{Po}_{2}$ e a $\mathrm{Pco}_{2}$ apresentaram altos valores no final da EENM (FIGURA 5b). Também foi constatado o aumento da Pa sistólica e a manutenção da Pa diastólica (TABELA 3).

No início da recuperação, os valores de $\mathrm{VO}_{2}, \mathrm{VCO}_{2}$ e $\mathrm{Ve}$ atingiram o platô rapidamente com valores similares ao período de repouso. Entretanto, a FC estava um pouco elevada e a Pa retornou aos valores de repouso.

Os valores de média e desvio padrão obtidos das variáveis cardiorespiratórias durante as fases de transição do teste são mostrados na Tabela 3.

\section{ESTUDO DE CASO 2}

O paciente 2, com lesão medular completa em T9, estava tomando o medicamento 4 AP - Amino Piridina, bloqueador de $\mathrm{K}^{+}$(APÊNDICE B). Durante o repouso apresentou FC elevada, enquanto os valores de Pa foram similares aos obtidos pelo sujeito saudável (APÊNDICE C).

Ainda, apresentou valores de $\mathrm{VO}_{2}$ e $\mathrm{VCO}_{2}$ inferiores comparados ao sujeito saudável (APÊNDICE C) durante o repouso e EENM.

Também foi observado durante a EENM, que a cinética dos gases $\left(\mathrm{VO}_{2}\right.$, $\mathrm{VCO}_{2}$ e $\mathrm{Ve}$ ) e a $\mathrm{FC}$ mostraram que o regime permanente foi atingido nos primeiros cinco minutos de EENM (FIGURA 6-a e 6-c). A $\mathrm{Po}_{2}$ apresentou altos valores e a $\mathrm{PCO}_{2}$ baixos valores (FIGURA 6-b). Foi constatado o aumento da Pa sistólica e a manutenção da Pa diastólica (TABELA 3).

Durante a recuperação houve o decréscimo linear na cinética dos gases $\left(\mathrm{VO}_{2}\right.$, $\mathrm{VCO}_{2}$ e $\mathrm{Ve}$ ) e os valores foram um pouco superiores aos de repouso. A FC e a $\mathrm{Pa}$ estavam um pouco elevadas.

Os valores de média e desvio padrão obtidos das variáveis cardiorespiratórias durante as fases de transição do teste são mostrados na Tabela 3.

\section{ESTUDO DE CASO 3}

O paciente 3, com lesão medular incompleta entre T6 e T7, já realizou implante de células tronco e já tomou 4 AP (APÊNDICE B). Durante o repouso 
apresentou valores de FC e Pa similares aos obtidos pelo sujeito saudável (APENNDICE C).

Ainda, apresentou valores de $\mathrm{VO}_{2}$ e $\mathrm{VCO}_{2}$ inferiores comparados ao sujeito saudável (APÊNDICE C) durante o repouso e EENM.

Também foi observado durante a EENM, que a cinética dos gases $\left(\mathrm{VO}_{2}\right.$, $\mathrm{VCO}_{2}$ e $\mathrm{Ve}$ ) mostrou que o regime permanente foi atingido nos primeiros cinco minutos de EENM (FIGURA 7-a). A FC apresentou aumento linear (FIGURA 7-c). A $\mathrm{Po}_{2}$ apresentou altos valores e a $\mathrm{PcO}_{2}$ baixos valores (FIGURA 7-b). Foi constatado o aumento da Pa sistólica e a manutenção da Pa diastólica (TABELA 3).

Durante a recuperação houve o decréscimo linear na cinética dos gases $\left(\mathrm{VO}_{2}\right.$, $\mathrm{VCO}_{2}$ e Ve), com valores superiores comparados ao repouso. A FC manteve-se elevada e a Pa sistólica estava um pouco acima do valor de repouso.

Os valores de média e desvio padrão obtidos das variáveis cardiorespiratórias durante as fases de transição do teste são mostrados na Tabela 3.

\section{ESTUDO DE CASO 4}

O paciente 4, com lesão medular completa em T6, durante o repouso apresentou valores de FC similares aos obtidos pelo sujeito saudável (APÊNDICE C), enquanto a Pa mostrou valores próximos.

Ainda, apresentou valores de $\mathrm{VO}_{2}$ e $\mathrm{VCO}_{2}$ inferiores comparados ao sujeito saudável (APÊNDICE C) durante o repouso e EENM.

Também foi observado durante a EENM, que a cinética dos gases $\left(\mathrm{VO}_{2}\right.$, $\mathrm{VCO}_{2}$ e $\mathrm{Ve}$ ) mostrou que o regime permanente foi atingido rapidamente nos primeiros três minutos (FIGURA 8-a). A FC elevou-se (FIGURA 8-c). A $\mathrm{Po}_{2}$ apresentou valores elevados e a $\mathrm{PCO}_{2}$ no início da EENM apresentou altos valores e posteriormente houve o decréscimo linear (FIGURA 8-b). Foi constatado o aumento da Pa sistólica e a manutenção da Pa diastólica (TABELA 3).

No início da recuperação, os valores de $\mathrm{VO}_{2}, \mathrm{VCO}_{2}$ e $\mathrm{Ve}$ atingiram o platô rapidamente com valores próximos ao período de repouso. A FC e Pa sistólica mantiveram-se elevadas. 
Os valores de média e desvio padrão obtidos das variáveis cardiorespiratórias durante as fases de transição do teste são mostrados na Tabela 3.

\section{ESTUDO DE CASO 5}

O paciente 5, com lesão medular completa em $\mathrm{T}$, durante o repouso apresentou valores de FC e Pa próximos aos obtidos pelo sujeito saudável (APENNDICE C).

Ainda, apresentou valores de $\mathrm{VO}_{2}$ e $\mathrm{VCO}_{2}$ inferiores comparado ao sujeito saudável (APÊNDICE C) durante o repouso e EENM.

Também foi observado durante a EENM, que a cinética dos gases $\left(\mathrm{VO}_{2}\right.$, $\mathrm{VCO}_{2}$ e $\mathrm{Ve}$ ) mostrou que o regime permanente foi atingido nos últimos dez minutos de EENM (FIGURA 9-a). Houve bradicardia no início da EENM, seguido de aumento linear da FC (FIGURA 9-c). $\mathrm{A} \mathrm{Po}_{2}$ apresentou aumento linear, enquanto a $\mathrm{PCO}_{2}$ também apresentou aumento linear, mas no final da EENM houve o decréscimo linear (FIGURA 9-b). Foi constatado o aumento da Pa sistólica e a redução da Pa diastólica (TABELA 3).

Durante a recuperação houve o decréscimo linear na cinética dos gases $\left(\mathrm{VO}_{2}\right.$, $\mathrm{VCO}_{2}$ e Ve), que atingiu os valores de repouso. A FC e a Pa sistólica apresentaram valores elevados.

Os valores de média e desvio padrão obtidos das variáveis cardiorespiratórias durante as fases de transição do teste são mostrados na Tabela 3.

\section{ESTUDO DE CASO 6}

O paciente 6, com lesão medular completa em C7, durante o repouso apresentou bradicardia, enquanto os valores de Pa foram próximos aos obtidos pelo sujeito saudável (APÊNDICE C).

Ainda, apresentou valores de $\mathrm{VO}_{2}$ e $\mathrm{VCO}_{2}$ inferiores comparado ao sujeito saudável (APÊNDICE C) e aos pacientes paraplégicos com lesão abaixo de T6 durante o repouso e EENM. 
Também foi observado durante a EENM, que a cinética dos gases mostrou $\left(\mathrm{VO}_{2}, \mathrm{VCO}_{2}\right.$ e Ve) que o regime permanente foi atingido nos últimos dez minutos de EENM (FIGURA 10-a). Não houve alteração da FC no início da EENM, mas a partir de transcorridos dez minutos houve o aumento linear da FC (FIGURA 10-c). $\mathrm{A} \mathrm{Po}_{2}$ apresentou altos valores e a $\mathrm{Pco}_{2}$ baixos valores (FIGURA 10-b). Foi constatado o aumento da Pa sistólica e o discreto aumento da Pa diastólica (TABELA 4).

Durante a recuperação houve o decréscimo linear na cinética dos gases $\left(\mathrm{VO}_{2}\right.$, $\mathrm{VCO}_{2}$ e Ve), que atingiu os valores de repouso. A FC apresentou valores elevados e a Pa retornou aos valores de repouso.

Os valores de média e desvio padrão obtidos das variáveis cardiorespiratórias durante as fases de transição do teste são mostrados na Tabela 4.

\section{ESTUDO DE CASO 7}

O paciente 7, com lesão medular incompleta entre C6 e C7, durante o repouso apresentou bradicardia e hipotensão.

Ainda, apresentou valores de $\mathrm{VO}_{2}$ e $\mathrm{VCO}_{2}$ inferiores comparados ao sujeito saudável (APÊNDICE C) e aos pacientes paraplégicos com lesão abaixo de T6 durante o repouso e EENM.

Também foi observado durante a EENM, que a cinética dos gases $\left(\mathrm{VO}_{2}\right.$, $\mathrm{VCO}_{2}$ e Ve) mostrou que o regime permanente foi atingido nos últimos dez minutos de EENM (FIGURA 11-a). Houve bradicardia inicial, seguido de aumento linear da FC (FIGURA 11-c). A $\mathrm{Po}_{2}$ e a $\mathrm{Pco}_{2}$ apresentaram altos valores (FIGURA 11-b). Foi constatado o aumento da Pa sistólica e o discreto aumento da Pa diastólica (TABELA 4).

Durante a recuperação houve o decréscimo linear na cinética dos gases $\left(\mathrm{VO}_{2}\right.$, $\mathrm{VCO}_{2}$ e Ve), com valores superiores comparados ao repouso. A Pa apresentou valores elevados comparados ao repouso.

Os valores de média e desvio padrão obtidos das variáveis cardiorespiratórias durante as fases de transição do teste são mostrados na Tabela 4 . 


\section{ESTUDO DE CASO 8}

O paciente 8, com lesão medular completa entre C5 e C6, durante o repouso apresentou bradicardia e hipotensão.

Ainda, apresentou valores de $\mathrm{VO}_{2}, \mathrm{VCO}_{2}$ e $\mathrm{Ve}$ inferiores comparado ao sujeito saudável (APÊNDICE C) e aos pacientes paraplégicos durante o repouso e EENM.

Também foi observado durante a EENM, que a cinética dos gases $\left(\mathrm{VO}_{2}\right.$, $\mathrm{VCO}_{2}$ e $\mathrm{Ve}$ ) mostrou que o regime permanente foi atingido rapidamente nos primeiros 3 minutos (FIGURA 12-a). Houve o aumento inicial da FC, seguido de redução e aumento linear, respectivamente (FIGURA 12-c). A $\mathrm{Po}_{2}$ e a $\mathrm{Pco}_{2}$ apresentaram altos valores (FIGURA 12-b). Foi constatado o aumento da Pa sistólica e a manutenção da Pa diastólica (TABELA 4).

Durante a recuperação houve o decréscimo linear na cinética dos gases $\left(\mathrm{VO}_{2}\right.$, $\mathrm{VCO}_{2}$ e Ve), com valores superiores comparado ao repouso. A Pa apresentou valores elevados comparado ao repouso.

Os valores de média e desvio padrão obtidos das variáveis cardiorespiratórias durante as fases de transição do teste são mostrados na Tabela 4.

\section{ESTUDO DE CASO 9}

O paciente 9, com lesão medular completa em C5, durante o repouso apresentou valores de FC e Pa próximos aos obtidos pelo sujeito saudável (APÊNDICE C).

Ainda, apresentou valores de $\mathrm{VO}_{2}$ e $\mathrm{VCO}_{2}$ inferiores comparados ao sujeito saudável (APÊNDICE C) e maiores comparado aos pacientes tetraplégicos durante o repouso e EENM.

Também foi observado durante a EENM, que a cinética dos gases $\left(\mathrm{VO}_{2}\right.$, $\mathrm{VCO}_{2}$ e $\mathrm{Ve}$ ) mostrou que o regime permanente foi atingido nos primeiros cinco minutos de EENM (FIGURA 13-a). Houve bradicardia inicial, seguido de aumento linear da FC (FIGURA 13-c). $\mathrm{A} \mathrm{Po}_{2}$ e a $\mathrm{Pco}_{2}$ apresentaram altos valores (FIGURA 
13-b). Foi constatado o aumento da Pa sistólica e a manutenção da Pa diastólica (TABELA 4).

Durante a recuperação houve o decréscimo linear da cinética dos gases $\left(\mathrm{VO}_{2}\right.$, $\mathrm{VCO}_{2}$ e Ve), que atingiu os valores de repouso. A FC apresentou valores elevados e a Pa retornou aos valores de repouso.

Os valores de média e desvio padrão obtidos das variáveis cardiorespiratórias durante as fases de transição do teste são mostrados na Tabela 4.

\section{ESTUDO DE CASO 10}

O paciente 10, com lesão medular completa entre C5 e C4, durante o repouso apresentou valores de FC e Pa próximos aos obtidos pelo sujeito saudável (APENNDICE C).

Ainda, apresentou valores de $\mathrm{VO}_{2}$ e $\mathrm{VCO}_{2}$ inferiores comparado ao sujeito saudável (APÊNDICE C) durante o repouso e EENM.

Também foi observado durante a EENM, que a cinética dos gases $\left(\mathrm{VO}_{2}\right.$, $\mathrm{VCO}_{2}$ e $\mathrm{Ve}$ ) mostrou que o regime permanente foi atingido nos últimos dez minutos de EENM (FIGURA 14-a). Houve bradicardia, com períodos alternados de aumento linear da FC (FIGURA 14-c). A $\mathrm{Po}_{2}$ apresentou altos valores e a $\mathrm{Pco}_{2}$ baixos valores (FIGURA 14-b). Foi constatado o aumento da Pa sistólica e a manutenção da Pa diastólica (TABELA 4).

Durante a recuperação houve o decréscimo linear da cinética dos gases $\left(\mathrm{VO}_{2}\right.$, $\mathrm{VCO}_{2}$ e $\mathrm{Ve}$ ), que atingiu os valores de repouso. A FC apresentou valores elevados e a Pa retornou aos valores de repouso.

Os valores de média e desvio padrão obtidos das variáveis cardiorespiratórias durante as fases de transição do teste são mostrados na Tabela 4. 
5.1.2 RESULTADOS COM OS VALORES BRUTOS DOS PACIENTES PARAPLÉGICOS E TETRAPLÉGICOS

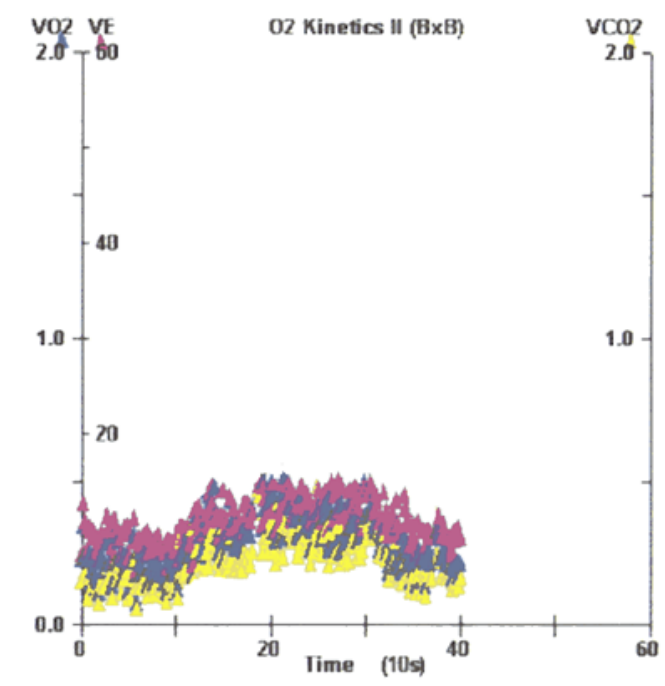

(a)

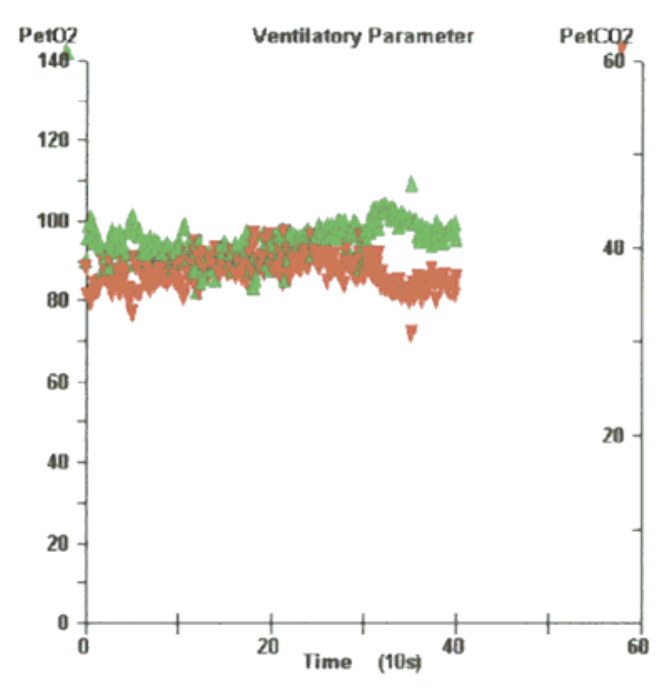

(b)

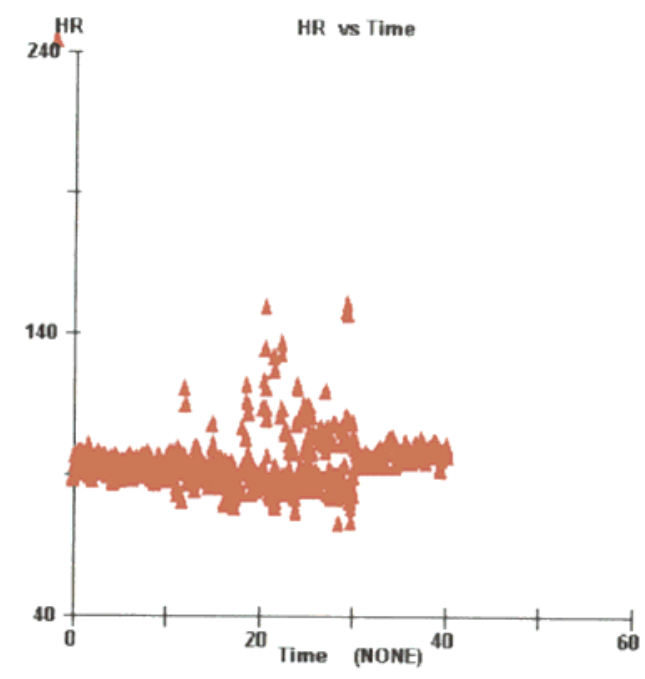

(c)

FIGURA 5 - Variáveis cardio-respiratórias do paciente 1 durante o repouso, EENM e recuperação: cinética dos gases (a); $\mathrm{Po}_{2}$ e $\mathrm{Pco}_{2}$ (b); resposta da $\mathrm{FC} \mathrm{(c).}$ 


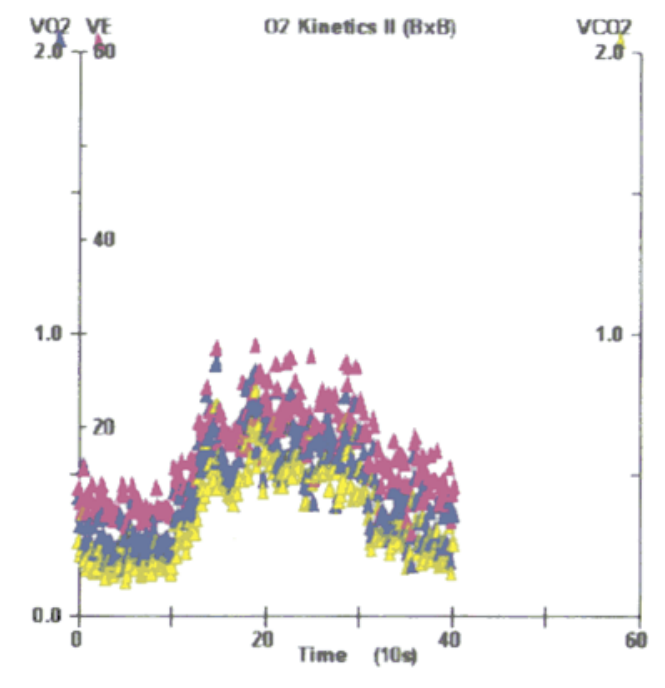

(a)

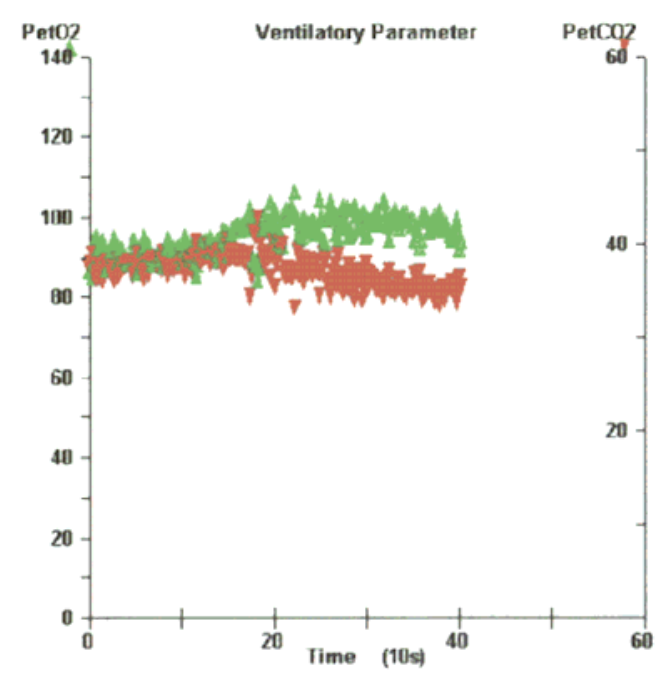

(b)

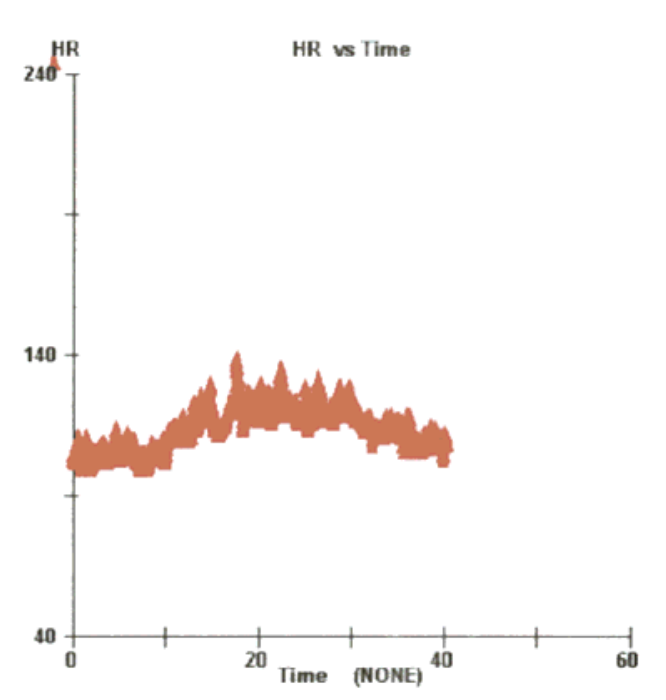

(c)

FIGURA 6 - Variáveis cardio-respiratórias do paciente 2 durante o repouso, EENM e recuperação: cinética dos gases (a); $\mathrm{Po}_{2}$ e $\mathrm{Pco}_{2}$ (b); resposta da $\mathrm{FC}$ (c). 


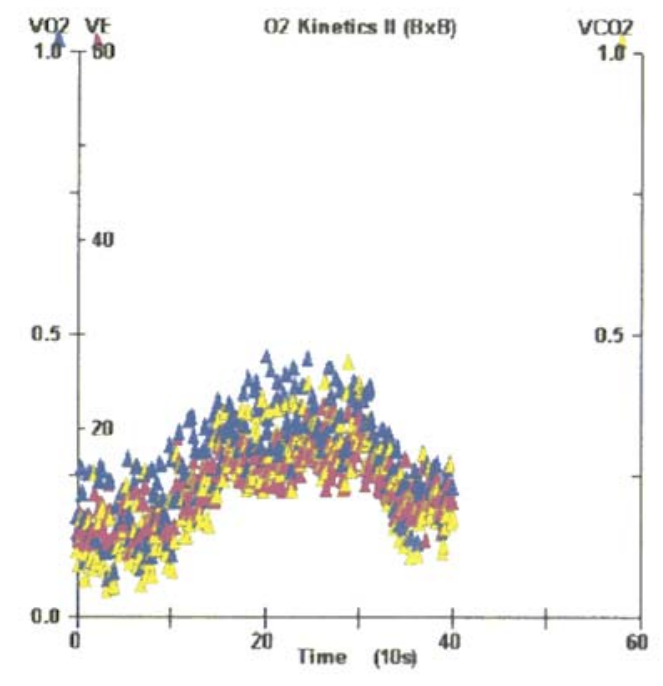

(a)

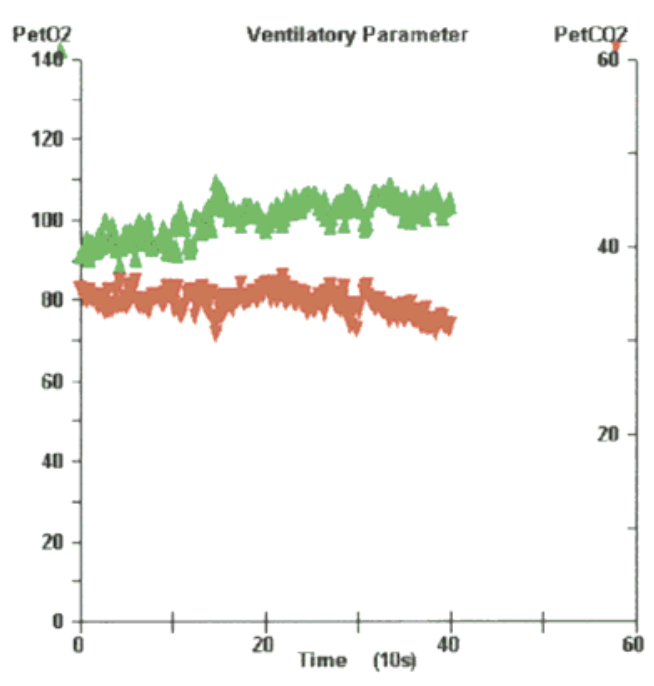

(b)

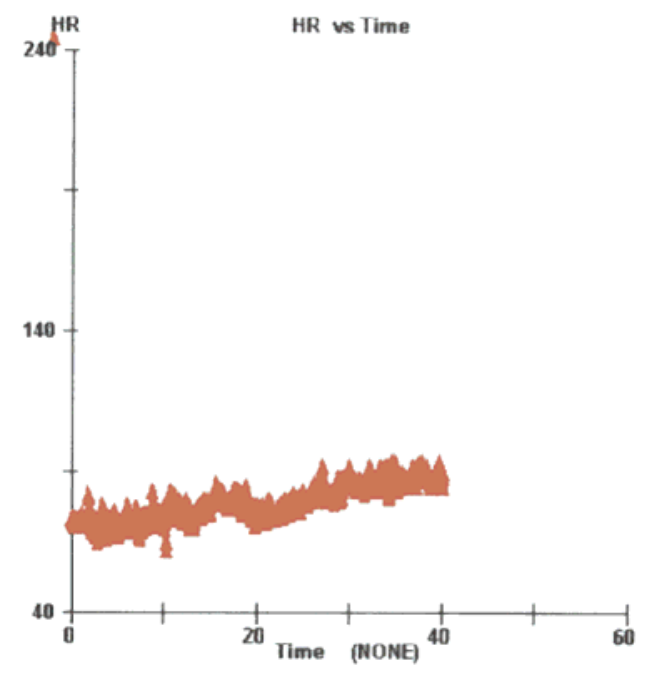

(c)

FIGURA 7 - Variáveis cardio-respiratórias do paciente 3 durante o repouso, EENM e recuperação: cinética dos gases (a); $\mathrm{Po}_{2}$ e $\mathrm{Pco}_{2}$ (b); resposta da $\mathrm{FC} \mathrm{(c).}$ 


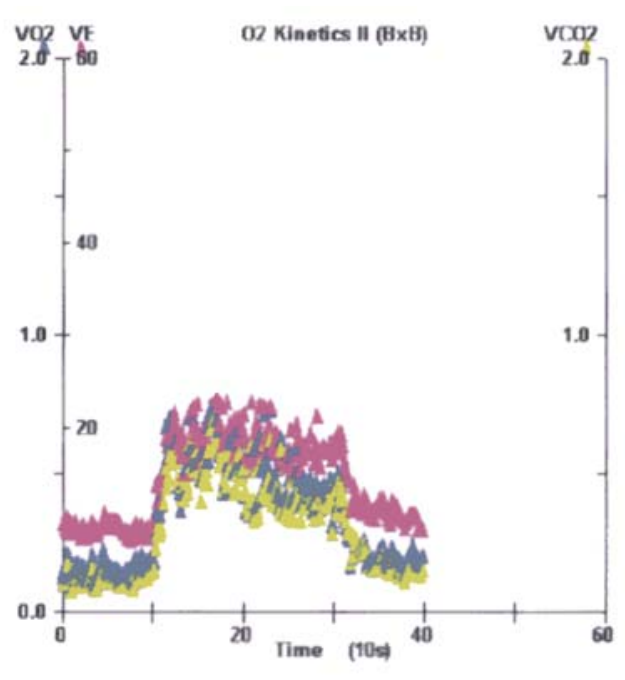

(a)

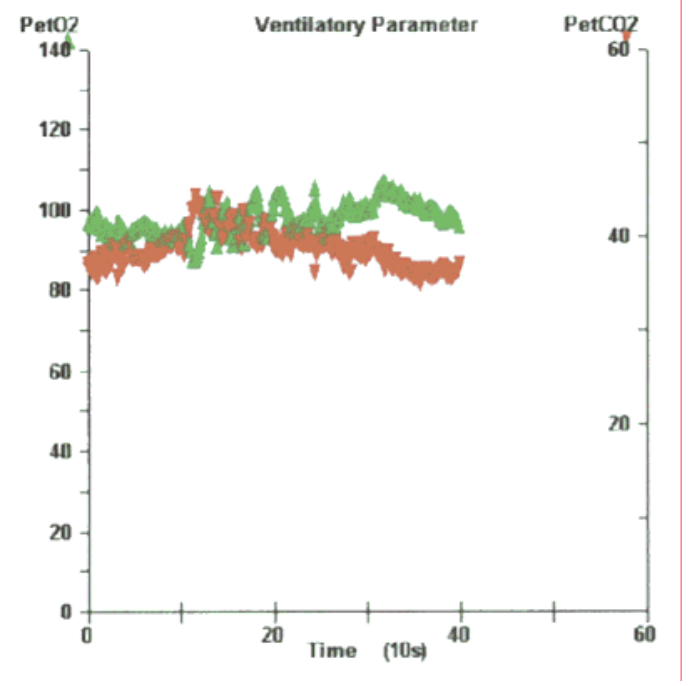

(b)

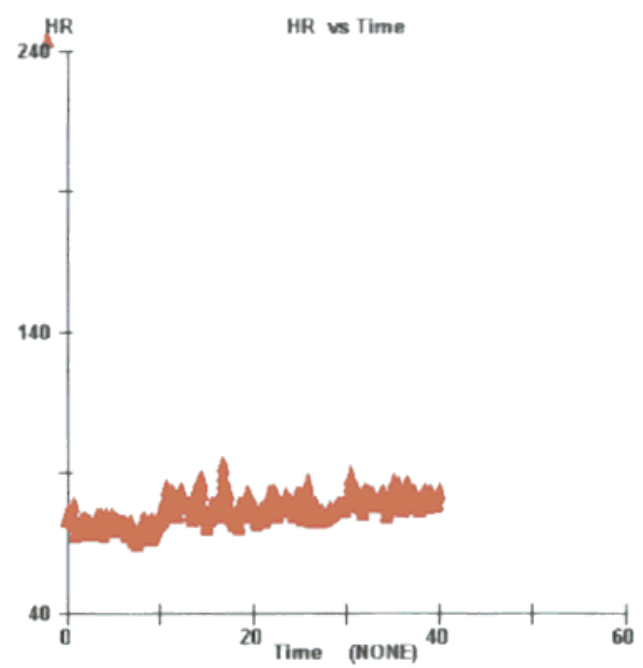

(c)

FIGURA 8 - Variáveis cardio-respiratórias do paciente 4 durante o repouso, EENM e recuperação: cinética dos gases (a); $\mathrm{Po}_{2}$ e $\mathrm{Pco}_{2}$ (b); resposta da $\mathrm{FC} \mathrm{(c).}$ 


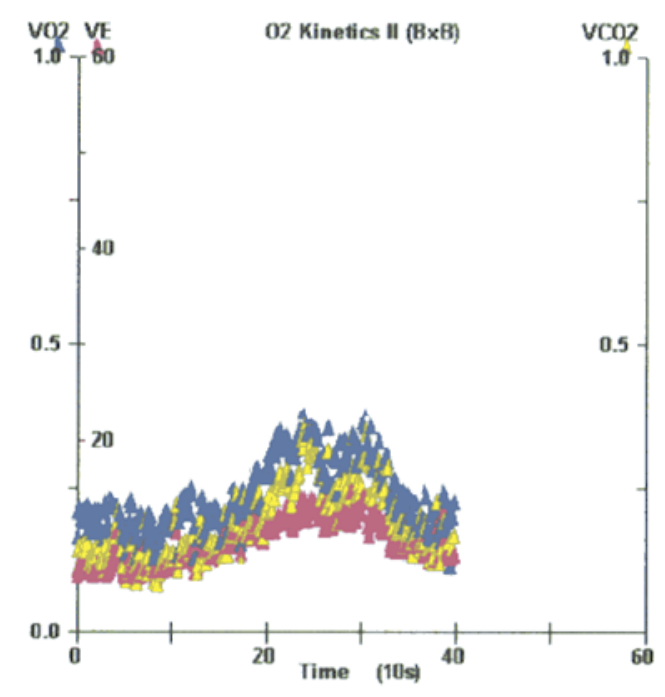

(a)

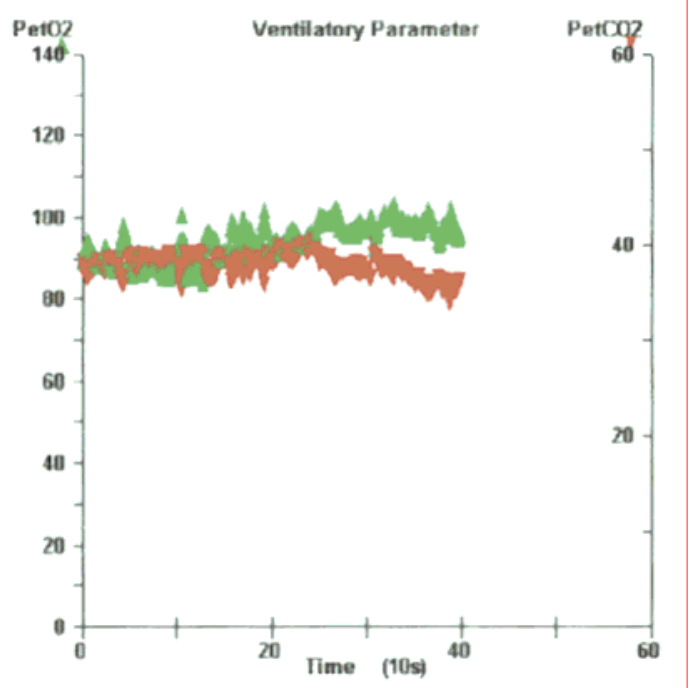

(b)

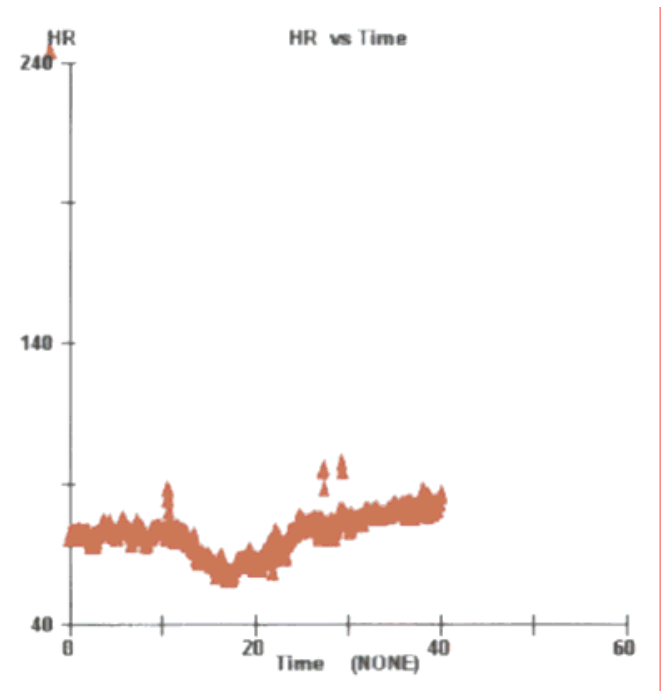

(c)

FIGURA 9 - Variáveis cardio-respiratórias do paciente 5 durante o repouso, EENM e recuperação: cinética dos gases (a); $\mathrm{Po}_{2}$ e $\mathrm{Pco}_{2}$ (b); resposta da $\mathrm{FC} \mathrm{(c).}$ 


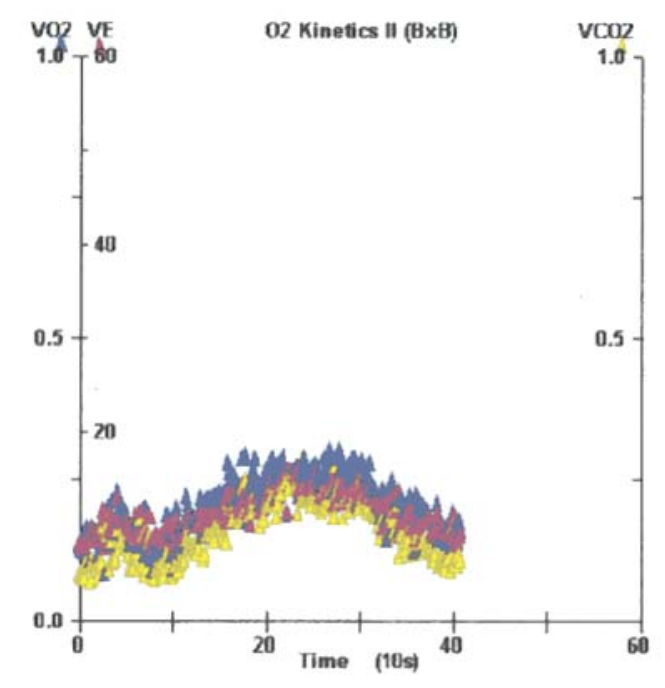

(a)

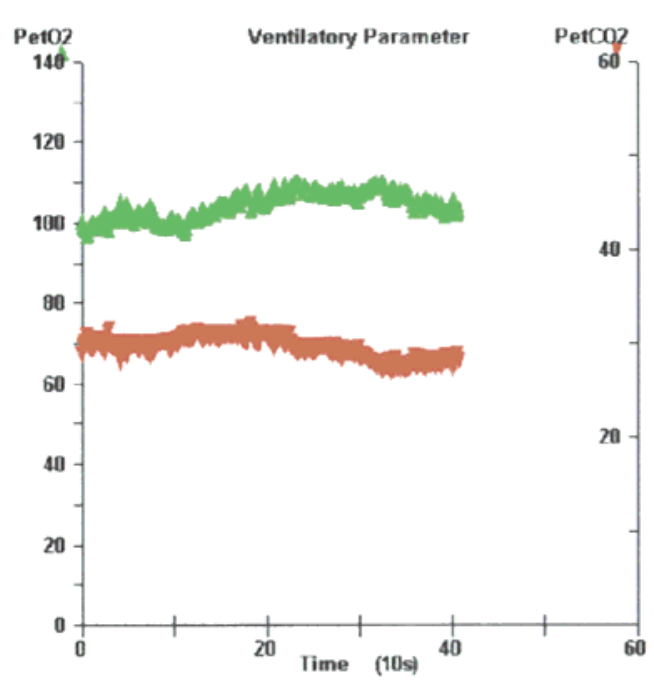

(b)

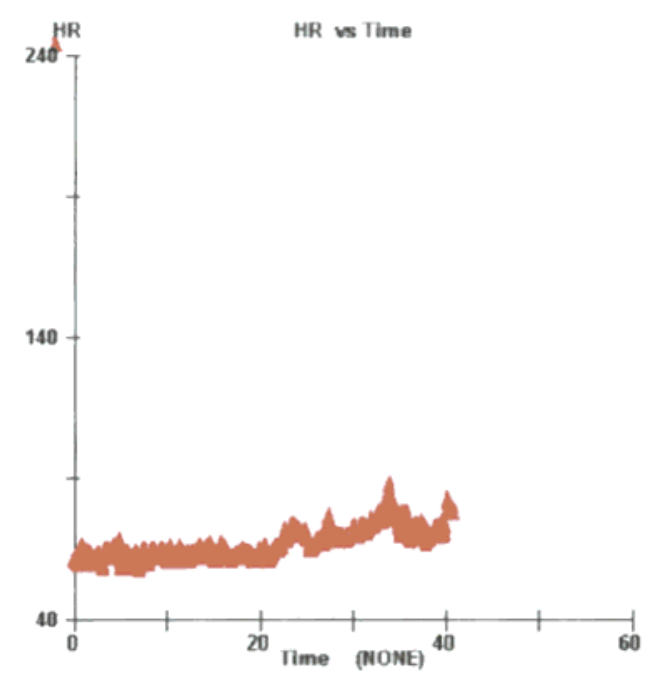

(c)

FIGURA 10 - Variáveis cardio-respiratórias do paciente 6 durante o repouso, EENM e recuperação: cinética dos gases (a); $\mathrm{Po}_{2}$ e $\mathrm{Pco}_{2}$ (b); resposta da FC (c). 


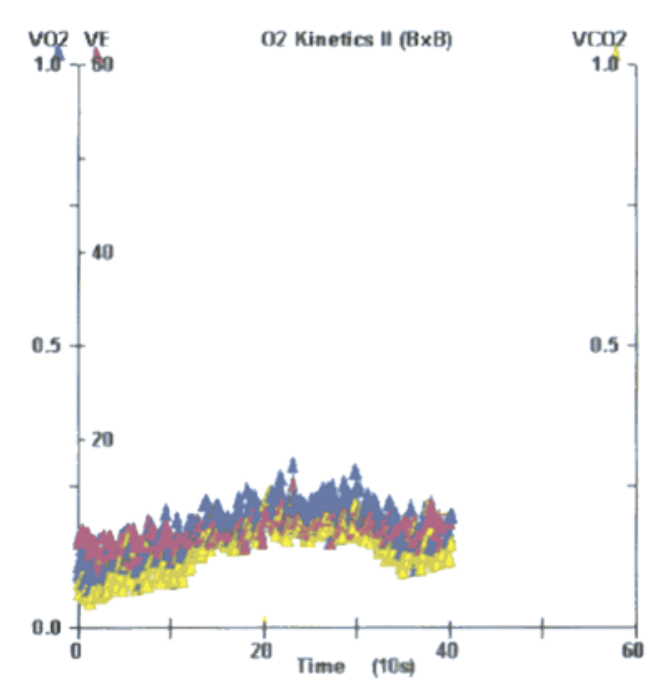

(a)

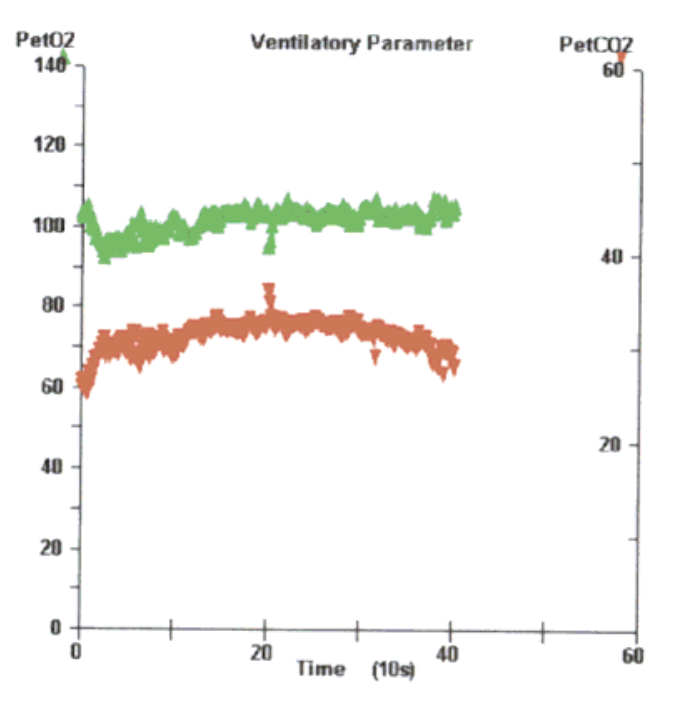

(b)

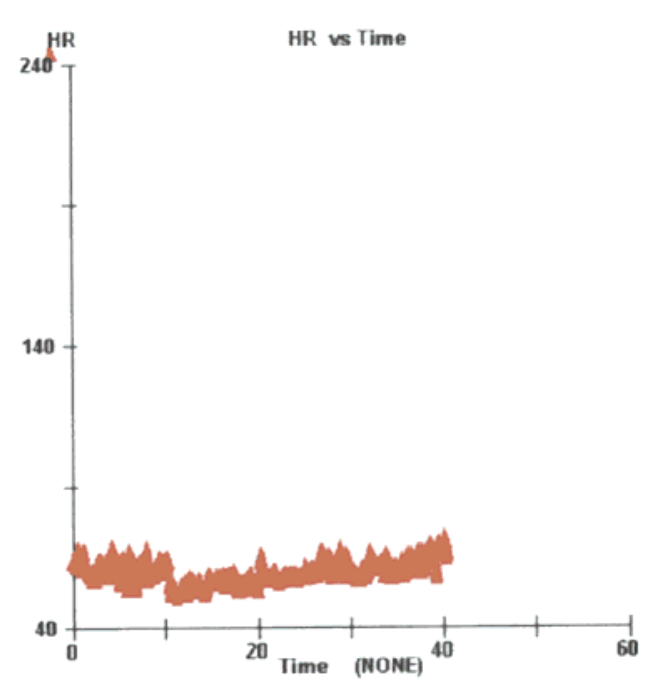

(c)

FIGURA 11 - Variáveis cardio-respiratórias do paciente 7 durante o repouso, EENM e recuperação: cinética dos gases (a); $\mathrm{Po}_{2}$ e $\mathrm{Pco}_{2}$ (b); resposta da $\mathrm{FC} \mathrm{(c).}$ 


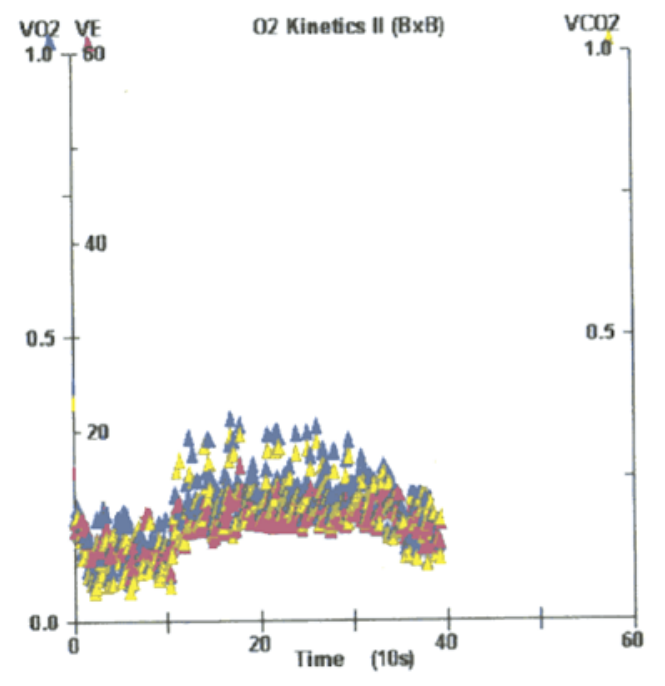

(a)

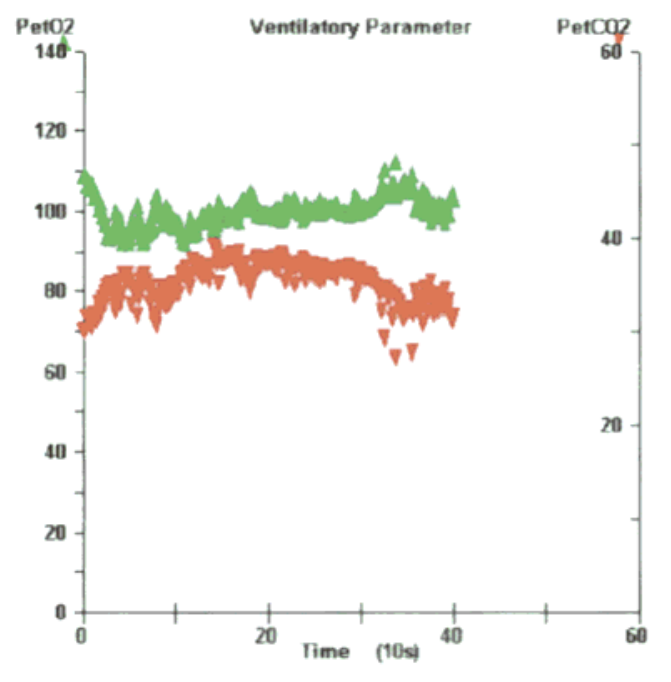

(b)

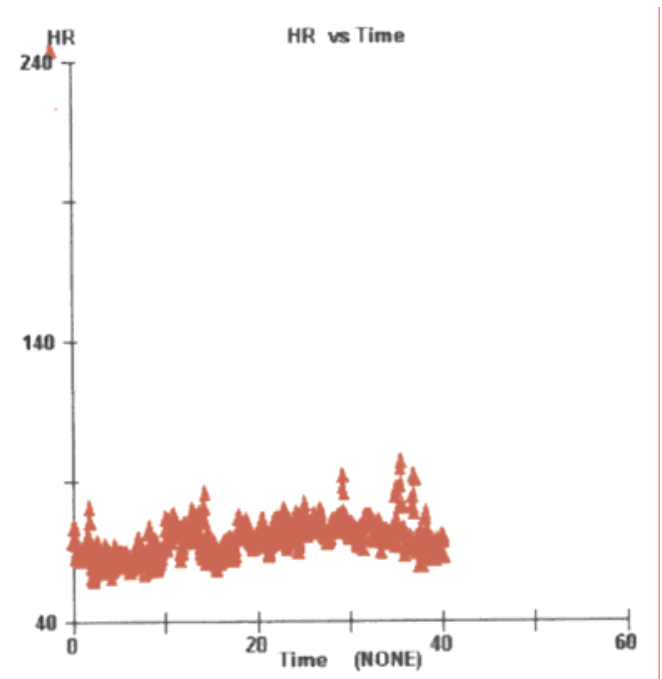

(c)

FIGURA 12 - Variáveis cardio-respiratórias do paciente 8 durante o repouso, EENM e recuperação: cinética dos gases (a); $\mathrm{Po}_{2}$ e $\mathrm{Pco}_{2}$ (b); resposta da FC (c). 


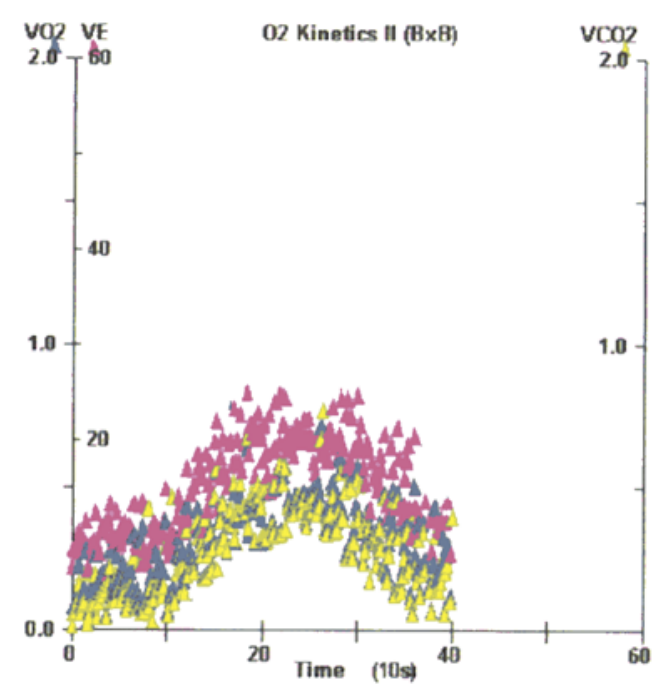

(a)

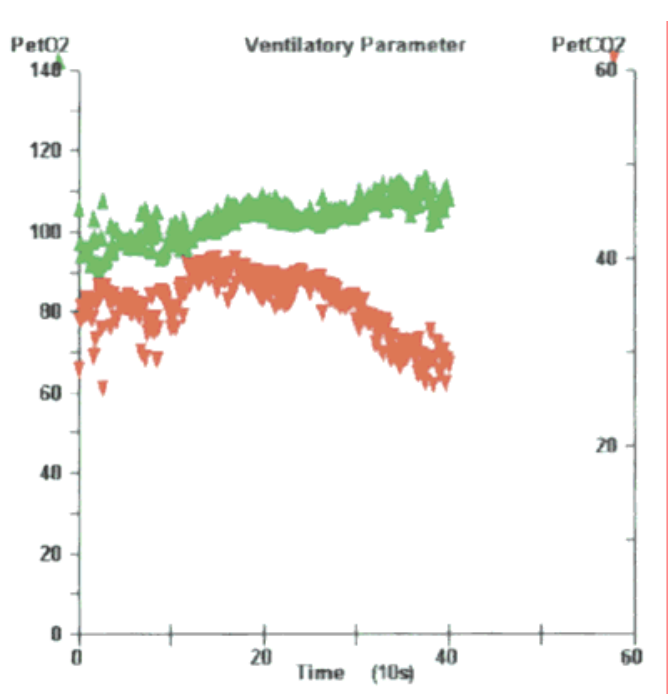

(b)

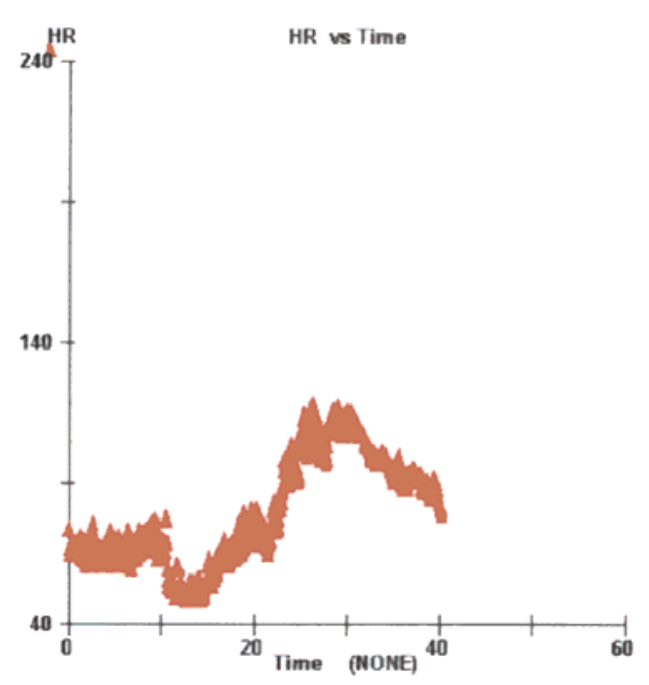

(c)

FIGURA 13 - Variáveis cardio-respiratórias do paciente 9 durante o repouso, EENM e recuperação: cinética dos gases (a); $\mathrm{Po}_{2}$ e $\mathrm{Pco}_{2}$ (b); resposta da FC (c). 


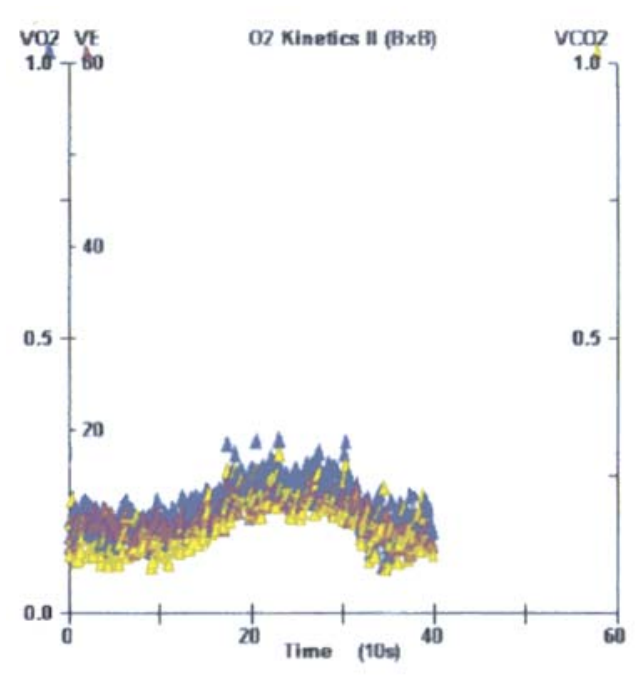

(a)

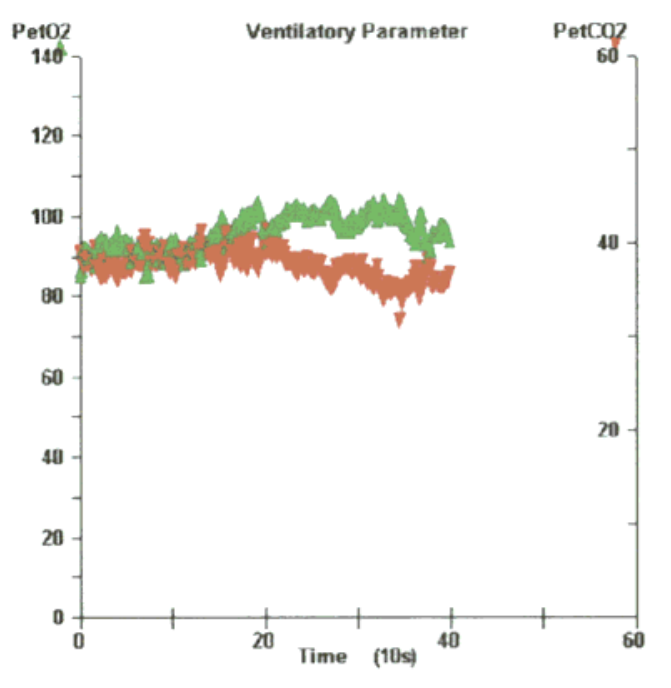

(b)

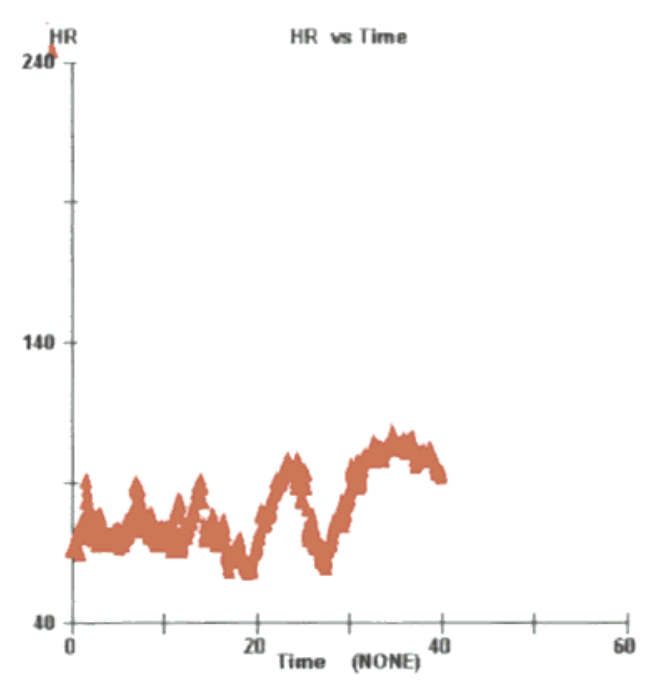

(c)

FIGURA 14 - Variáveis cardio-respiratórias do paciente 10 durante o repouso, EENM e recuperação: cinética dos gases (a); $\mathrm{Po}_{2}$ e $\mathrm{Pco}_{2}$ (b); resposta da FC (c).

TABELA 3 - Média e desvio padrão das variáveis cardio-respiratórias durante o repouso, EENM e recuperação em paraplegia. 


\begin{tabular}{|c|c|c|c|c|}
\hline $\begin{array}{c}\text { Pacientes } \\
\text { Paraplégicos } \\
\end{array}$ & $\begin{array}{c}\text { Variáveis } \\
\text { Cardio-respiratórias } \\
\end{array}$ & Repouso & EENM & Recuperação \\
\hline \multirow{7}{*}{$\begin{array}{c}1 \\
(\mathrm{~T} 9-\mathrm{T} 10)\end{array}$} & $\mathrm{VO}_{2}(\mathrm{l} / \mathrm{min})$ & $0,21 \pm 0,02$ & $0,47 \pm 0,03$ & $0,27 \pm 0,02$ \\
\hline & $\mathrm{VCO}_{2}(\mathrm{l} / \mathrm{min})$ & $0,14 \pm 0,01$ & $0,37 \pm 0,03$ & $0,2 \pm 0,02$ \\
\hline & Ve (l/min) BTPS & $9,97 \pm 0,79$ & $15,37 \pm 1,52$ & $11,22 \pm 0,79$ \\
\hline & $\mathrm{Po}_{2}(\mathrm{mmHg}) \mathrm{STPD}$ & $93,83 \pm 2,50$ & $97 \pm 3,24$ & $98,96 \pm 1,35$ \\
\hline & $\mathrm{PCO}_{2}$ (mmHg) STPD & $37,34 \pm 1,28$ & $39,21 \pm 1,30$ & $36,14 \pm 0,67$ \\
\hline & FC (bpm) & $90,62 \pm 2,66$ & $102,15 \pm 17,24$ & $97,87 \pm 3,44$ \\
\hline & $\mathrm{Pa}(\mathrm{mmHg})$ & $120 \times 80$ & $140 \times 80$ & 120x80 \\
\hline \multirow{7}{*}{$\begin{array}{c}2 \\
\text { (T9) }\end{array}$} & $\mathrm{VO}_{2}(\mathrm{l} / \mathrm{min})$ & $0,26 \pm 0,03$ & $0,65 \pm 0,04$ & $0,28 \pm 0,02$ \\
\hline & $\mathrm{VCO}_{2}(\mathrm{l} / \mathrm{min})$ & $0,19 \pm 0,02$ & $0,52 \pm 0,04$ & $0,22 \pm 0,02$ \\
\hline & Ve (l/min) BTPS & $11,46 \pm 0,85$ & $22,47 \pm 1,40$ & $14,27 \pm 1,10$ \\
\hline & $\mathrm{Po}_{2}(\mathrm{mmHg}) \mathrm{STPD}$ & $93,12 \pm 1,72$ & $99,40 \pm 2,44$ & $99,87 \pm 2,35$ \\
\hline & $\mathrm{PCO}_{2}$ (mmHg) STPD & $38,32 \pm 0,68$ & $37,27 \pm 1,31$ & $35,40 \pm 1,07$ \\
\hline & FC (bpm) & $100,88 \pm 2,76$ & $125,56 \pm 3,74$ & $109,05 \pm 3,23$ \\
\hline & $\mathrm{Pa}(\mathrm{mmHg})$ & 120x80 & 140x80 & 130x80 \\
\hline \multirow{7}{*}{$\begin{array}{c}3 \\
(\mathrm{~T} 6-\mathrm{T} 7)\end{array}$} & $\mathrm{VO}_{2}(\mathrm{l} / \mathrm{min})$ & $0,24 \pm 0,02$ & $0,49 \pm 0,04$ & $0,28 \pm 0,03$ \\
\hline & $\mathrm{VCO}_{2}(\mathrm{l} / \mathrm{min})$ & $0,16 \pm 0,02$ & $0,39 \pm 0,02$ & $0,22 \pm 0,03$ \\
\hline & Ve (l/min) BTPS & $11,08 \pm 0,83$ & $20,35 \pm 2,09$ & $14,40 \pm 1,44$ \\
\hline & $\mathrm{Po}_{2}(\mathrm{mmHg}) \mathrm{STPD}$ & $96,22 \pm 2,41$ & $105,64 \pm 1,82$ & $104,57 \pm 2,10$ \\
\hline & $\mathrm{PCO}_{2}(\mathrm{mmHg}) \mathrm{STPD}$ & $35,31 \pm 0,58$ & $33,85 \pm 0,57$ & $32,72 \pm 0,59$ \\
\hline & FC (bpm) & $78,14 \pm 3,71$ & $91,55 \pm 3,08$ & $90,34 \pm 2,92$ \\
\hline & $\mathrm{Pa}$ (mmHg) & 120x80 & 150x80 & 130x80 \\
\hline \multirow{7}{*}{$\begin{array}{c}4 \\
(\mathrm{~T} 6)\end{array}$} & $\mathrm{VO}_{2}(\mathrm{l} / \mathrm{min})$ & $0,20 \pm 0,01$ & $0,48 \pm 0,04$ & $0,22 \pm 0,02$ \\
\hline & $\mathrm{VCO}_{2}(\mathrm{l} / \mathrm{min})$ & $0,15 \pm 0,01$ & $0,44 \pm 0,03$ & $0,17 \pm 0,02$ \\
\hline & Ve (l/min) BTPS & $9,70 \pm 0,39$ & $19,22 \pm 1,99$ & $10,52 \pm 0,59$ \\
\hline & $\mathrm{Po}_{2}(\mathrm{mmHg}) \mathrm{STPD}$ & $95,16 \pm 0,85$ & $102,25 \pm 1,42$ & $99,89 \pm 0,96$ \\
\hline & $\mathrm{PCO}_{2}(\mathrm{mmHg}) \mathrm{STPD}$ & $39,90 \pm 0,71$ & $38,57 \pm 1,09$ & $36,52 \pm 0,64$ \\
\hline & FC (bpm) & $75,09 \pm 4,39$ & $83,66 \pm 3,67$ & $85,60 \pm 2,50$ \\
\hline & $\mathrm{Pa}$ (mmHg) & 110x70 & 140x70 & 130x70 \\
\hline \multirow{7}{*}{$\begin{array}{c}5 \\
(\mathrm{~T} 5)\end{array}$} & $\mathrm{VO}_{2}(\mathrm{l} / \mathrm{min})$ & $0,17 \pm 0,01$ & $0,35 \pm 0,03$ & $0,20 \pm 0,02$ \\
\hline & $\mathrm{VCO}_{2}(\mathrm{l} / \mathrm{min})$ & $0,11 \pm 0,01$ & $0,28 \pm 0,03$ & $0,15 \pm 0,02$ \\
\hline & Ve (l/min) BTPS & $7,84 \pm 0,35$ & $13,59 \pm 1,01$ & $9,5 \pm 1,61$ \\
\hline & $\mathrm{Po}_{2}(\mathrm{mmHg}) \mathrm{STPD}$ & $89,09 \pm 1,75$ & $98,87 \pm 1,34$ & $99,80 \pm 2,81$ \\
\hline & $\mathrm{PCO}_{2}(\mathrm{mmHg}) \mathrm{STPD}$ & $39,11 \pm 1,47$ & $38,26 \pm 0,50$ & $35,88 \pm 0,93$ \\
\hline & FC (bpm) & $72,41 \pm 2,35$ & $83,35 \pm 2,23$ & $87,09 \pm 2,38$ \\
\hline & $\mathrm{Pa}(\mathrm{mmHg})$ & $110 \times 70$ & $150 \times 60$ & $145 \times 60$ \\
\hline
\end{tabular}

TABELA 4 - Média e desvio padrão das variáveis cardio-respiratórias durante o repouso, EENM e recuperação em tetraplegia. 


\begin{tabular}{|c|c|c|c|c|}
\hline $\begin{array}{c}\text { Pacientes } \\
\text { Tetraplégicos }\end{array}$ & $\begin{array}{c}\text { Variáveis } \\
\text { Cardio-respiratórias }\end{array}$ & Repouso & EENM & Recuperação \\
\hline \multirow{7}{*}{$\begin{array}{c}6 \\
(\mathrm{C} 7)\end{array}$} & $\mathrm{VO}_{2}(\mathrm{l} / \mathrm{min})$ & $0,15 \pm 0,01$ & $0,28 \pm 0,02$ & $0,17 \pm 0,01$ \\
\hline & $\mathrm{VCO}_{2}(\mathrm{l} / \mathrm{min})$ & $0,09 \pm 0,01$ & $0,22 \pm 0,01$ & $0,1 \pm 0,02$ \\
\hline & Ve (l/min) BTPS & $9,47 \pm 0,54$ & $14,64 \pm 0,94$ & $10,1 \pm 0,55$ \\
\hline & $\mathrm{Po}_{2}(\mathrm{mmHg}) \mathrm{STPD}$ & $101,52 \pm 0,89$ & $109,55 \pm 0,86$ & $105,19 \pm 1,09$ \\
\hline & $\mathrm{PCO}_{2}(\mathrm{mmHg}) \mathrm{STPD}$ & $30,22 \pm 0,5$ & $29,41 \pm 0,55$ & $28,69 \pm 0,34$ \\
\hline & $\mathrm{FC}(\mathrm{bpm})$ & $62,9 \pm 2,66$ & $85,52 \pm 2,87$ & $84,54 \pm 5,54$ \\
\hline & $\mathrm{Pa}(\mathrm{mmHg})$ & $110 \times 70$ & $140 \times 80$ & $110 \times 70$ \\
\hline \multirow{7}{*}{$\begin{array}{c}7 \\
(\mathrm{C} 6-\mathrm{C} 7)\end{array}$} & $\mathrm{VO}_{2}(\mathrm{l} / \mathrm{min})$ & $0,15 \pm 0,02$ & $0,25 \pm 0,02$ & $0,16 \pm 0,01$ \\
\hline & $\mathrm{VCO}_{2}(\mathrm{l} / \mathrm{min})$ & $0,09 \pm 0,02$ & $0,20 \pm 0,02$ & $0,12 \pm 0,02$ \\
\hline & Ve (l/min) BTPS & $9,48 \pm 0,96$ & $12,03 \pm 1,14$ & $10,84 \pm 1,20$ \\
\hline & $\mathrm{Po}_{2}$ (mmHg) STPD & $99,91 \pm 1,88$ & $104,38 \pm 1,34$ & $106,33 \pm 0,99$ \\
\hline & $\mathrm{PCO}_{2}(\mathrm{mmHg}) \mathrm{STPD}$ & $31,33 \pm 0,73$ & $32,99 \pm 0,54$ & $28,31 \pm 2,27$ \\
\hline & FC (bpm) & $62,45 \pm 2,73$ & $74,83 \pm 2,99$ & $78,92 \pm 4,19$ \\
\hline & $\mathrm{Pa}(\mathrm{mmHg})$ & $90 \times 60$ & $120 \times 70$ & $110 \times 70$ \\
\hline \multirow{7}{*}{$\begin{array}{c}8 \\
(\mathrm{C} 5-\mathrm{C} 6)\end{array}$} & $\mathrm{VO}_{2}(\mathrm{l} / \mathrm{min})$ & $0,11 \pm 0,01$ & $0,26 \pm 0,02$ & $0,15 \pm 0,02$ \\
\hline & $\mathrm{VCO}_{2}(\mathrm{l} / \mathrm{min})$ & $0,08 \pm 0,01$ & $0,23 \pm 0,02$ & $0,11 \pm 0,02$ \\
\hline & Ve (l/min) BTPS & $7,53 \pm 0,82$ & $11,83 \pm 1,39$ & $8,27 \pm 0,72$ \\
\hline & $\mathrm{Po}_{2}$ (mmHg) STPD & $100,7 \pm 2,85$ & $101,65 \pm 1,15$ & $102 \pm 1,95$ \\
\hline & $\mathrm{PCO}_{2}(\mathrm{mmHg}) \mathrm{STPD}$ & $34,45 \pm 1,26$ & $37,08 \pm 0,63$ & $33,6 \pm 0,99$ \\
\hline & FC (bpm) & $65 \pm 4,73$ & $80,66 \pm 5,04$ & $68,4 \pm 4,57$ \\
\hline & $\mathrm{Pa}(\mathrm{mmHg})$ & $90 \times 60$ & $110 \times 60$ & $110 \times 60$ \\
\hline \multirow{7}{*}{$\begin{array}{c}9 \\
(\mathrm{C} 5)\end{array}$} & $\mathrm{VO}_{2}(\mathrm{l} / \mathrm{min})$ & $0,19 \pm 0,02$ & $0,39 \pm 0,02$ & $0,20 \pm 0,03$ \\
\hline & $\mathrm{VCO}_{2}(\mathrm{l} / \mathrm{min})$ & $0,15 \pm 0,02$ & $0,32 \pm 0,02$ & $0,17 \pm 0,03$ \\
\hline & Ve (l/min) BTPS & $10,82 \pm 1,30$ & $20,80 \pm 2,00$ & $9,98 \pm 1,88$ \\
\hline & $\mathrm{Po}_{2}$ (mmHg) STPD & $98,42 \pm 4,35$ & $106,4 \pm 1,52$ & $107,28 \pm 3,25$ \\
\hline & $\mathrm{PCO}_{2}(\mathrm{mmHg}) \mathrm{STPD}$ & $35,99 \pm 1,89$ & $36,01 \pm 1,29$ & $30,52 \pm 1,58$ \\
\hline & FC (bpm) & $71,33 \pm 3,86$ & $110,78 \pm 3,42$ & $88,54 \pm 3,93$ \\
\hline & $\mathrm{Pa}(\mathrm{mmHg})$ & 110x70 & 130x70 & 110x70 \\
\hline \multirow{7}{*}{$\begin{array}{c}10 \\
(\mathrm{C} 4-\mathrm{C} 5)\end{array}$} & $\mathrm{VO}_{2}(\mathrm{l} / \mathrm{min})$ & $0,16 \pm 0,01$ & $0,27 \pm 0,03$ & $0,16 \pm 0,02$ \\
\hline & $\mathrm{VCO}_{2}(\mathrm{l} / \mathrm{min})$ & $0,11 \pm 0,01$ & $0,22 \pm 0,03$ & $0,13 \pm 0,02$ \\
\hline & Ve (l/min) BTPS & $9,64 \pm 0,82$ & $13,11 \pm 0,66$ & $9,3 \pm 0,76$ \\
\hline & $\mathrm{Po}_{2}$ (mmHg) STPD & $93,12 \pm 1,72$ & $99,99 \pm 2,21$ & $97,71 \pm 1,32$ \\
\hline & $\mathrm{PCO}_{2}(\mathrm{mmHg}) \mathrm{STPD}$ & $38,44 \pm 0,85$ & $37,63 \pm 1,06$ & $36,64 \pm 0,60$ \\
\hline & FC (bpm) & $75,28 \pm 2,61$ & $96,41 \pm 4,19$ & $98,81 \pm 4,02$ \\
\hline & $\mathrm{Pa}(\mathrm{mmHg})$ & $120 \times 80$ & $140 \times 80$ & $120 \times 80$ \\
\hline
\end{tabular}

\subsection{DISCUSSÃO}




\subsubsection{RESPOSTAS CARDIO-RESPIRATÓRIAS À ESTIMULAÇÃO ELÉTRICA NEUROMUSCULAR DO QUADRÍCEPS}

Durante o repouso, os pacientes 1 e 2 com lesão torácica baixa apresentaram FC elevada. Embora, possam apresentar inervação simpática íntegra para o coração (pois a origem das fibras ocorrem entre T1-T4 com maior porção entre T3-T5), a FC de repouso elevada pode estar relacionada com a diminuição da eficiência cardíaca devido a disfunção somática, referente à paralisia muscular abaixo do nível de lesão, bem como, a disfunção simpática para resposta vasomotora, com conseqüente função vascular alterada, concentração sangüínea nos membros inferiores e redução do retorno venoso, débito cardíaco e volume sistólico, fatores que podem resultar em aumento compensatório da FC (HUONKER et al., 1998).

Ainda, a FC elevada no paciente 1 também pode estar relacionada com a distorção do sinal durante o ECG, devido a presença de três balas de arma de fogo alojadas no corpo, sendo uma delas no peitoral maior esquerdo, local próximo às derivações do ECG, que foram escolhidas para evitar ruído durante a EENM.

Em relação ao paciente 2, a FC elevada pode também estar relacionada com algum efeito colateral da droga 4 AP (bloqueador de $\mathrm{K}^{+}$), efeitos ainda desconhecidos. Entretanto, após sete meses sem o uso do medicamento, foi observado que a FC de repouso apresentou valores ótimos (APÊNDICE B).

Foi observado que os pacientes 7 e 8 com lesão cervical apresentaram bradicardia e hipotenção durante o repouso, enquanto o paciente 6, também com lesão cervical, só apresentou bradicardia.

A bradicardia e a hipotensão podem estar relacionadas com a regulação neural da função cardiovascular, devido à disfunção simpática para o coração e para os vasos sangǘneos abaixo do nível de lesão, que juntamente com a perda da bomba muscular esquelética conduzem à redução do retorno venoso e da eficiência cardíaca (INOUE et al., 1995); (THEISEN et al., 2001).

Embora, os tetraplégicos possam apresentar inervação simpática íntegra em especial para o coração, o controle cardiovascular também depende dos centros cerebrais superiores e a lesão medular gera a interrupção do Sistema Nervoso Central 
para o Periférico. Portanto, apresentam disfunção autonômica e o controle simpático irá depender principalmente dos reflexos espinhais e supraespinhais (LEGRAMANTE ET AL., 2001); (SCHIMID et al., 1998 a).

Embora apresentem disfunções do Sistema Nervoso Somático e Simpático, $50 \%$ dos pacientes avaliados apresentaram durante o repouso valores de FC próximos aos obtidos pelo sujeito saudável (APÊNDICE C) e 80\% apresentaram valores ótimos de Pa.

Durante o repouso e EENM foram observados baixos valores de $\mathrm{VO}_{2}$ e $\mathrm{VCO}_{2}$ nos pacientes paraplégicos e tetraplégicos comparados ao sujeito saudável (APÊNDICE C). Ainda, esses valores foram inversamente proporcionais ao nível de lesão, ou seja, em pacientes com nível de lesão abaixo de T6 os valores foram superiores aos obtidos pelos pacientes com lesão acima de T6.

Um fator que pode influenciar na captação de $\mathrm{O}_{2}$ e na eliminação de $\mathrm{CO}_{2}$ é a fraqueza ou algum grau de paralisia dos músculos respiratórios, além da menor distensibilidade do pulmão e do gradil torácico (BAYDUR, ADKINS \& MILICEMILI, 2001), pois a raiz motora para o diafragma ocorre entre C3-C5, para os músculos abdominais entre T7-T12 e para os músculos torácicos e intercostais entre T8-T12 (GLASER, 2002). Entretanto, vários estudos são realizados objetivando a contribuição mecânica para gerar pressão positiva nos músculos respiratórios com o uso da EENM dos músculos inspiratórios e expiratórios (Di MARCO et al., 1999).

A ventilação - troca de ar entre a atmosfera e os alvéolos para ocorrer hematose - depende da freqüência respiratória e do volume corrente. A passagem de fluído ocorre de uma região de maior pressão para uma de menor pressão, de acordo com a Lei de Boyle: P1.V1 = P2.V2, ocorrendo alterações de pressão e volume. Assim durante a inspiração, a pressão pulmonar é menor do que a da atmosfera e na expiração, maior. Os músculos respiratórios são responsáveis pela diferença de pressão pulmonar, alterando o diâmetro da caixa torácica e conseqüentemente da pressão pleural. Após a hematose, os gases são transportados pelo sistema 
circulatório por difusão, o que depende do gradiente de pressão parcial (concentração) para cada gás - $\mathrm{Po}_{2}$ e $\mathrm{Pco}_{2}$ (VANDER, SHERMAN \& LUCIANO, 1981).

Ainda, a demanda de oxigênio no músculo paralisado pode ser reduzida e a circulação hipocinética pode conduzir ao reduzido transporte de $\mathrm{O}_{2}$ e $\mathrm{CO}_{2}$ devido à ausência de bomba muscular esquelética e controle vasomotor (HOPMAN et al., 2002).

Olive et al. (2003) avaliaram o fluxo sangüíneo durante a EENM do quadríceps e constataram o aumento linear na cinética do fluxo em pacientes com lesão medular comparado aos sujeitos saudáveis que atingiram o platô rapidamente. Entretanto, a magnitude do fluxo foi similar entre os grupos. Os autores concluíram que a lenta cinética do fluxo sangüíneo nos pacientes pode limitar a capacidade oxidativa do músculo e influenciar no processo da fadiga muscular.

Então, para potencializar a circulação sangüínea nos pacientes com lesão medular são utilizados ergômetros de braço para aumentar o fluxo sangüíneo nos membros inferiores e a EENM para favorecer o retorno venoso, além de propiciar o maior número de grupos musculares a serem exercitados. Fatores que resultam em aumento da capacidade cardio-vascular, respiratória e muscular (BROWN et al., 2001); (FRANKEN et al., 1997); (HOPMAN et al., 1998).

Durante a marcha com EENM, os pacientes se exercitam em altos níveis cardio-respiratórios comparados aos resultados obtidos por estes pacientes durante a EENM do quadríceps. Este fato pode estar relacionado com a mudança postural, esforço dos membros superiores, bem como, com a fase de flexão/extensão do joelho e reequilíbrio postural durante a marcha (CLIQUET, BAXENDALE \& ANDREWS, 1989); (NENE \& PATRICK, 1990).

Em indivíduos saudáveis, as altas taxas metabólicas e cardio-respiratórias durante o exercício estão relacionadas ao aumento da temperatura corporal e ao elevado nível de adrenalina e noradrenalina (WILMORE \& COSTILL, 1994). Ainda, 
o aumento do fluxo sangüíneo muscular ocorre principalmente devido ao aumento do débito cardíaco. Então, o fluxo sangüíneo é consideravelmente maior nos músculos que estão sendo exercitados comparados aos outros tecidos. Isto ocorre devido à regulação vascular central (Sistema Nervoso Autônomo Simpático e Parassimpático), regulação hormonal (fibras constritoras adrenérgicas e fibras vasodilatadoras) e das condições metabólicas locais dos próprios músculos, como o número de capilares ativos que é determinado pela resposta vasomotora que ocorre de acordo com a taxa metabólica (McARDLE, KATCH \& KATCH, 1991).

Os pacientes com lesão medular, em especial aqueles com lesão acima de T6, podem apresentar circulação hipocinética e perda do controle simpático para o coração, medula adrenal e resposta vasomotora, bem como, perda da resposta temorregulatória (BHAMBHANI, 2002); (DEC, SPARROW \& McKEAG, 2000); (HOPMAN et al., 1998); (SCHIMID et al., 1998 b) o que pode estar relacionado com os baixos níveis cardio-respiratórios, com a lenta cinética dos gases e conseqüente alterações dos valores de $\mathrm{Po}_{2}$ e $\mathrm{Pco}_{2}$.

Vários são os métodos de avaliar a potência aeróbica (capacidade funcional em captar, transportar e utilizar o $\mathrm{O}_{2}$ ) sendo um deles a quantificação do déficit de $\mathrm{O}_{2}$. Entretanto, a potência anaeróbica também pode ser avaliada simultaneamente, através do débito de $\mathrm{O}_{2}$ (POWERS \& HOWLEY, 1994).

$\mathrm{O}$ déficit de $\mathrm{O}_{2}$ está intimamente relacionado com a transição do metabolismo anaeróbico para o aeróbico, ou seja, quando se inicia um exercício a produção de ATP ocorre primeiramente através da fosfocreatina (PCr) e posteriormente pela glicólise anaeróbica, até atingir o regime permanente, momento em que ocorre o processo de oxidação celular. Enquanto, o débito de $\mathrm{O}_{2}$ (também denominado EPOC - Excesso Post-Exercise Oxygen Consuption), está intimamente relacionado ao acúmulo de ácido lático e restauração das reservas de PCr e ATP (Di PRAMPERO \& FERRETTI, 1999).

O sujeito saudável (APÊNDICE C), apresentou valores superiores de $\mathrm{VO}_{2}$ e $\mathrm{VCO}_{2}$ comparado aos pacientes com lesão medular e mostrou rápida cinética dos gases $\left(\mathrm{VO}_{2}, \mathrm{VCO}_{2}\right.$ e Ve) durante o início da atividade motora e recuperação (ambos 
nos primeiros três minutos), de maneira semelhante aos pacientes 1 e 4 . Em relação ao paciente 8 foi observada rápida cinética dos gases no início da atividade motora (nos primeiros três minutos), mas lenta cinética dos gases durante a recuperação, com valores superiores comparados ao repouso. Nos pacientes 2, 3 e 9 a cinética dos gases mostrou que o regime permanente foi atingido nos primeiros cinco minutos de atividade motora, entretanto durante a recuperação constatou-se lenta cinética dos gases. Nos pacientes 5, 6, 7 e 10 a cinética dos gases mostrou que o regime permanente foi atingido nos primeiros dez minutos de atividade motora, o que caracteriza o componente lento da curva, também observado no período de recuperação.

Então, o regime permanente atingido no início da EENM e o retorno das variáveis cardio-respiratórias aos valores de repouso após a EENM, indicam bom condicionamento, pois a rápida cinética do $\mathrm{VO}_{2}$ no início do exercício demonstra que há oxigênio necessário para o músculo exercitado gerar ATP, com predominância da via aeróbica. Enquanto, a rápida cinética do $\mathrm{VO}_{2}$ no período de recuperação indica que a restauração de ATP e PCr ocorreu rapidamente (WILMORE \& COSTILL, 1994).

A lenta cinética dos gases no início e após a EENM refletem a predominância da via anaeróbica lática. Ainda, a rápida cinética dos gases no início da EENM e a lenta cinética dos gases no período de recuperação também podem refletir a predominância da via anaeróbica, pois a lenta cinética do $\mathrm{VO}_{2}$ no início do exercício, indica $\mathrm{O}_{2}$ insuficiente para o músculo exercitado gerar ATP, então a produção de ATP é decorrente da glicólise aneróbica. A lenta cinética dos gases no período de recuperação está relacionada com a restauração das reservas de carboidrato, pela ressíntese de ácido lático e sua transformação novamente em glicogênio no figado, bem como, com a função de catabolizar o ácido lático restante através da via ácido pirúvico - ciclo de Krebs. Ainda, outros fatores relacionados com a lenta cinética do $\mathrm{VO}_{2}$ no período de recuperação são os ajustes respiratórios, iônicos, circulatórios, térmicos e hormonais, como restabelecer os níveis de adrenalina e noradrenalina 
(WILMORE \& COSTILL, 1994). Entretanto, os portadores de lesão medular podem apresentar disfunções destes sistemas (FREY et al., 1997).

Theisen et al. (2002) avaliaram a cinética do $\mathrm{VO}_{2}$ em pacientes com lesão medular durante quarenta minutos pedalando com o uso da EENM em cargas constantes. Os autores sugeriram que a lenta cinética dos gases está relacionada com o aumento da amplitude do sinal de EENM e com a predominância da via anaeróbica lática. O platô permaneceu até o período de 20 minutos de exercício e posteriormente houve declínio, como resultado da fadiga muscular.

A lenta cinética dos gases observada em alguns pacientes, reflete a predominância da via anaeróbica, que resulta em elevada concentração de ácido lático muscular, o que pode resultar em interrupção abrupta do exercício. O ácido lático quando difundido para o plasma causa acidez metabólica e se não tamponada o indivíduo não conseguirá manter o exercício. A presença de ácido lático na circulação sangüínea faz com que o tampão bicarbonato de sódio plasmático reaja com o ácido lático, formando um sal (lactato de sódio) e ácido carbônico que, rapidamente, dissocia-se em água e $\mathrm{CO}_{2}$. O controle da $\mathrm{pCO}_{2}$ é realizado pelo sistema respiratório, graças à existência de quimiorreceptores centrais e periféricos, sensíveis ao $\mathrm{CO}_{2}$ e também aos íons hidrogênio e, em menor sensibilidade, a $\mathrm{pO}_{2}$ (McARDLE, KATCH \& KATCH, 1991). Então, o controle da ventilação durante o exercício está intimamente relacionado aos valores das pressões parciais de $\mathrm{CO}_{2}$ e $\mathrm{O}_{2}$, além da ação dos fatores humorais e neurogênicos, como a influência cortical e periférica relacionada aos mecanoceptores.

Durante a EENM, os pacientes apresentaram valores alterados da $\mathrm{Po}_{2}$ e $\mathrm{Pco}_{2}$, ou seja, os pacientes 2, 3, 6 e 10 apresentaram altos valores de $\mathrm{Po}_{2}$ e baixos valores de $\mathrm{PCO}_{2}$, Os pacientes $1,7,8$ e 9 apresentaram altos valores de $\mathrm{Po}_{2}$ e $\mathrm{Pco}_{2}$, os pacientes 4 e 5 apresentaram altos valores de $\mathrm{Po}_{2}$, enquanto o $\mathrm{Pco}_{2}$ apresentou valores superiores no início da EENM e menores no final. Estas alterações indicam realização de exercício exaustivo. Diferentemente, os resultados obtidos pelo sujeito saudável mostraram que os valores de $\mathrm{Po}_{2}$ diminuíram e mantiveram-se constantes, 
enquanto os valores de $\mathrm{Pco}_{2}$ aumentaram e também mantiveram-se constantes durante o exercício.

Em exercício exaustivo a ventilação aumenta mais que o $\mathrm{VO}_{2}$ e resulta em maior $\mathrm{Po}_{2}$. Altos valores de $\mathrm{Po}_{2}$ diminuem a fixação de oxigênio na hemoglobina, efeito Bohr, o que reduz a capacidade do sangue em transportar oxigênio até os músculos ativados durante o exercício, e assim, diminui o desempenho. Em exercício exaustivo, pelas mesmas razões apontadas para o oxigênio, a $\mathrm{Pco}_{2}$ constante ou diminuída indica que não há acumulo excessivo de íons $\mathrm{H}^{+}$como resultado do excesso de $\mathrm{CO}_{2}$. Já o aumento da $\mathrm{Pco}_{2}$, resulta no aumento da ventilação para eliminar o excesso de $\mathrm{CO}_{2}$ (McARDLE, KATCH \& KATCH, 1994); (McARDLE, KATCH \& KATCH, 1991); (POWERS \& HOWLEY, 1994); (VANDER, SHERMAN \& LUCIANO, 1981); (WILMORE \& COSTILL, 1994).

Na literatura, não foram encontrados dados referentes às respostas de $\mathrm{Po}_{2} \mathrm{e}$ $\mathrm{PCO}_{2}$ em pacientes com lesão medular.

Embora foram constatados valores alterados de $\mathrm{Po}_{2}$ e $\mathrm{Pco}_{2}$, bem como lenta cinética dos gases em alguns pacientes, observou-se que desde o estudo piloto (APÊNDICE A), os pacientes 3, 4, 5, 6, 7 e 10 apresentaram mudanças na cinética dos gases, o que demostra o aumento da predominância da via aeróbica, além de possíveis adaptações decorrentes de seis meses de treinamento com EENM.

Essas adaptações podem estar relacionadas, por exemplo, com o aumento da força muscular, da proporção das fibras musculares mais oxidativas, das mitocôndrias e dos capilares, além da melhora na circulação sangüínea (BARSTOW et al., 1996).

Durante a EENM, todos os paciente apresentaram aumento da Pa, entretanto, a resposta da FC apresentou variabilidade intersujeitos.

O sujeito saudável (APÊNDICE C) e o paciente 2 apresentaram aumento da FC durante a atividade motora e atingiram o regime permanente. O sinal 
eletrocardiográfico do paciente 1 apresentou ruído durante a EENM, já explicado anteriormente este paciente apresenta balas de arma de fogo alojadas no corpo. Os pacientes 3, 4, 6 e 8 apresentaram aumento da FC, entretanto no paciente 6 este aumento foi observado no final da EENM e no paciente 8 houve aumento inicial com uma ligeira queda, seguido de aumento linear. Os pacientes 5, 7 e 9 apresentaram bradicardia inicial seguido de aumento linear, enquanto o paciente 10 apresentou bradicardia alternada com períodos de aumento linear da FC.

Durante a EENM, foi observado o aumento da FC em alguns pacientes e o aumento da Pa sistólica em todos os pacientes, embora os portadores de lesão medular possam apresentar perda da resposta vasoconstritora abaixo do nível de lesão (membros inferiores, área esplânica e abdominal), o que pode resultar em concentração sangüínea nos membros inferiores e hipotensão durante o exercício com os membros superiores ou ortostatismo (postura sentada ou ereta passivamente). Então, estes resultados estão relacionados aos benefícios hemodinâmicos propiciados pela EENM, como a ativação da bomba muscular esquelética, que aumenta o retorno venoso, o enchimento ventricular, a distensibilidade das fibras do miocárdio, a força de contração, o volume sistólico, a FC, o débito cardíaco e a Pa, segundo a Lei de Frank Starling (HOPMAN et al., 1998).

O aumento da Pa e da FC durante o exercício pode também estar relacionada com a influência dos volume- e baroceptores (KJAER et al., 1999).

Ainda, a ativação da bomba muscular esquelética e o aumento do retorno venoso, propiciados pela EENM nos membros inferiores, favorecem a ação dos fatores humorais, isto é, o transporte dos substratos metabólicos do músculo ativado artificialmente (por exemplo, o ácido lático e a elevada temperatura corpórea), que pode ajudar os pacientes a responderem ao stress do exercício físico resultando em aumento da FC e Ve. O feedback humoral pode estar relacionado com a elevada FC no período de recuperação.

No estudo de Kjaer et al. (1999), foi constatado o aumento da FC em paraplégicos e tetraplégicos durante o ato de pedalar induzido por EENM e estes 
valores permaneceram elevados no período de recuperação, devido à ação do feedback humoral, pois quando o mesmo procedimento foi realizado com oclusão vascular nos membros inferiores, a resposta da FC ao exercício foi inferior e reflete o reduzido retorno venoso que limita o transporte dos substratos metabólitos do músculo ativado artificialmente.

A FC inalterada no início da EENM, pode estar relacionada com o controle do tônus parassimpático vagal para o nódulo S-A e os fatores humorais podem explicar o aumento tardio da FC, como no caso do paciente 6.

Então, o aumento da FC no início da EENM pode estar relacionado com a saída do tônus vagal (GLASER, 2002) e (ROGERS, 2002), como no caso do paciente 8 que apresentou aumento inicial da FC seguido de queda e aumento linear, respectivamente. Este aumento tardio da FC também pode estar relacionado com os fatores humorais.

Ainda, o aumento da FC observado em alguns pacientes durante a EENM também pode estar relacionado com algum grau de controle simpático preservado para a medula adrenal, pois a inervação ocorre entre T3-L3 com maior porção entre T6-T10) e para o coração (nos pacientes com nível de lesão medular acima T6), pois a perda do controle simpático para o coração pode não resultar em cardioaceleração durante o exercício e a perda do controle simpático para medula adrenal pode resultar em liberação anormal das catecolaminas, ou seja, adrenalina e noradrenalina (SCHIMID et al., 1998 b); (STEINBERG et al., 2000).

Os pacientes 5, 7, 9 e 10 apresentaram aumento da Pa durante a EENM, mas ocorreu bradicardia seguida de aumento linear da FC, mostrando dissociação entre FC e Pa.

Assim, a dissociação entre FC e Pa provavelmente não foi associada com a disreflexia autonômica, pois o aumento da Pa sistólica não ocorreu acima de 40 mmHg do valor basal. Segundo Curt, Weinhart e Dietz (1996) a hipertensão pode atingir $220 \mathrm{mmHg}$, embora possam ocorrer episódios moderados e leves (INOUE et al., 1995). Também não foi observado suor acima do nível de lesão, piloereção e 
mal-estar. Acredita-se então, que houve o aumento do retorno venoso, resultando em efeito de Starling, com aumento da pressão sangüínea e ativação do reflexo baroceptor, com conseqüente bradicardia. Este resultado é semelhante aos encontrados em portadores de lesão medular que retornaram à posição supina, após o estress ortostático com EENM nos membros inferiores (ELOKDA, NIELSEN \& SHIELDS, 2000).

Então, para que estes pacientes possam se adaptar às variações de Pa e FC, é importante que realizem o treinamento ortostático e o da marcha através do sistema de Suspensão Corpórea juntamente com a EENM, pois Legramante et al. (2001) sugerem que a regulação cardiovascular ocorre por um mecanismo integrado feedback positivo que interage dinamicamente com o feedback negativo - mediado neuralmente e tipo feed-forward de curto tempo.

As respostas dos pacientes foram diferentes do sujeito saudável (APÊNDICE C) devido às seqüelas da lesão medular, bem como pela ativação artificial por meio de EENM, que recruta primeiramente axônios de maior calibre e fibras musculares rápidas, depois que estas fibras fadigam, ocorre o recrutamento dos axônios de menor calibre e das fibras musculares lentas. Ainda, a contração via EENM ativa o maior número de fibras em uma única contração independente da vontade e esforço próprio. De maneira contrária ocorre a contração em sujeitos saudáveis, com recrutamento inicial de axônios de menor calibre e das fibras musculares lentas, além das fibras musculares se contraírem alternadamente (GANDEVIA, 2001).

Foi observado nos pacientes avaliados na atual pesquisa que o tipo de lesão (completa ou incompleta) não interferiu nos parâmetros cardio-respiratórios durante o repouso e EENM. Mas as respostas diferiram-se de acordo com o nível de lesão, de atividade física e de independência funcional, ou seja, os paraplégicos realizam o treinamento da marcha e também apresentam maior índice de Independência Funcional (FIM) comparado aos pacientes tetraplégicos, que ainda estão na fase de condicionamento para marcha e apresentam menor Índice de Independência Funcional (TABELA 1). 
Embora as respostas e os ajustamentos fisiológicos foram individualizados e indicaram realização de exercício exaustivo, os pacientes demonstraram capacidade de realização de exercício induzido artificialmente.

A capacidade de realização de exercício físico sugere possíveis mecanismos compensatórios relacionados à utilização do ácido lático como fonte de energia para o trabalho muscular.

Então, Jacobs e Mahoney (2002) constataram que durante a marcha com EENM a capacidade de realização de exercício foi maior comparada ao cicloergômetro de braço, pois o exercício voluntário com os membros superiores é diferente da ativação artificial dos membros inferiores paralisados, possivelmente pela utilização do ácido lático como fonte de energia, com menor $\mathrm{VCO}_{2}$ e aumento da resistência à fadiga.

Embora, as respostas cardio-respiratórias dos pacientes avaliados na atual pesquisa apresentem algumas limitações centrais e periféricas, estudos evidenciam a influência de fatores neurais durante a EENM, o que pode influenciar no aumento da resistência à fadiga (GANDEVIA, 2001).

O treinamento da marcha realizado por paraplégicos com EENM evidencia a ativação do CPG e a presença de reflexos intramembros. Em tetraplégicos, que realizam a EENM do quadríceps, do nervo fibular e dos membros superiores foi constatada a presença de reflexos intermembros durante a Estimulação do nervo fibular (APÊNDICE D).

Em relação aos reflexos intramembros, Kim e Yoon (2003) constataram durante a EENM do quadríceps mudanças na excitabilidade dos músculos dos membros inferiores, com atividade ipslateral do quadríceps e sóleo, ou seja, entre os segmentos proximal e distal durante a execução de movimentos coordenados. 
Ainda, é importante ressaltar que os reflexos intermembros - respostas motoras nos músculos distais dos membros superiores de tetraplégicos evocadas por estimulação de nervos periféricos mistos dos membros inferiores (CALANCIE, MOLANO \& BROTON, 2002) - indicam reorganização dos reflexos, aumento da excitabilidade neural e possível regeneração medular, decorrentes dos efeitos terapêuticos do Programa de Estimulação Elétrica Neuromuscular (APÊNDICE D).

Portanto, os resultados desta pesquisa mostraram algumas limitações nas respostas cardio-respiratórias, entretanto, os pacientes apresentaram capacidade de realização de exercício induzido artificialmente, possivelmente pela ativação de grupos musculares paralisados, que favorece o retorno venoso, a função cardiovascular, respiratória e muscular, bem como a ação dos fatores humorais; além de possíveis mecanismos compensatórios (por exemplo, a utilização do ácido lático como fonte de energia) e influência de fatores neurais, como a presença de reflexos intramembros e intermembros que podem conduzir ao aumento da resistência à fadiga. Estes fatos constituem paradigmas do exercício em pacientes com lesão medular, então, são necessárias maiores investigações. 


\section{CONSIDERAÇÕES FINAIS}

A lesão medular gera a interrupção das vias do Sistema Nervoso Central para o Sistema Nervoso Periférico que resulta na perda de sensibilidade e movimento voluntário abaixo do nível de lesão.

Ocorrem também mudanças patológicas na inervação simpática, dependendo da organização anatômica das vias na medula espinhal, por exemplo, a perda da termorregulação e do controle simpático para os vasos sangüíneos abaixo do nível de lesão, bem como a perda da inervação simpática para a medula adrenal e coração em especial nos portadores de lesão medular acima da $6^{\mathrm{a}}$ vértebra torácica.

A atuação do Sistema Nervoso Simpático é essencial para a funcionalidade de vários sistemas fisiológicos durante o repouso, mudança postural e em especial durante o exercício. Assim, apresenta alta influência sobre a função cardiovascular, pulmonar e processos metabólicos, como a FC, volume sistólico, PA, glicogenólise, glicólise e lipólise.

Várias são as seqüelas que os portadores de paraplegia e tetraplegia podem apresentar, por exemplo, osteopenia/osteoporose, atrofia do sistema muscular, transformação do tipo de fibra muscular I para o tipo II, mudanças metabólicas, hormonais e neuromusculares, redução da capacidade respiratória, da circulação sangüínea e das dimensões das estruturas cardíacas, que juntamente com o estado sedentário podem conduzir a obesidade, diabetes mellitus (tipo II), doenças cardiovasculares e respiratórias. Entretanto, o processo de reabilitação através de EENM promove adaptações ao treinamento, que reverte algumas seqüelas da lesão medular.

Então para que sejam elaboradas estratégias para otimizar o desempenho durante o exercício induzido artificialmente, é necessário o conhecimento dos sistemas fisiológicos dos pacientes com lesão medular durante a EENM. 
Portanto, foi constatado nesta pesquisa que a maioria dos pacientes apresentaram algumas limitações às respostas cardio-respiratórias durante a EENM, por exemplo baixos valores de $\mathrm{VO}_{2}$ e $\mathrm{VCO}_{2}$, lenta cinética dos gases e valores alterados de $\mathrm{Po}_{2}$ e $\mathrm{Pco}_{2}$, indicando realização de exercício exaustivo e predominância da via anaeróbica lática. Ainda, outros pacientes apresentaram rápida cinética dos gases, que refletem a predominância da via aeróbica e sugere bom condicionamento. Também foi constatado que a EENM promove benefícios hemodinâmicos, por propiciar o aumento da Pa e FC, mas em alguns casos houve limitação nas respostas da FC.

Entretanto, os pacientes apresentaram capacidade de realização de exercício induzido artificialmente abaixo do nível de lesão, devido aos benefícios da EENM, como a ativação de grupos musculares paralisados, que favorece o retorno venoso, a função cardio-vascular, respiratória e muscular, bem como a ação dos fatores humorais; além de possíveis mecanismos compensatórios (por exemplo, a utilização do ácido lático como fonte de energia) e influência de fatores neurais, como a presença de reflexos intramembros e intermembros que podem conduzir ao aumento da resistência à fadiga. 


\section{REFERÊNCIAS BIBLIOGRÁFICAS}

APPLE Jr., D.F.; CODY, R; ALLEN, A. Overuse Injuries in the Upper Limb in
People with Spinal Cord Injury. Disponível na Internet
http://www.vard.org/mono/sci/sciapple.htm. [12 mar. 2002]. ASANO, M. et al. Post-Traumatic Syringomyelia. Spine, V. 21, N. 12: p. 1446-453, June, 1996.

BARBEAU, H. et al. Tapping into Spinal Circuits to Restore Motor Function. Brain Research Reviews, V. 30: p. 27-51, 1999.

BARROS FILHO, T.E.P et al. Avaliação Padronizada nos Traumatismos Raquimedulares. Revista Brasileira de Ortopedia, V. 29, N. 3: p. 99-106, Março, 1994.

BARSTOW, T.J. et al. Changes in Gas Exchange Kinetics with Training in Patients with Spinal Cord Injury. Medicine and Science in Sports and Exercise, V. 28 N. 10: p. 1221-1228, 1996.

BAYDUR, A.; ADKINS, R.H.; MILIC-EMILI, J. Lung Mechanics in Individuals with Spinal cord Injury Level and Posture. J. Appl. Physiol., 90: p. 405-411, 2001.

BELANGER, E.; LEVI, A.DO. The Acute and Chronic Management of Spinal Cord Injury. J. American College of Surgeons, V. 190, N. 5: p. 589-604, May, 2000.

BHADRA, N.; KILGORE, K.L. \& PECKHAN, P.H. Implanted Stimulators for Restoration of Function in Spinal Cord Injury. Medical Engineering \& Physics, V. 23: p.19-28, 2001.

BHAMBHANI, Y. Physiology of Wheelchair Racing in Athletes with Spinal Cord Injury. Sports Med., V. 32, N. 2: p. 23-51, 2002.

BIJAK, M. et al. Functional and Biological Test of a 20 Channel Implantable Stimulator in Shepp in View of Functional Electrical Stimulation Walking for Spinal Cord Injury Persons. Artificial Organs, V. 25, N. 6: p. 467-474, 2001.

BLOOMFIELD, S. Changes in Musculoskeletal Struture and Function with Prolonged Bed Rest. Med. Sci. Sports. Exerc., V. 29, N. 2: p. 197-206, Feb., 1997. 
BOURJEILY-HABR, G. et al. Randomised Controlled Trial of Transcutaneous Electrical Muscle Stimulation of the Lower Extremities in Patients with Chronic Obstrutive Pulmonary Disease. Thorax, V. 57: p. 1045-1049, 2002.

BROOKE, J.D. et al. H-Reflex Modulation During Reverse Passive Pedalling. J. Electromyogr. Kinesiol., V. 6, N. 2: p. 111-116, June, 1995.

BROOKE, J.D. et al. Sensori-Sensory Afferent Conditioning with Leg Movement: Gain Control in Spinal Reflex and Ascending Paths. Progress in Neurobiology, V. 51: p. 393-421, 1996.

BROWN, H.E. et al. Acute Cardiovascular Responses to Static and Dinamic Electrically Stimulated Leg Exercise Combined with Arm Cranking in Spinal Cord Injury. Disponível na Internet http://guide.stanford.edu/2ndVA/brown. htm. [27 out. 2001].

CALANCIE, B.; MOLANO, M.R.; BROTON, J.G. Interlimb Reflexes and Synaptic Plasticity become Evident Months after Human Spinal Cord Injury. Brain. V.125: p.1150-1161, 2002.

CAMPAGNOLO et al. Adrenal and Pituitary Hormone Patterns After Spinal Cord Injury. Am. J. Phys. Med. Rehabil., V. 78, N. 4: p. 361-366, July/Aug., 1999.

CARVALHO, D.C.L.; CARVALHO, M.M.; CLIQUET Jr., A. Osteoporose por Desuso: Aplicação na Reabilitação do Lesado Medular. Acta Ortop. Bras., V. 9, N. 3: p. 34-43, 2001.

CASTRO, M.J. et al. Influence of Complete Spinal Cord Injury on Skeletal Muscle within 6 mo of Injury. J. Appl. Physiol., V. 86, N. 1: p. 350-358, 1999.

CLIQUET Jr, A. A Comprehensive Sensorymotor Rehabilitation Programe for Spinal Cord Injured Patients Using Neuromuscular Electrical Stimulation. World Congress on Medical Physics and Biomedical Engineering, Sydney, Austrália. ANAIS, P.7/CD, 24-29 August, 2003.

CLIQUET Jr., A. Man-Machine Systems for Restoring Movement to the Disabled. World Congress on Medical Physics and Biomedical Engineering, Rio de Janeiro, p. 855, 21-26 August, 1994.

CLIQUET Jr., A.; BAXELANDALE, R.H.; ANDREWS, B.J. Paraplegic Locomotion and Its Metabolic Energy Expenditure. In ROSE, F.C.; JONES, R.; VRBOVÁ, G. Neuromuscular Stimulation: Basic Concepts and Clinical Implications. Vol 3, USA, Demos, 1989. p.273-274.

COOPER, R.A. Rehabilitation Enginneering Applied to Mobility and Manipulation. Institute of Physics Publishing Bristol and Philadelphia, 1995. 
CURT, A.; WEINHARDT, C., DIETZ, V. Significance of Sympathetic Skin Response in the Assessment of Autonomic Failure in Patients with Spinal Cord Injury. J. of the Autonomic Nervous System, V. 61: p. 175-180, 1996.

DALLMEIJER, A.J.; van der WOUDE, L.H.V.; HOLLANDER, A.P. \& van AS, H.H.J. Physical Performance During Rehabilitation in Persons with Spinal Cord Injuries. Medicine \& Science in Sports \& Exercise, V31, N. 9: p. 1330-1335, 1999.

DALY, J.J. et al. Therapeutic Neural Effects of Electrical Stimulation. IEEE Transaction on Rehabilitation Engineering, V. 4, N. 4, Dec, 1996.

DAVIS, G. Exercise Capacity of Individuals with Paraplegia. Med. Sci. Sports Exerc., V. 25, N. 4: p. 423-432, 1993.

DAVIS, R. Twenty-Eight Years of Clinical Experience with Implantable Neuroprotheses for Various Applications. Artificial Organs, V. 26, N. 3:p. 280-283, 2002.

DEC, K.L.; SPARROW, K.J.; McKEAG, D.B. The Physically-Challenged Athlete: Medical Issues and Assessment. Sports Med., V. 29, N. 4: p.245-258, Apr, 2000.

DIETZ, V. Interaction Between Central Programs and Afferent Input in the Control of Posture and Locomotion. J. Biomechanics, V.29, N.7: p. 841-844, 1996.

DIETZ, V.; GOLLHOFER, A.; TRIPPEL, M. Regulation of Bipedal Stance: Dependency on “Load” Receptors. Experimental Brain Research, V. 89: p. 229-231, 1992.

DIETZ, V. et al. Locomotor Capacity and Recovery of Spinal Cord Function in Paraplegic Patients: a Clinical and Electrophysiological Evaluation. Electroencephalography and Clinical Neurophysiology, V. 109: p. 140-153, 1998.

Di MARCO, A.F. et al. Mechanical Contribution of Expiratory Muscles to Pressure Generation During Spinal Cord Stimulation. J. Appl. Physiol., V. 87, N. 4: p. 14331439, 1999.

Di PRAMPERO, P.E. \& FERRETTI, G. The Energetcs of Anaerobc Muscle Metabolism: a Reappraisal of Older and Recent Concepts. Respiration Physiology V. 118: p. 103-115, 1999.

DUNE, J.W.; HEYE, N.; DUNE, S.L. Treatment of Chronic Limb Spasticity with Botulinum Toxin A. Journal of Neurology, Neurosurgery \& Psychiatry, V. 58, N. 2: p. 232-235, 1995.

EDGERTON, V.R. et al. How the Science and Engineering of Spaceflight Contribute to Understanding the Plasticity of Spinal Cord Injury. Acta Astronautica, V. 47, N. 1: p. 51-62, 2000. 
ELOKDA, A.S.; NIELSEN, D.H.; SHIELDS, R.K. Effect of Functional Neuromuscular Stimulation on Postural Related Orthostatic Stress in Individuals with Acute Spinal Cord Injury. Journal of Rehabilitation Research and Development, V. 37, N. 5, Sep/Oct, 2000. Disponível na Internet http://www.vard.org/jour/37/5/elokd375.htm [14 fev. 2002].

ERNI, Th.; COLOMBO, G. Locomotor Training in Paraplegic Patients: a New Approach to Assess Changes in Leg Muscle EMG Paterrns. Electroencephalography and Clinical Neurophysiology, V. 109: p. 135-139, 1998.

FISEKOVIC, N.; POPOVIC, D.B. New Controller for Functional Electrical Stimulation Systems. Medical Engineering \& Physics, V. 23: p. 391-399, 2001.

FOUAD, K. et al. Treadmill Training in Incomplete Spinal Cord Injury Rats. Behavioural Brain Research, V. 115: p. 107-113, 2000.

FRANCO, J. C. et al. Knee Kinetics During Functional Electrical Stimulation Induced Cycling in Subjects with Spinal Crd Injury. Journal of Rehabilitation Research and Development, V. 36, N. 6, July, 1999. Disponível na Internet http://www.vard.org/jour/36/6/franc363.htm. [14 fev. 2002].

FRANKEN, M.H. et al. The Influence of Voluntary Upper Body Exercise on the Performance of Stimulated Paralysed Human Quadriceps. J. Electromyography and Kinesiology, V. 7: p.67-77, 1997.

FREY, G.C. et al. Plasm Cathecholamine and Lactate Relationship During Graded Exercise in Men with Spinal Cord Injury. Med. Sci. Sports Exerc., V. 29, N. 4: p. 451-456, April, 1997.

FRIGO, C. et al. EMG Signals Detection and Processing for On-Line Control of Functional Electrical Stimulation. J. Electromyography and Kinesiology, V. 10: p. 351-360, 2000.

GANDEVIA, S.C. Spinal and Supraspinal Factors in Human Muscle Fatigue. Physiological Reviews. V. 81, N. 4: p. 1726-1771, 2001.

GLASER, R.M. et al. The Physiology of Exercise for People with Spinal Cord Injury. Disponível na Internet http://www.vard.org/mono/sci/sciglase.htm [12 mar. 2002].

GREEN, S. Specific Exercise Programs. Disponível na Internet http://www.vard.org/mono/sci/scigreen.htm [12 mar. 2002].

GRILL, W.M. et al. At the Interface: Emerging Clinical Applications of Electrical Stimulation: opportunities for restoration of function. Journal of Rehabilitation Research and Development, V.38, N. 6, Nov/Dec, 2001. Disponível na Internet http://www.vard.org/jour/38/6/grill386.htm [14 fev. 2002]. 
GUADAGNOLI, M.A.; ETNYRE, B.; RODRIGUE, M.L. A Test of a Dual Central Pattern Generator Hypothesis for Subcortical Control of Locomotion. J. Electromyography and Kinesiology, V.10: p. 241-247, 2000.

HANDA, Y. Current Topics in Clinical Functional Electrical Stimulation in Japan. J. Electromyography and Kinesiology, V. 7: p. 269-274, 1997.

HARTKOPP, A. et al. High Expression of MHC I in the Tibialis Anterior Muscle of a Paraplegic Patient. Muscle \& Nerve, V. 22: p. 1731-1737, 1999.

HINES, A.E. et al. Stimulus Artifact Removal in EMG from Muscles Adjacent to Stimulated Muscle. Journal of Neuroscience Methods, V. 64: p. 55-62, 1996.

HJELTNES, N., et al. Regulation of UCP2 and UCP3 by Muscle Disuse and Physical Activity in Tetraplegic Subjects. Diabetologia, 42: p. 826-830, 1999.

HOPMAN, M.T.E. et al. Blood Redistribution and Circulatory Responses to Submaximal Arm Exercise in Persons with Spinal Cord Injury. Scand. J. Reab. Med., V. 30: p. 167-174, 1998.

HOPMAN, M.T.E. et al. Increased Vascular Resistance in Paralysed Legs After Spinal Cord Injury is Reversible by Training. J. Appl. Physiol. V. 93: p. 1966-1972, 2002.

HUONKER, M., et al. Cardiovascular Differences between Sedentary and Wheelchair-Trained Subjects with Paraplegia. Med. Sci. Sports Exerc., V. 30 N. 4: p. 609-613, April, 1998.

INOUE, K. et al. Assessment of Autonomic Function in Traumatic Quadriplegic and Paraplegic Patients by Spectral Analysis of Heart Rate Variability. J. of the Autonomic Nervous System, V. 54: p. 225-234, 1995.

IOANNIDES, A.A. et al. Brain Activation Sequences Following Electrical Limb Stimulation of Normal and Paraplegic Subjects. NeuroImage, V.16: p. 115-129, 2002.

JACOBS, P.L.; MAHONEY, E.T. Peak Exercise Capacity of Electrically Induced Ambulation in Persons with Paraplegia. Med. Sci. Sports Exerc., V. 34, N. 10: p. 1551-1556, 2002.

JACOBS, P.L.; NASH, M.S.; RUSINOWSKI Jr., J.W. Circuit Training Provides Cardiorespiratory and Strenght Benefits in Persons with Paraplegia. Med. Sci. Sports Exerc., V. 33, N. 5: p. 711-717, 2001.

JEAN, J.Y. et al. Intact Sympathetic Nervous System Is Required for Leptin Effects on Rest Metabolic Rate in People with Spinal Cord Injury. J. Clin. Endocrinol. Metabol., V. 88, N. 1: p. 402-407, 2003. 
KARLSSON, A.K. et al. Regional Sympathetic Function in High Spinal Cord Injury During Mental Stress and Autonomic Dysreflexia. Brain, 121: p. 1711-1719, 1998.

KELLER, T. et al. Transcutaneous Functional Electrical Stimulador "Compex Motion”. Artificial Organs, V. 26, N. 3: p. 219-223, 2002.

KERN, H. Functional Electrical Stimulation in Paraplegic Spastic Patients. Artificial Organs, V. 21, N. 3: p. 195-196, March, 1997.

KILGORE, K.L. et al. Neuroprothesis Consumers' Forum: Consumer Priorities for Research Directions. Journal of Rehabilitation Research and Development, V. 38, N. 6, Nov/Dec, 2001. Disponível na Internet http://www.vard.org/jour/38/6/kilgo386.htm. [14 fev. 2002].

KIM, E.J.; YOON, T.S. The Effect of Quadriceps-Electrocutaneous Stimulation on The T-Reflex and the H-Reflex of The Soleus Muscle. Clinical Neurophysiology, V. 114: p. 1189-1193, 2003.

KJAER, M. et al. Heart Rate During Exercise with Leg Vascular Occlusion in Spinal Cord Injury. J. Appl. Physiol., V. 86, N. 3: p. 806-811, 1999.

KOJIMA N.; NAKAZAWA, K.; YANO, H. Effects of Limb Loading on the Lowerlimb Electromyografic Activity During Orthotic Locomotion in a Paraplegic Patient. Neuroscience Letters, V. 274: p. 211-213, 1999.

KOSKINEN, S.O.A. et al. Type IV Collagen and Its Degradation in Paralysed Human Muscle: Effect of Functional Electrical Stimulation. Muscle \& Nerve, V. 23: p. 580-589, 2000.

KRALJ, A.R.; BAJD, T. Functional Electrical Stimulation: Standing and Walking after Spinal Cord Injury. CRC Press, Inc. Boca, Raton, Florida, 1989.

LEGRAMANTE, J.M. et al. Positive and Negative Feedback Mechanisms in the Neural Regulation of Cardiovascular Function in Healthy and Spinal Cord Injured Humans. Circulation, 103: p. 1250-1255, 2001.

LEMAN, S.; BERNET, F.; SEQUEIRA, H. Autonomic Dysreflexia Increases Plasma Adrenaline Level in the Chronic Spinal Cord-Injured Rat. Neuroscience Letters, 286: p. 159-162, April, 2000.

LEROUX, A.; FUNG, J.; BARBEAU, H. Adaptation of the Walking Pattern to Uphill Walking in Normal and Spinal-Cord Injured Subjects. Experimental Brain Research, V. 126: p. 359-368, 1999.

LEVIN, O.; MIZRAHI, J.; IZAKOV, E. Transcutaneous FES of the Paralyzed Quadriceps: Is Knee Torque Affected by Unintended Activation of the Hamistrings? J. Electromyografy and Knesiology, V. 10: p. 47-58, 2000. 
McARDLE, W.D.; KATCH, F.I.; KATCH, V.L. Fisiologia do Exercício: Energia, Nutrição e Desempenho Humano. $3^{\circ}$ ed. Rio de Janeiro, RJ, Copyright, 1991.

McARDLE, W.D.; KATCH, F.I.; KATCH, V.L. Essentials of Exercise Physiolgy. USA, Lea \& Febiger, 1994.

MAYR, W. et al. Basic Design and Construction of the Vienna FES Implants: Existing Solutions and Prospects for New Generations of Implants. Medical Engineering \& Physics, V. 23: p. 53-60, 2001.

MELA, P.; VELTINK, P.H.; HUIJING, P.A. Excessive Reflexes in Spinal Cord Injury Triggered by Electrical Stimulation. Archives of Physiology and Biochemistry, V. 109, N. 4: p. 309-315, 2001.

MEYER, K. et al. Effects of Short-Term Exercise Training and Activity Restriction on Functional Capacity in Patients With Severe Chronic Congestive Heart Failure.. The American Journal of Cardiology, V. 78: p. 1017-1022, 1996.

MEYER, T; GABRIEL, H.W.H.; KINDERMANN, W. Is Determination of Exercise Intensities as Percentages of VO2 max ou FC max Adequate? Medicine \& Science in Sports \& Exercise, V. 31, N. 9: p. 1342-1345, 1999.

MIZRAHI, J. Fatigue in Functional Electrical Stimulation in Spinal Cord Injury. J. Electromyografy and Knesiology, V. 7, N. 1: p.1-2, 1997. /editorial/

MIZRAHI, J. et al. Muscle Fatigue in Interrupted Stimulation: Effect of Partial Recovery on Force and EMG Dynamics. J. Electromyography and Kinesiology, V. 7, N. 1: p. 51-61, 1997.

MOHR, T. et al. Insulin Action and Long-Term Ellectrically Induced Training in Individuals with Spinal Cord Injuries. Med. Sci. Sports. Exerc., V. 33, N. 8: p. 12471252, 2001.

MOHR, T. et al. Measurement of Heart Hate During Exercise Induced by Cyclic FES in Spinal Cord Injured Individuals. Artificial Organs, V. 20, N. 11: p. 1252, 1996 /resumo /

MORRISON, S.A. Guidelines for the Clinician for Development of Fitness Programs for Individuals with Spinal Cord Injury. Disponível na Internet http://www.vard.org/mono/sci/scimorri.htm [12 mar. 2002].

MOURSELAS, N. \& GRANAT, M.H. Evaluation of Patterned Stimulation for Use in Surface Functional Electrical Stimulation Systems. Medical Engineering \& Physics, V. 20: p. 319-324, 1998.

MUCCIO, P.; ANDREWS, B.; MARSOLAIS, E.B. Eletronic Orthoses: Technology, Prototypes, and Practices. Journal of Prosthetics and Orthotics, V.1, N. 1: p. 3-17, 1989. 
MUKHERJEE, G.; SAMANTA, A. Physiological Response to the Ambulatory Performance of Hand-rim and Arm-crank Propulsion Systems. Journal of Rehabilitation Research and Development, V. 38, N. 4, July/Aug, 2001. Disponível na Internet http://www.vard.org/jour/38/4/mukhe384.htm [14 fev. 2002].

MUNIH, M.; ICHIE, M. Current Status and Future Prospects for Upper and Lower Extremity Motor System Neuroprostheses. Neuromodulation, V. 4, N. 4: p. 176-186, 2001.

NENE, A.V.; PATRICK, J.H. Energy Cost of Paraplegic Locomotion Using the ParaWalker - Electrical Stimulation "Hybrid" Orthosis. Arch Phys Med Rehabil, 71: p. 116-119, 1990.

O’CONNOR, T.J. et al. Does Computer Game Play Aid in Motivation of Exercise and Increase Metabolic Activity During Whellchair ergometry? Medical Enginnering \& Physics, 23: p. 267-273, 2001.

OLIVE, J.L. et al. Blood Flow and Muscle Fatigue in SCI Individuals During Electrical Stimulation. J. Appl. Physiol. V. 94: p. 701-708, 2003.

PAOLILLO, A.R.; PAOLILLO, F.R.; CLIQUET Jr., A. É Possível Voltar a Andar Após a Lesão Medular? XVIII Congresso Brasileiro de Engenharia Biomedica, São José dos Campos, SP, p. 288, 9-12 de Setembro, 2002.

PEIXOTO, B.O.; CLIQUET Jr, A. Redução da Fadiga Muscular através da Estimulação Elétrica Neuromuscular em Pacientes Portadores de Lesão Medular. RBE - Caderno de Engenharia Biomédica, V. 12, N. 2: p. 21-46, Jul/Dez, 1996.

POWERS, S.K.; HOWLEY, E.T. Exercise Physiology - Theory and Application to Fitness and Performance. 2 2a ed. Dubuque, Iowa, Brown \& Benchmark, 1994.

PRICE, D.T.; DAVIDOFF, R.; BALADY, G.J. Comparison of Cardiovascular Adaptations to Long-Term Arm and Leg Exercise in Wheelchair Athletes Versus Long-Distance Runners. Am. J. Cardiol., 85: p. 996-101, April, 2000.

RABISCHONG, E. \& CHAVET, P. Regression-based Indices of Fatigue in Paraplegics' Electrically Stimulated Quadriceps. Medical Engineering \& Physics, V. 19, N. 8: p. 749-754, 1997.

REDE SARAH DE HOSPITAIS DO APARELHO LOCOMOTOR. Disponível na Internet http://www.sarah.br [3 de Julho, 2002].

RIENER, R.; QUINTERN, J. A Phisyologically Based Model of Muscle Activation Verified by Electrical Estimulation. Bioelectrochemistry and Bioenergetcs, V. 43: p. 257-264, 1997. 
ROGERS, S.M. Factors that Influence Exercise Tolerance. Disponível na Internet http://www.vard.org/mono/sci/sciroger.htm [12 mar. 2002].

SALMONS, S. et al. ASIC or PIC? Implantable Stimulators Based on Semi-Custom CMOS Technology or Low-Power Microcontroller Architecture. Medical Engineering \& Physics, V. 23: p. 37-43, 2001.

SCHMID, A. et al. Physical Performance and Cardiovascular and Metabolic Adaptation of Elite female Weelchair Basqketball Players in Weelchair Ergometry and in Competition. Am. J. Phys. Med. Rehabil., V. 77, N. 6: p. 527-533, Nov/Dec., 1998 a.

SCHMID, A. et al. Free Plasma Catecholamines in Spinal Cord Injury Persons with Different Injury Levels at Rest and During Exercise. J. of The Autonomic Nervous System, 68: p. 96-100, 1998 b.

SCHIMIDT, B.J.; JORDAN, L.M. The Role of Serotonin in Reflex Modulation and Locomotor Rhythm Production in the Mammalian Spinal Cord. Brain Reserch Bulletin, V. 53, N. 5: p. 689-710, 2000.

SCOTT, T.R.D.; HAUGLAND, M. Command/Control Interfaces for Advances Neuroprosthetic Applications. Disponível na Internet http://feswww.fes/papers/paperSH.htm. [2 Jan 2001].

SHERMAN, M.; MATITYAHU, A.; CAMPBELL, D.A Method for Stimating Respiratory Muscle Efficiency Using an Automated Metabolic Cart. Respiration Physiology V. 106: p. 171-177, 1996.

SEKHON, L.H.S.; FEHLINGS, M.G. Epidemiology, Demographics, and Pathophysiology of Acute Spinal Cord Injury. Spine, V. 26, N. 24S: p. S2-S12, 2001.

SKÖLD, C. et al. Effects of Functional Electrical Stimulation Training for Six Months on Body Composition and Spasticity in Motor Complete Tetraplegic Spinal Cord Injury. J. Rehabil. Med., V. 34: p. 25-32, 2002.

SMITH, S.E. et al. Phisiological and Anatomic Determinants of Exercise Response in Spinal Cord Injury. Disponível na Internet http://guide.stanford.edu/2ndVA/smith1.html. [27 out. 2001].

STEINBERG, L.L. et al. Catecholamine Response to Exercise in Individuals with Different Levels of Paraplegia. Braz. J. Med. Biol. Res., V. 33, N.8: p. 913-918, 2000.

TEPAVAC, D. \& SCHWIRTLICH, L. Detection and Prediction of FES-induced Fatigue. J. Electromyography and Kinesiology, V. 7, N. 1: p. 39-50, 1997. 
THEISEN, D. et al. Central and Peripheral Haemodynamics in Individuals with Paraplegia During Light and Heavy Exercise. J. Reab. Med., 33: p. 16-20, 2001.

THEISEN, D. et al. External Power Output Changes During Prolonged Cycling With Electrical Stimulation. J. Rehabil Med, V. 34: p. 171-175, 2002.

THOUMIE, P. et al. Restoration of Functional Gait in Paraplegic Patients with the RGO-II Hybrid Orthosis. A Multicenter Controlled Study. II: Physiological Evaluation. Paraplegia, V. 33: p. 654-659, 1995.

TREMBLAY, M. Going Back to Civvy Street: a Historical Account of the Impact of the Everest and Jennings Wheelchair for Canadian World War II Veterans with Spinal Cord Injury. Disability \& Society, V. 11, N. 2: p. 149-169, 1996.

TRIMBLE, M.H.; KUKULKA, C.G.; BHERMAN, A.L. The Effect of Treadmill Gait Training on Low-Frequency Depression of the Soleus H-reflex: Comparison of a Spinal Cord Injured Man to Normal Subjects. Neuroscience Letters, V. 246: p. 186-188, 1998.

TROYK, P.R.; DONALDSON, N. de N. Implantable FES Stimulation Systems: What is Needed? Neuromodulation, V. 4, N. 4: p. 196-204, 2001.

VANDER, A.J.; SHERMAN, J.H.; LUCIANO, D.S. Fisiologia Humana: Os Mecanismos da Função de Órgãos e Sistemas. São Paulo, McGraw-Hill do Brasil, 1981.

van der WOUDE, L.H., et al. Handcycling: Different Modes and Gear Ratios. J. of Medical Engineering \& Technology, V. 24, N. 6: p. 242-249, Nov/Dec, 2000.

WALWYN, W.M. et al. Extracellular Glutamate in the Dorsal Horn of the Lumbar Spinal Cord in the Freely Moving Rat During Hindlimb Stepping. Pharmacology Biochemistry and Behavior, V, 63, N. 4: p. 581-588, 1999.

WHELAN, P.J. Control of Locomotion in the Decerebrate Cat. Progress in Neurobiology, V. 49: p. 481-515, 1996.

WICKELGREN, I. Teaching the Spinal Cord to Walk. Science Magazine, V. 279, N. 5349: p. 319-321, Jan, 1998.

WILMORE, J.H.; COSTTIL, D.L. Physiology of Sport and Exercise. Champaingn, USA, Human Kinetics, 1994.

YOO, K.Y. et al. Hemodynamic and Catecholamine Responses to Laringoscopy and Tracheal Intubation in Patients with Complete Spinal Cord Injuries. Anesthesiology, V. 95, N. 3: p. 647-651, 2001. 


\section{Apêndice A}

\section{O ESTUDO PILOTO: POLAR OU ECG? UMA QUESTÃO METODOLÓGICA}

O Estudo piloto das avaliações cardio-respiratórias foi realizado com dois diferentes métodos de mensuração da FC, com o Polar e ECG.

Os pacientes 2, 5, 7 e 10 realizaram o teste com o Polar e os pacientes 3, 4 e 7 realizaram o teste com ECG.

A avaliação cardio-respiratória consistiu em 10 minutos de repouso, 20 minutos de EENM dos quadríceps direito/esquerdo (contração isotônica concêntrica) e 10 minutos de recuperação em repouso.

Foram utilizados Estimulador portátil, analisador de gases Sensormedics Vmax 29C, Eletrocardiógrafo, Polar S810 e Esfigmomanômetro.

Os gráficos dos parâmetros cardio-respiratórios foram plotados utilizando o Vmax Software (a cada respiração para o $\mathrm{VO}_{2}, \mathrm{VCO}_{2}, \mathrm{Ve}, \mathrm{Po}_{2}, \mathrm{Pco}_{2}$; a cada freqüência para a FC) e o Software Polar Precision Performance (a cada freqüência para a FC). Foi realizada a inspeção visual dos gráficos e a descrição dos resultados, posteriormente foram apresentados os valores iniciais e de pico das variáveis cardiorespiratórias durante a EENM. Em outras circunstâncias foram obtidos a média e desvio padrão dos valores das variáveis cardio-respiratórias durante os últimos dois minutos em cada fase de transição do teste. Os dados do estudo piloto foram analisados por meio de estudos de caso devido a variabilidade intersujeitos. 


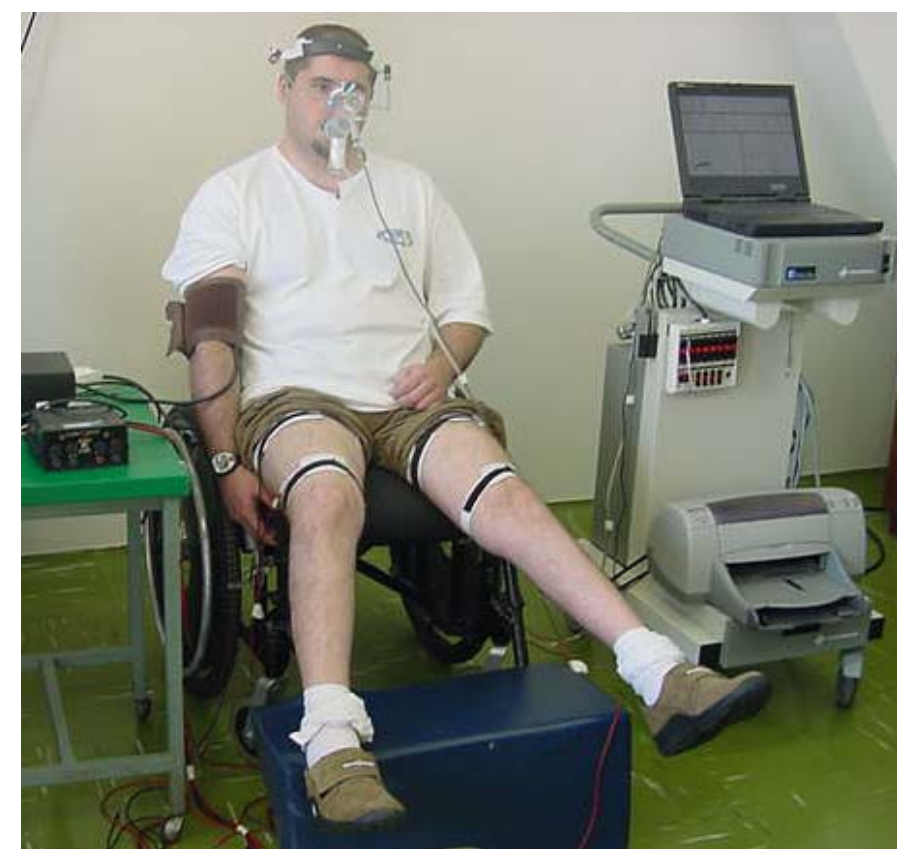

(a)

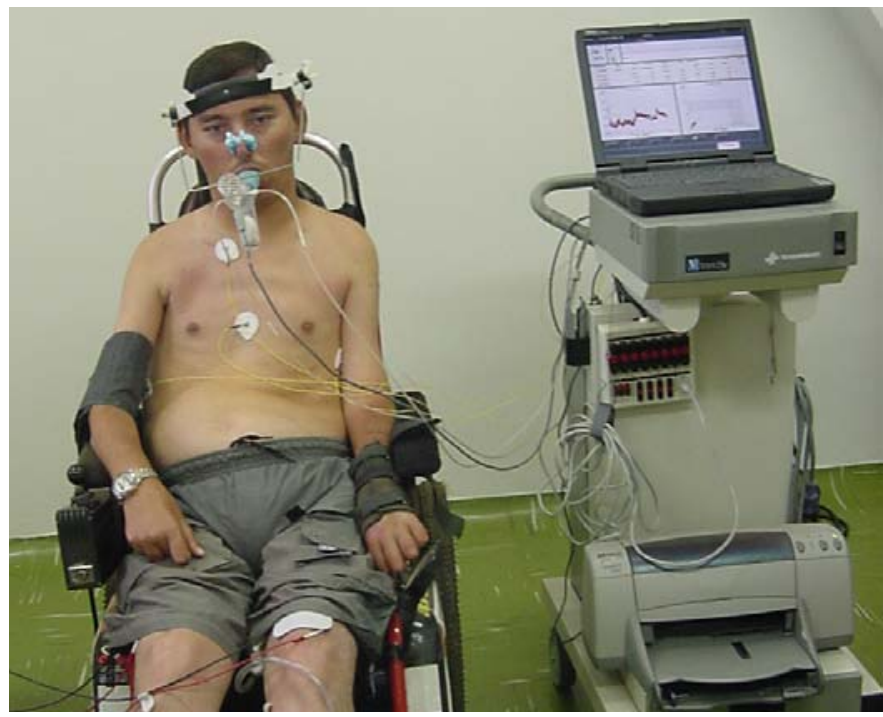

(b)

FIGURA 15 - Procedimento experimental com o Polar (a) e ECG (b). 


\section{RESULTADOS COM O POLAR}

Paciente 2: durante a EENM, a cinética dos gases $\left(\mathrm{VO}_{2}, \mathrm{VCO}_{2}\right.$ e $\left.\mathrm{Ve}\right)$ mostrou

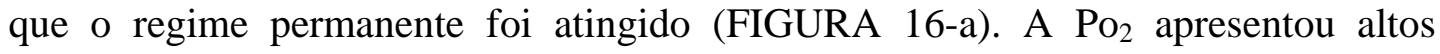
valores e a $\mathrm{PCO}_{2}$ baixos valores, a FC apresentou aumento linear e houve hipertensão fisiológica (TABELA 5). Durante a recuperação houve o decréscimo linear do $\mathrm{VO}_{2}$, $\mathrm{VCO}_{2}$ e Ve, com valores inferiores comparados ao repouso e a FC manteve-se elevada.

Paciente 5: foi constatado durante a EENM, que a cinética dos gases (FIGURA 16-b) e a FC mostraram aumento linear e alguns intervalos Freqüência por Freqüência apresentaram ruídos. A Pa aumentou pouco, a $\mathrm{Po}_{2}$ e a $\mathrm{Pco}_{2}$ não foram constantes e no final da EENM apresentaram valores elevados (TABELA 6). Durante a recuperação a FC foi elevada e houve decréscimo linear do $\mathrm{VO}_{2}, \mathrm{VCO}_{2}$ e Ve.

Paciente 7: durante o repouso apresentou bradicardia e hipotenção. Os valores de $\mathrm{VO}_{2}, \mathrm{VCO}_{2}$ e Ve foram inferiores durante o repouso e EENM (FIGURA 16-c). Durante a EENM houve aumento linear na cinética dos gases e os parâmetros não se mantiveram constantes até o final, apresentando decréscimo linear antes de completar vinte minutos de EENM. A $\mathrm{Po}_{2}$ também atingiu altos valores e a $\mathrm{PCO}_{2}$ baixos valores, ainda houve o aumento da FC e Pa (TABELA 6). No período de recuperação a FC retornou aos valores de repouso e a $\mathrm{Pa}, \mathrm{VO}_{2}, \mathrm{VCO}_{2}$ e $\mathrm{Ve}$ mantiveram-se um pouco elevadas.

Paciente 10: durante o repouso foi constatado hipotensão. Os valores de $\mathrm{VO}_{2}$, $\mathrm{VCO}_{2}$ e Ve foram inferiores durante o repouso e EENM. Durante a EENM houve aumento linear na cinética dos gases e os parâmetros não se mantiveram constantes até o final, apresentando decréscimo linear antes de completar vinte minutos de EENM (FIGURA 16-d). A $\mathrm{Po}_{2}$ também atingiu altos valores e a $\mathrm{PCO}_{2}$ baixos valores no final da EENM, ainda houve o aumento da FC e Pa (TABELA 6). No período de recuperação a FC foi elevada e houve decréscimo linear do $\mathrm{VO}_{2}, \mathrm{VCO}_{2}$ e Ve.

Quando utilizado o Polar, a cinética dos gases é mostrada na Figura 16, as respostas da FC são exemplificadas pela Figura 18 e os resultados das variáveis 
cardio-respiratórias do paciente 2 são mostrados na Tabela 5 e dos pacientes 5, 7 e 10 são mostrados na Tabela 6.

\section{RESULTADOS COM O ECG}

Paciente 3: durante a EENM, a cinética dos gases mostrou o aumento linear (FIGURA 17-a). A $\mathrm{Po}_{2}$ apresentou altos valores e a $\mathrm{Pco}_{2}$ diminuiu. Foi constatado aumento da FC, da Pa sistólica e o discreto aumento da Pa diastólica (TABELA 7). Durante a recuperação houve o decréscimo linear na cinética dos gases $\left(\mathrm{VO}_{2}, \mathrm{VCO}_{2}\right.$ e Ve). A FC e a Pa estavam um pouco elevadas comparada ao repouso.

Paciente 4: durante a EENM, a cinética dos gases mostrou o aumento linear (FIGURA 17-b). A $\mathrm{Po}_{2}$ e a $\mathrm{Pco}_{2}$ não foram constantes e elevaram-se. Foi constatado o aumento da FC e Pa sistólica, além da redução da Pa diastólica (TABELA 7). Durante a recuperação houve o decréscimo linear na cinética dos gases $\left(\mathrm{VO}_{2}, \mathrm{VCO}_{2}\right.$ e Ve) e a FC manteve-se elevada comparada ao repouso.

Paciente 6: apresentou valores inferiores de $\mathrm{VO}_{2}, \mathrm{VCO}_{2}$ e Ve, bem como, hipotensão. Durante a EENM, a cinética dos gases mostrou aumento linear (FIGURA 17-c). A $\mathrm{Po}_{2}$ apresentou altos valores e a $\mathrm{PcO}_{2}$ diminuiu. Houve bradicardia inicial seguido por aumento linear da FC. Também foi constatado o aumento da Pa sistólica e o discreto aumento da Pa diastólica (TABELA 7). Durante a recuperação houve decréscimo linear na cinética dos gases $\left(\mathrm{VO}_{2}, \mathrm{VCO}_{2}\right.$ e $\left.\mathrm{Ve}\right)$ e a $\mathrm{Pa}$ apresentou valores mais elevados comparado ao repouso.

Quando utilizado o ECG, a cinética dos gases é mostrada na Figura 17, as respostas da FC são exemplificadas pela Figura 19 e os resultados das variáveis cardio-respiratórias dos pacientes 3, 4 e 6 são mostrados na Tabela 7. 


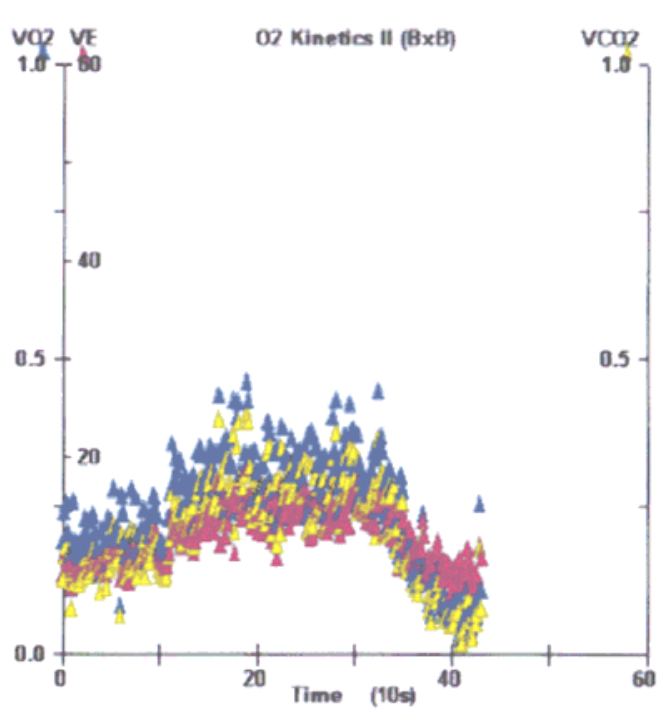

(a)

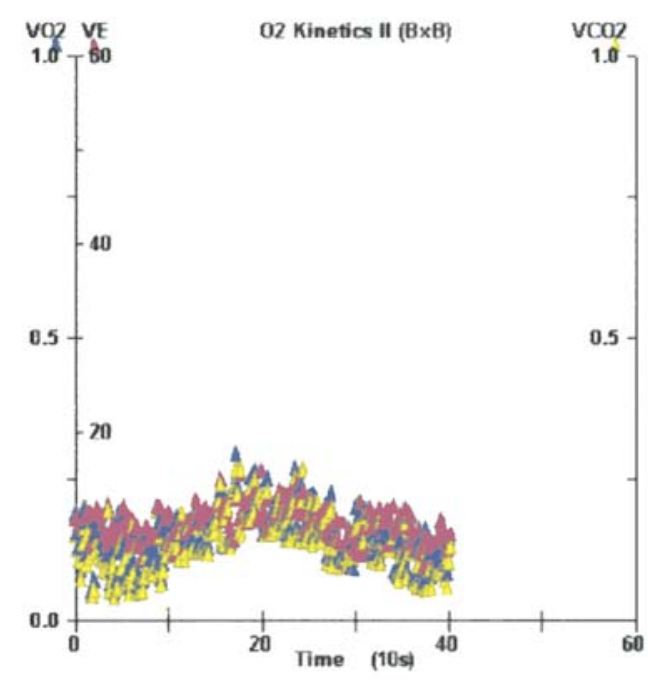

(c)

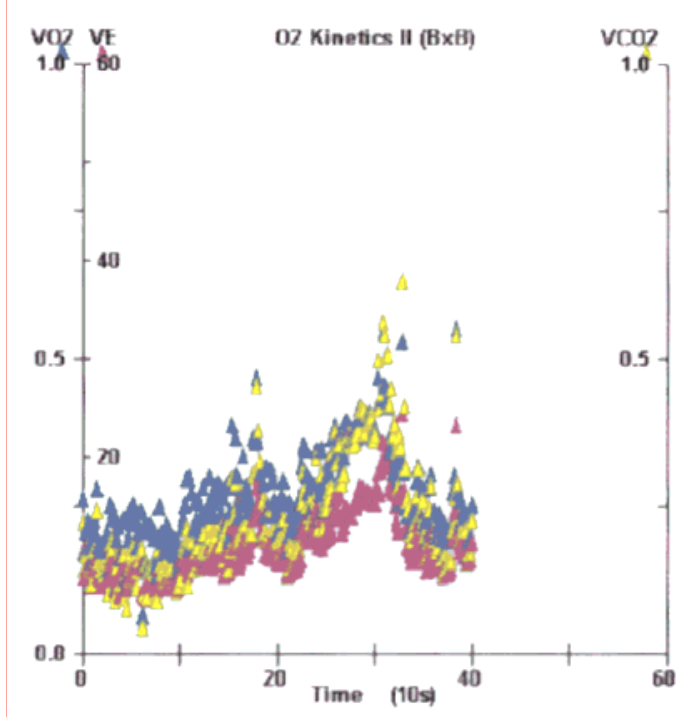

(b)

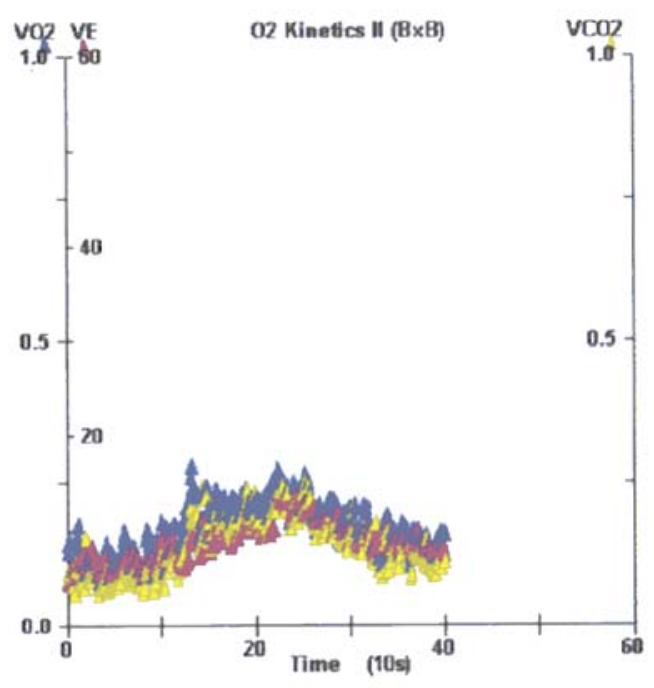

(d)

FIGURA 16 - Cinética dos gases - pacientes 2 (a), 5 (b), 7 (c) e 10 (d) que utilizaram o Polar. 


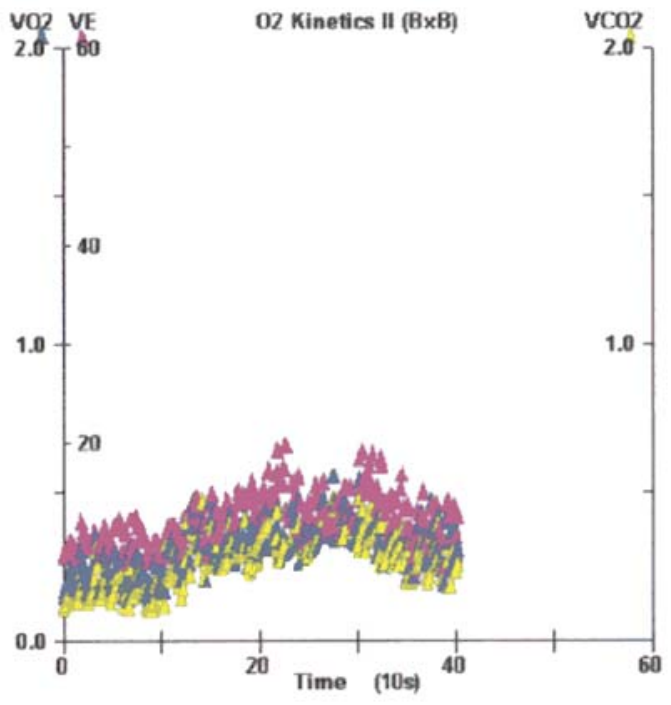

(a)

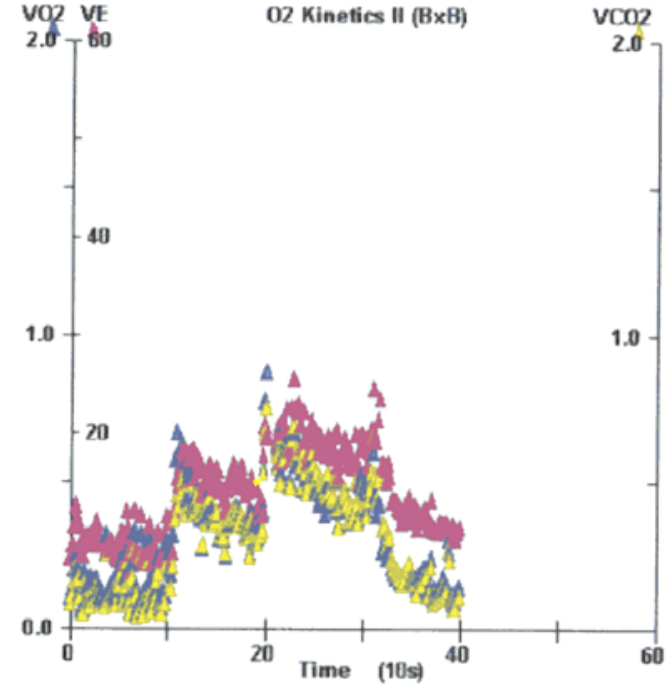

(b)

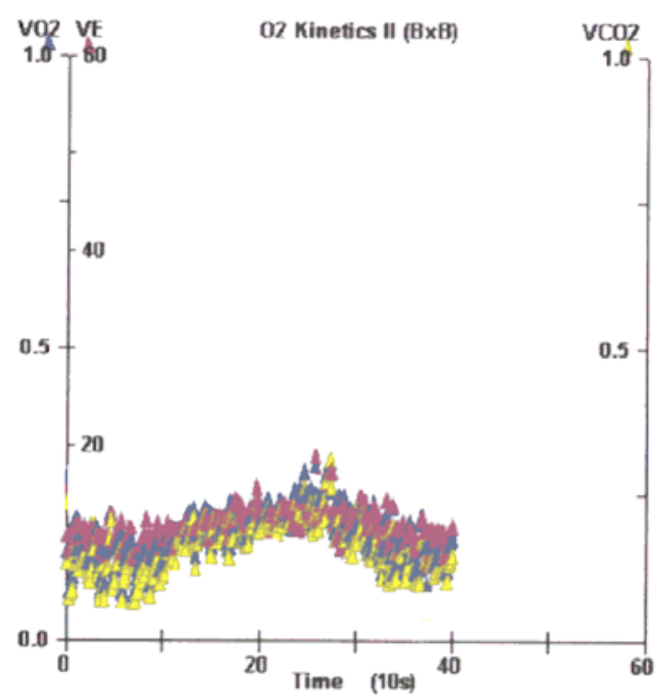

(c)

FIGURA 17 - Cinética dos gases - pacientes 3 (a), 4 (b) e 6 (c), que utilizaram o Eletrocardiógrafo. 
TABELA 5 - Média e desvio padrão das varáveis cardio-respiratórias durante o repouso, regime permanente e recuperação, com FC monitorada por Polar.

\begin{tabular}{clccc}
\hline \multirow{2}{*}{ Paciente } & \multicolumn{1}{c}{ Variáveis } \\
& $\mathrm{Cardio-respiratórias}^{2}$ & Repouso & EENM & Recuperação \\
\hline & $\mathrm{VO}_{2}(\mathrm{l} / \mathrm{min})$ & $0,24 \pm 0,02$ & $0,40 \pm 0,03$ & $0,13 \pm 0,02$ \\
& $\mathrm{VCO}_{2}(\mathrm{l} / \mathrm{min})$ & $0,18 \pm 0,02$ & $0,35 \pm 0,03$ & $0,11 \pm 0,02$ \\
& $\mathrm{Ve}(\mathrm{l} / \mathrm{min}) \mathrm{BTPS}$ & $12,09 \pm 2,5$ & $16,68 \pm 1,22$ & $10,46 \pm 1,05$ \\
2 & $\mathrm{Po}_{2}(\mathrm{mmHg}) \mathrm{STPD}$ & $98,30 \pm 1,69$ & $102,32 \pm 2,8$ & $103,41 \pm 2,06$ \\
& $\mathrm{PCO}_{2}(\mathrm{mmHg}) \mathrm{STPD}$ & $36,03 \pm 0,97$ & $35,76 \pm 1,32$ & $33,26 \pm 1,03$ \\
& $\mathrm{FC}(\mathrm{bpm})$ & $84,65 \pm 3,24$ & $101,2 \pm 1,98$ & $94,69 \pm 3,71$ \\
$\mathrm{~Pa}(\mathrm{mmHg})$ & $134 \times 84$ & $171 \times 84$ & $138 \times 84$ \\
\hline
\end{tabular}


TABELA 6 - Média e desvio padrão das variáveis cardio-respiratórias durante o repouso e recuperação. Valores iniciais e de pico do aumento linear durante a EENM e FC monitorada por Polar.

\begin{tabular}{|c|c|c|c|c|c|}
\hline \multirow[b]{2}{*}{ Pacientes } & \multirow[b]{2}{*}{$\begin{array}{c}\text { Variáveis } \\
\text { Cardio-respiratórias }\end{array}$} & \multicolumn{4}{|c|}{ EENM } \\
\hline & & Repouso & $\begin{array}{l}\text { Valores } \\
\text { Iniciais }\end{array}$ & $\begin{array}{l}\text { Valores } \\
\text { de Pico }\end{array}$ & Recuperação \\
\hline \multirow{7}{*}{5} & $\mathrm{VO}_{2}(\mathrm{l} / \mathrm{min})$ & $0,2 \pm 0,95$ & 0,23 & 0,4 & $0,22 \pm 0,02$ \\
\hline & $\mathrm{VCO}_{2}(\mathrm{l} / \mathrm{min})$ & $0,15 \pm 0,01$ & 0,17 & 0,39 & $0,20 \pm 0,02$ \\
\hline & Ve (l/min) BTPS & $7,97 \pm 0,95$ & 8,5 & 16,4 & $10,27 \pm 0,69$ \\
\hline & $\mathrm{Po}_{2}(\mathrm{mmHg}) \mathrm{STPD}$ & $94,24 \pm 1,2$ & 95 & 102,6 & $106,46 \pm 2,06$ \\
\hline & $\mathrm{PCO}_{2}(\mathrm{mmHg}) \mathrm{STPD}$ & $38,81 \pm 0,57$ & 38,76 & 39,52 & $34,51 \pm 0,6$ \\
\hline & FC (bpm) & $72,35 \pm 3,81$ & 78 & 98 & $83,95 \pm 3,53$ \\
\hline & $\mathrm{Pa}$ (mmHg) & 110x74 & \multicolumn{2}{|c|}{ 120x82 } & $110 \times 70$ \\
\hline \multirow{7}{*}{7} & $\mathrm{VO}_{2}(\mathrm{l} / \mathrm{min})$ & $0,1 \pm 0,01$ & 0,1 & 0,32 & $0,15 \pm 0,03$ \\
\hline & $\mathrm{VCO}_{2}(\mathrm{l} / \mathrm{min})$ & $0,08 \pm 0,01$ & 0,08 & 0,29 & $0,12 \pm 0,03$ \\
\hline & Ve (l/min) BTPS & $9,4 \pm 0,83$ & 9,2 & 15,3 & $10,98 \pm 1,46$ \\
\hline & $\mathrm{Po}_{2}(\mathrm{mmHg}) \mathrm{STPD}$ & $106,80 \pm 1,79$ & 107,92 & 113,20 & $111,48 \pm 1,61$ \\
\hline & $\mathrm{PcO}_{2}(\mathrm{mmHg}) \mathrm{STPD}$ & $30,75 \pm 0,58$ & 30,40 & 29,64 & $27,50 \pm 0,88$ \\
\hline & FC (bpm) & $51,22 \pm 2,1$ & 51 & 73 & $52,28 \pm 2,87$ \\
\hline & $\mathrm{Pa}(\mathrm{mmHg})$ & 90x60 & \multicolumn{2}{|c|}{ 120x70 } & 110x70 \\
\hline \multirow{7}{*}{10} & $\mathrm{VO}_{2}(\mathrm{l} / \mathrm{min})$ & $0,14 \pm 0,01$ & 0,13 & 0,35 & $0,11 \pm 0,01$ \\
\hline & $\mathrm{VCO}_{2}(\mathrm{l} / \mathrm{min})$ & $0,09 \pm 0,01$ & 0,09 & 0,29 & $0,09 \pm 0,01$ \\
\hline & Ve (l/min) BTPS & $7,28 \pm 0,67$ & 8,5 & 15 & $10,1 \pm 1,07$ \\
\hline & $\mathrm{Po}_{2}(\mathrm{mmHg}) \mathrm{STPD}$ & $87,96 \pm 2,19$ & 88,16 & 100,32 & $105,11 \pm 0,7$ \\
\hline & $\mathrm{PcO}_{2}(\mathrm{mmHg}) \mathrm{STPD}$ & $38,39 \pm 0,61$ & 38 & 35,72 & $32,03 \pm 0,42$ \\
\hline & FC (bpm) & $71,65 \pm 3,92$ & 70 & 105 & $88,77 \pm 4,59$ \\
\hline & $\mathrm{Pa}$ (mmHg) & $90 \times 60$ & \multicolumn{2}{|c|}{ 120x70 } & $100 \times 65$ \\
\hline
\end{tabular}


TABELA 7 - Média e desvio padrão das variáveis cardio-respiratórias durante o repouso e recuperação. Valores iniciais e de pico do aumento linear durante a EENM e FC registrada por ECG.

\begin{tabular}{|c|c|c|c|c|c|}
\hline \multirow[b]{2}{*}{ Pacientes } & \multirow[b]{2}{*}{$\begin{array}{c}\text { Variáveis } \\
\text { Cardio-respiratórias }\end{array}$} & \multicolumn{4}{|c|}{ EENM } \\
\hline & & Repouso & $\begin{array}{l}\text { Valores } \\
\text { Iniciais }\end{array}$ & $\begin{array}{l}\text { Valores } \\
\text { de Pico }\end{array}$ & Recuperação \\
\hline \multirow{7}{*}{3} & $\mathrm{VO}_{2}(\mathrm{l} / \mathrm{min})$ & $0,20 \pm 0,02$ & 0,21 & 0,40 & $0,32 \pm 0,06$ \\
\hline & $\mathrm{VCO}_{2}(\mathrm{l} / \mathrm{min})$ & $0,15 \pm 0,02$ & 0,15 & 0,39 & $0,28 \pm 0,06$ \\
\hline & Ve (l/min) BTPS & $9,67 \pm 0,78$ & 9,20 & 19,20 & $12,94 \pm 2,20$ \\
\hline & $\mathrm{Po}_{2}(\mathrm{mmHg}) \mathrm{STPD}$ & $96,52 \pm 3,98$ & 95 & 104,12 & $105,74 \pm 3,10$ \\
\hline & $\mathrm{PCO}_{2}(\mathrm{mmHg}) \mathrm{STPD}$ & $36,29 \pm 0,84$ & 37,24 & 34,96 & $32,02 \pm 1,06$ \\
\hline & FC (bpm) & $78,04 \pm 1,32$ & 78 & 105 & $84,07 \pm 3,40$ \\
\hline & $\mathrm{Pa}(\mathrm{mmHg})$ & 110x70 & \multicolumn{2}{|c|}{ 150x80 } & 130x75 \\
\hline \multirow{7}{*}{4} & $\mathrm{VO}_{2}(\mathrm{l} / \mathrm{min})$ & $0,18 \pm 0,03$ & 0,16 & 0,84 & $0,14 \pm 0,03$ \\
\hline & $\mathrm{VCO}_{2}(\mathrm{l} / \mathrm{min})$ & $0,14 \pm 0,02$ & 0,13 & 0,75 & $0,12 \pm 0,02$ \\
\hline & Ve (l/min) BTPS & $8,50 \pm 0,92$ & 9,2 & 26,8 & $10,56 \pm 0,85$ \\
\hline & $\mathrm{Po}_{2}$ (mmHg) STPD & $94,11 \pm 1,96$ & 95,76 & 98,04 & $103,69 \pm 1,59$ \\
\hline & $\mathrm{PCO}_{2}(\mathrm{mmHg}) \mathrm{STPD}$ & $39,83 \pm 1,04$ & 38 & 44,84 & $35,43 \pm 0,67$ \\
\hline & FC (bpm) & $71,8 \pm 3,25$ & 75 & 94 & $91,68 \pm 5,88$ \\
\hline & $\mathrm{Pa}(\mathrm{mmHg})$ & 125x80 & \multicolumn{2}{|c|}{$135 \times 70$} & $125 \times 75$ \\
\hline \multirow{7}{*}{6} & $\mathrm{VO}_{2}(\mathrm{l} / \mathrm{min})$ & $0,16 \pm 0,02$ & 0,16 & 0,36 & $0,15 \pm 0,02$ \\
\hline & $\mathrm{VCO}_{2}(\mathrm{l} / \mathrm{min})$ & $0,12 \pm 0,01$ & 0,13 & 0,34 & $0,12 \pm 0,01$ \\
\hline & Ve (l/min) BTPS & $11,22 \pm 1,1$ & 11 & 18,8 & $11,16 \pm 0,66$ \\
\hline & $\mathrm{Po}_{2}$ (mmHg) STPD & $106,28 \pm 1,36$ & 106,4 & 112,48 & $109,93 \pm 0,74$ \\
\hline & $\mathrm{PCO}_{2}(\mathrm{mmHg}) \mathrm{STPD}$ & $30,34 \pm 0,84$ & 30,4 & 29,64 & $28,48 \pm 0,45$ \\
\hline & FC (bpm) & $81,57 \pm 1,71$ & 61 & 75 & $80,2 \pm 2,78$ \\
\hline & $\mathrm{Pa}(\mathrm{mmHg})$ & $100 \times 65$ & \multicolumn{2}{|c|}{$145 \times 75$} & $115 \times 70$ \\
\hline
\end{tabular}




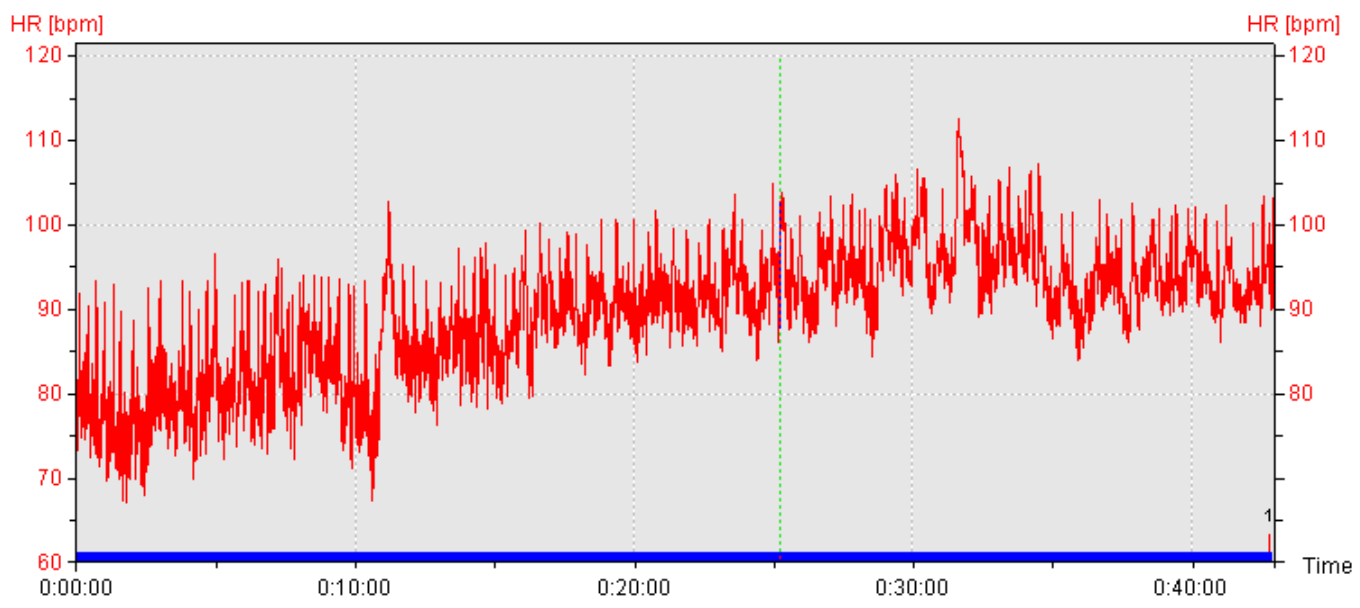

(a)

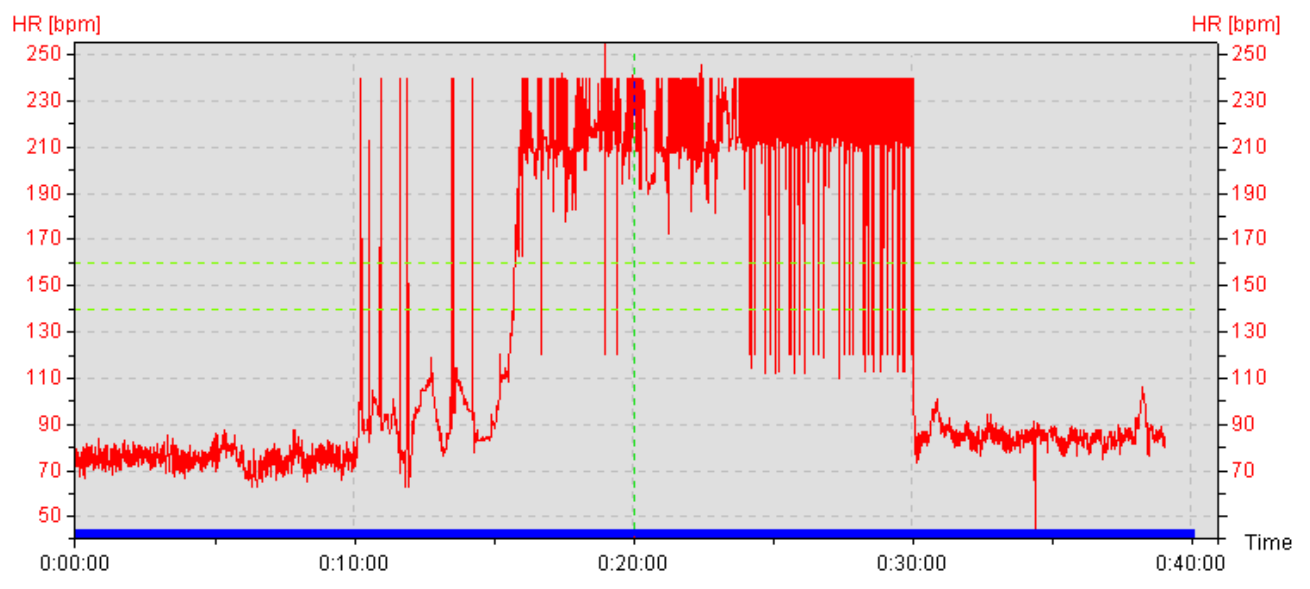

(b)

FIGURA 18 - Respostas da FC com o Polar (a) e ruídos presentes nos resultados da FC (b). 


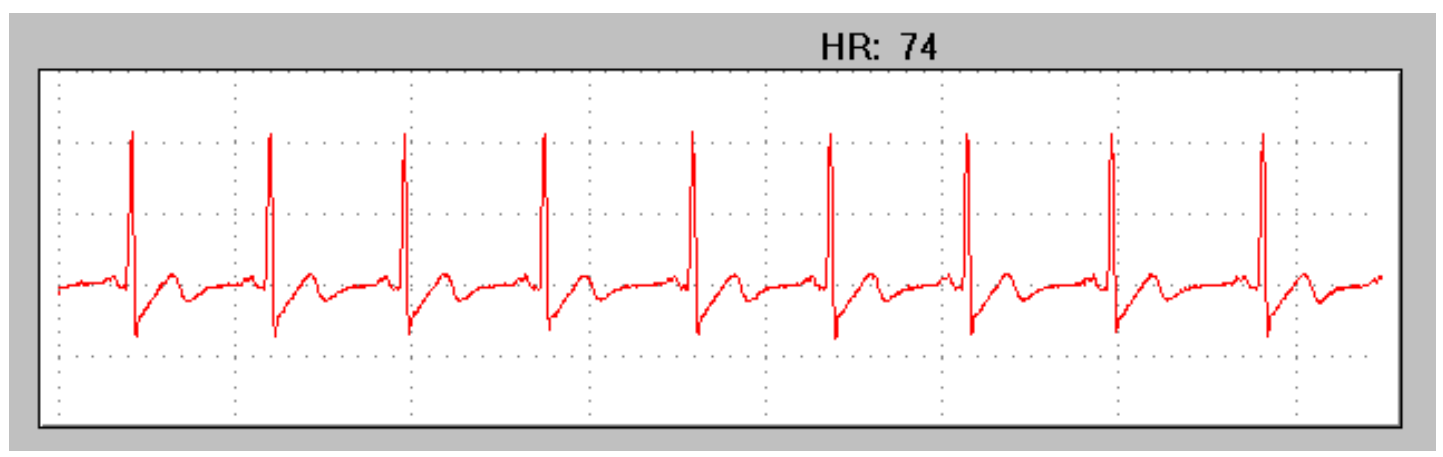

(a)

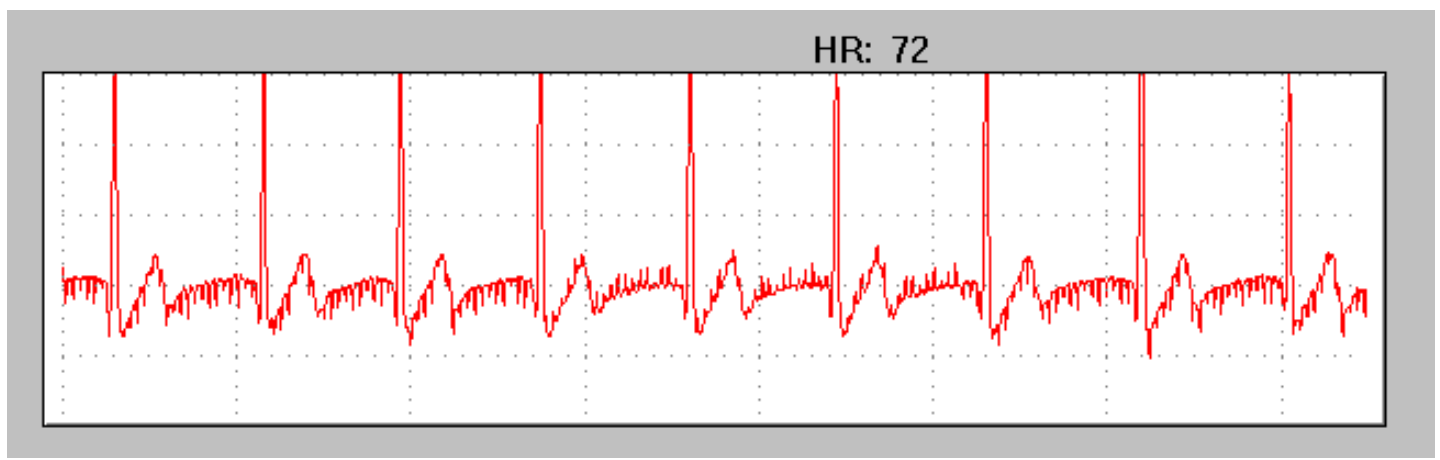

HR: 112

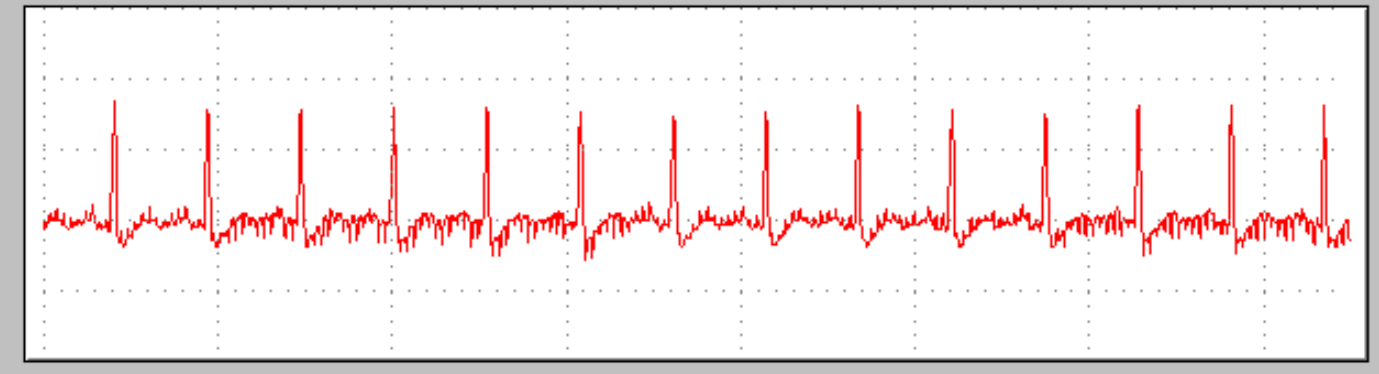

(b)

FIGURA 19 - Sinais do ECG durante o repouso (a) e EENM (b).

Os valores inferiores das variáveis cardio-respiratórias de alguns pacientes, durante o repouso estão relacionados com a disfunção simpática e somática abaixo do nível de lesão (INOUE et al., 1995); (THEISEN et al., 2001). Entretanto, foi 
constatado na maioria dos pacientes avaliados o aumento da FC e Pa durante a EENM, que estão relacionados aos benefícios hemodinâmicos, como a ativação da bomba muscular esquelética, que aumenta o retorno venoso e a eficiência cardíaca, segundo a Lei de Frank Starling (HOPMAN et al., 1998). O aumento das FC também sugere ação do feedback humoral (KJAER et al., 1999). O aumento da Pa e a bradicardia do paciente 3 no final da EENM e do paciente 6 no início da EENM, pode estar relacionado com o aumento do retorno venoso, que resulta em efeito de Starling, com aumento da pressão sangüínea e ativação do reflexo baroceptor, com conseqüente bradicardia (ELOKDA, NIELSEN \& SHIELDS, 2000).

Durante a EENM do quadríceps houve o aumento linear dos parâmetros ventilatórios na maioria dos pacientes, o que indica realização de exercício exaustivo. O aumento linear durante cargas constantes reflete a predominância da via anaeróbica lática. Quando o regime permanente é atingido, ocorre a predominância da via aeróbica, demonstrando bom condicionamento (McARDLE, KATCH \& KATCH, 1991); (WILMORE \& COSTILL, 1994).

Foram também constatados valores alterados da $\mathrm{Po}_{2}$ e $\mathrm{Pco}_{2}$ que indicam estado de exaustão.

Portanto, os resultados encontrados na maioria destes pacientes indicam a realização de exercício exaustivo, entretanto os pacientes apresentaram tolerância ao exercício induzido artificialmente possivelmente devido aos benefícios da EENM, como a ativação de grupos musculares paralisados, que favorece o retorno venoso, a eficiência cardíaca, a ação dos fatores humorais, além de um possível mecanismo compensatório de utilização do ácido lático como fonte de energia, que resultam no aumento da resistência à fadiga (JACOBS \& MAHONEY, 2002).

Em relação aos métodos de monitoração da FC, o uso do Polar é questionável, devido a presença de ruído, que resulta em leitura desordenada da FC durante a EENM, enquanto o ECG permite mais possibilidades quanto a definição das derivações para evitar o ruído e filtragem dos sinais.

Provavelmente, com o uso do ECG durante a EENM, houve a filtragem do complexo QRS permitindo o registro da FC, entretanto as ondas P e T mostraram bastante ruído. 
Ainda, é importante ressaltar que alguns pacientes possuem hastes metálicas, pinos e até balas de arma de fogo alojadas no corpo, o que pode distorcer o sinal.

Morh et al. (1996) constatou o padrão de estimulação refletido nos sinais obtidos por Eletrocardiograma, alterando os resultados da FC em portadores de lesão medular, enquanto com o método de mensuração de pulso por absorção de luz, isto não ocorreu.

Diante destes problemas, Jacobs e Mahoney (2002), optaram pelo método palpatório durante as avaliações. Entretanto, não é um método científico.

Então, questiona-se a fidedignidade dos resultados da FC encontrados na literatura que utilizaram os métodos citados.

A mensuração da FC realmente se constitui em um problema metodológico durante a EENM.

Entretanto, durante os atendimentos ambulatoriais do Programa de EENM, a resposta da FC de 10 pacientes (8 paraplégicos e 2 tetraplégicos) foi registrada durante a marcha com EENM, utilizando o Polar, e não apresentaram ruído com conseqüente leitura desordenada (os resultados são mostrados na Tabela 8 e exemplificado na Figura 20). O registro da FC por ECG durante a postura ereta e marcha com EENM também não apresentou ruído e pode ser exemplificado na Figura 21-c.

TABELA 8 - Valores de pico da FC obtidos por paraplégicos e tetraplégicos durante a marcha com EENM.

\begin{tabular}{ccc}
\hline \multicolumn{2}{c}{ Pacientes } & $\mathrm{FC}_{\text {pico }}(\mathrm{bpm})$ \\
\hline & Paciente 1 & 145 \\
& Paciente 2 & 190 \\
& Paciente 3 & 140 \\
Paraplegia & Paciente 6 & 150 \\
& T5 & 155 \\
& T5-T6 & 170 \\
& T10 & 140 \\
Tetraplegia & T11-T12 & 160 \\
& C7 & 120 \\
& C7 & 120 \\
\hline
\end{tabular}


Observa-se que todos os pacientes apresentaram aumento da FC e que os valores de $\mathrm{FC}_{\text {pico }}$ nos tetraplégicos foram inferiores comparados aos dos paraplégicos. Ainda, os pacientes 1, 3 e 6 que apresentaram limitações na resposta da FC durante a EENM do quadríceps, apresentaram aumento da FC durante a marcha, necessitando de maiores investigações sobre os efeitos do esforço dos membros superiores no andador e sobre a mudança postural e equilíbrio corpóreo.

Sugere-se então, a realização de testes em diferentes protocolos, por exemplo durante a mudança postural com e sem EENM, exercício com o cicloergômetro de braço com e sem EENM nos membros inferiores e durante a marcha com e sem EENM juntamente com o Sistema de Suspensão Corpórea. Ainda, necessita-se de maiores conhecimentos sobre os valores máximos de $\mathrm{VO}_{2}$ e $\mathrm{FC}$ nestes pacientes, e portanto, testes de esforço devem ser realizados. 


\section{Apêndice B}

\section{INFORMAÇÕES COMPLEMENTARES REFERENTES AOS ESTUSDOS DE CASO}

No Programa de EENM os pacientes não são instruídos a tomarem medicamentos ou realizarem procedimentos, como o implante de células tronco, que objetivam a recuperação neurológica. O objetivo atual do Programa é a restauração dos movimentos por EENM para o treinamento da marcha de paraplégicos e tetraplégicos, além da realização de atividades funcionais com os membros superiores de tetraplégicos, que resultam em recuperação neurológica.

Pelo desconhecimento dos efeitos colaterais dos novos procedimentos que objetivam a recuperação neurológica, por exemplo, o medicamento 4 AP (Amino Piridina, bloqueador de $\mathrm{K}^{+}$), o paciente 2 realizou várias avaliações cardiorespiratórias no período de Julho de 2003 à Abril de 2004, pois em Setembro de 2003 foi o último mês em que tomou 4 AP, e as doses foram prescritas gradativamente.

A primeira avaliação, em Julho de 2003, foi realizada durante a EENM do quadríceps, com FC monitorada por Polar S810 e pode ser observada no estudo piloto (FIGURAS 16-a e 18-a, bem como na TABELA 5).

Posteriormente, em agosto de 2003, foi utilizado o Polar S810 para avaliação da Freqüência Cardíaca (FC) durante o treinamento da marcha com EENM, no qual o paciente caminhou 6 metros por 5 vezes com intervalos de recuperação e observouse valores de pico de 190 bpm (FIGURA 20). 
Em Setembro de 2003, foi realizada avaliação cardio-respiratória durante a EENM do quadríceps, com a FC monitorada por ECG. Os resultados podem ser visualizados na Figura 6, bem como, na Tabela 3.

Em Outubro de 2003, foi realizada outra avaliação durante a postura ereta e marcha com EENM. O protocolo utilizado consistiu em 5 minutos de repouso; 2 minutos na postura ereta; 4 minutos de recuperação; 4 minutos na postura ereta; 4 minutos de recuperação; 3 metros caminhando; 4 minutos de recuperação; 6 metros caminhando e; 10 minutos de recuperação. O resultados são mostrados na Figura 21. O valore da $\mathrm{Pa}$ (mmHg) durante o repouso foi de 120x80; durante a EENM, 170x70 e; na recuperação, 130x90.

Em abril de 2004, foi realizada a reavaliação cardio-respiratória durante a EENM do quadríceps, com a FC monitorada por ECG (FIGURA 22). O valor da Pa (mmHg) durante o repouso foi de 120x75; durante a EENM foi de 135x70 e; na recuperação foi de $120 \times 75$.

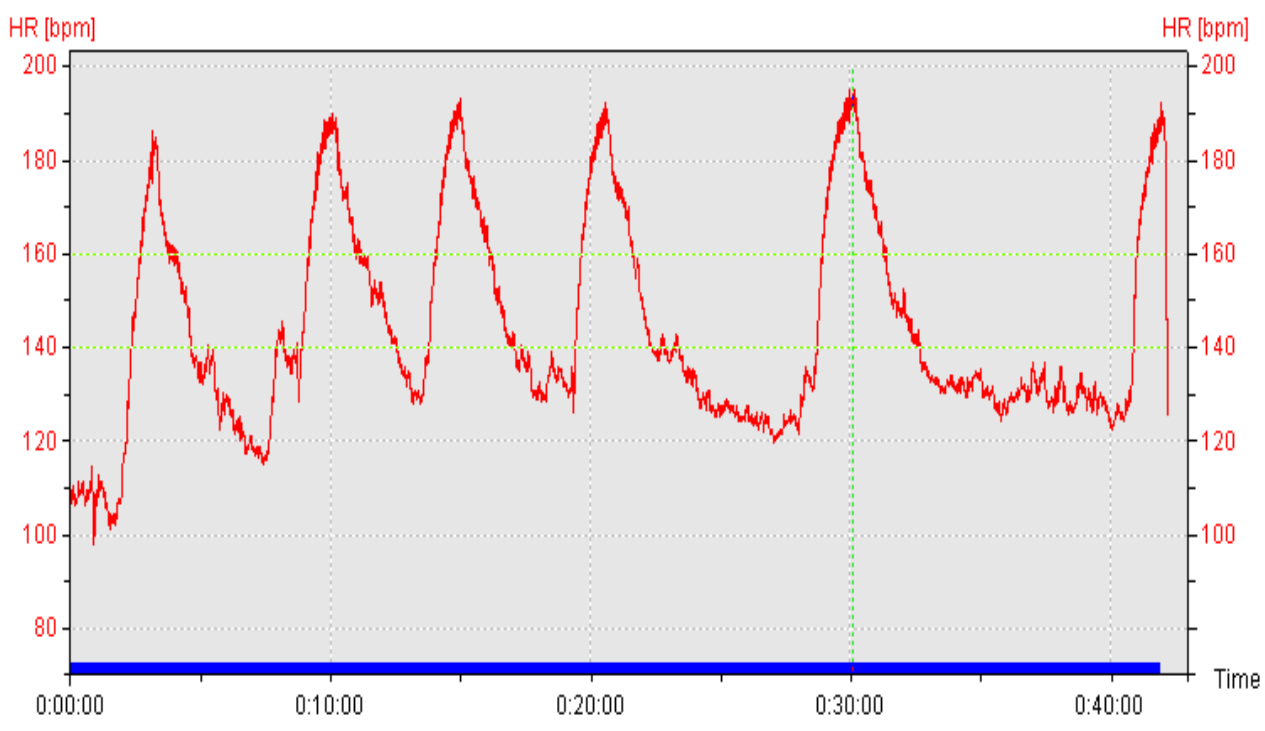

FIGURA 20: Resposta da FC, por Polar, durante a Marcha com EENM. 


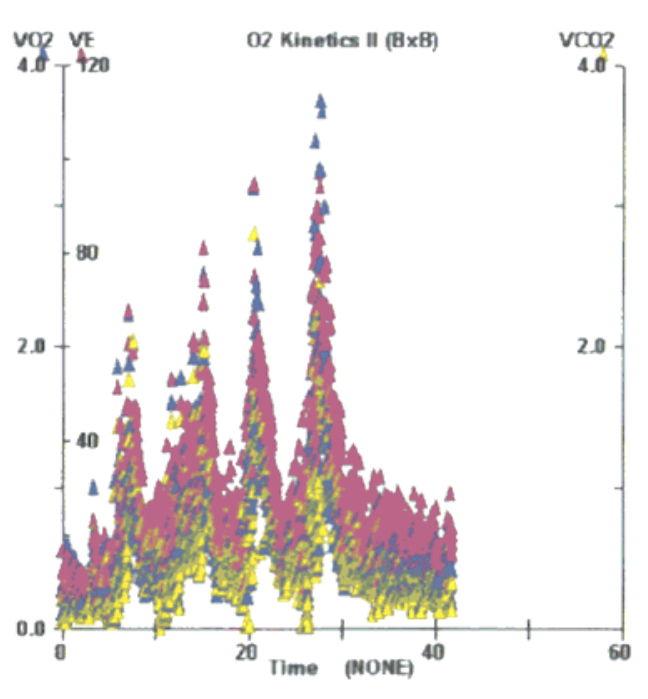

(a)

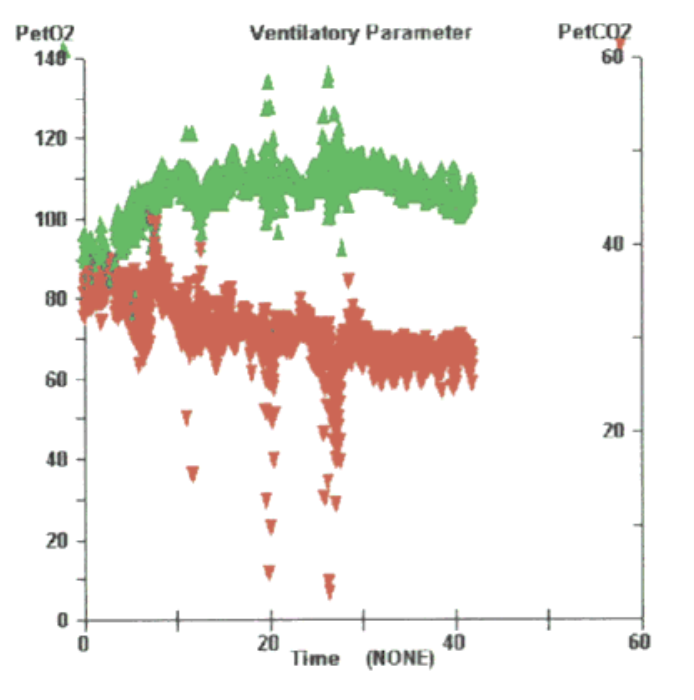

(b)

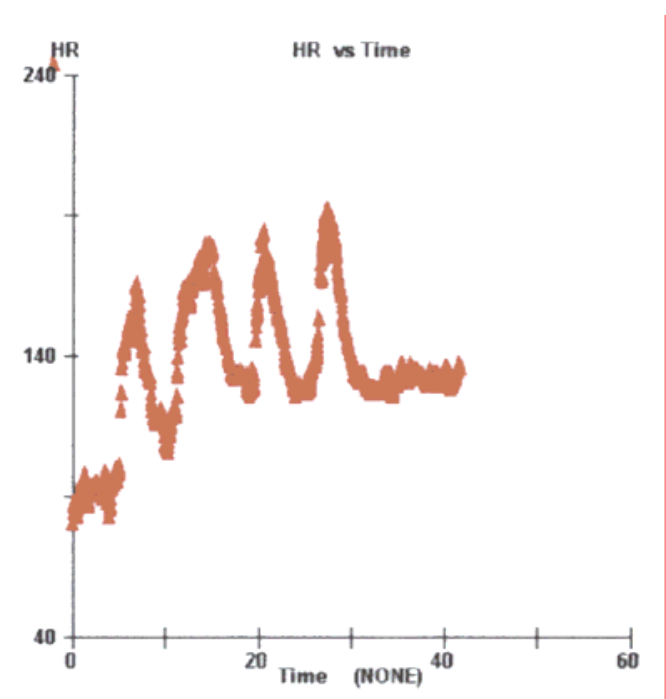

(c)

FIGURA 21: Respostas cardio-respiratórias durante a postura ereta e marcha: cinética dos gases (a); pressão parcial de $\mathrm{O}_{2}$ e $\mathrm{CO}_{2}$ (b); resposta da FC por ECG (c). 


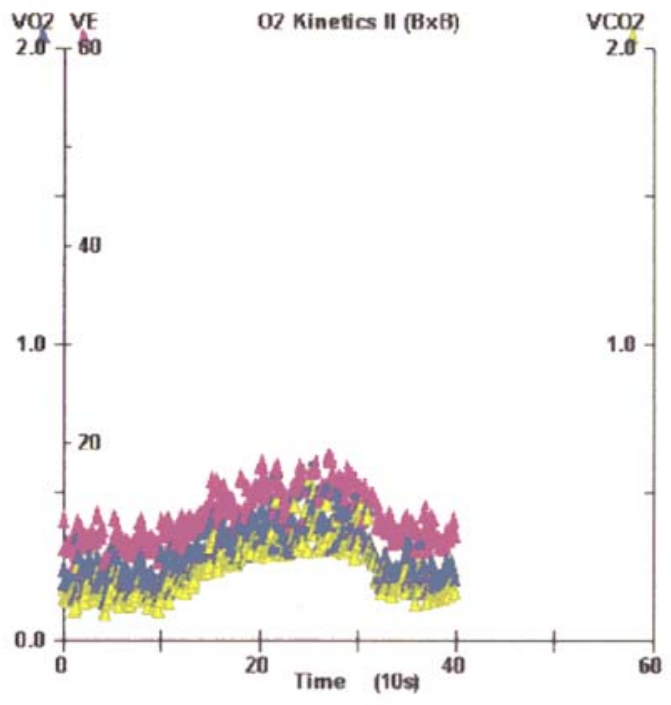

(a)

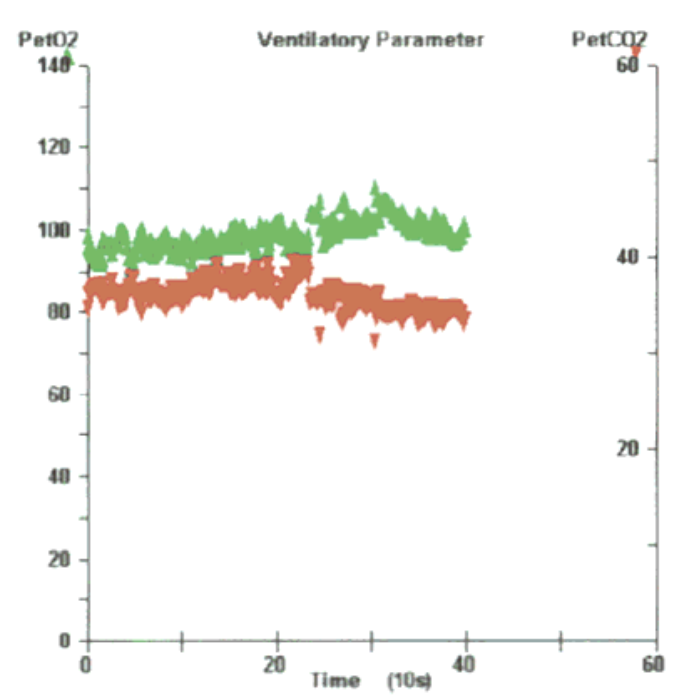

(b)

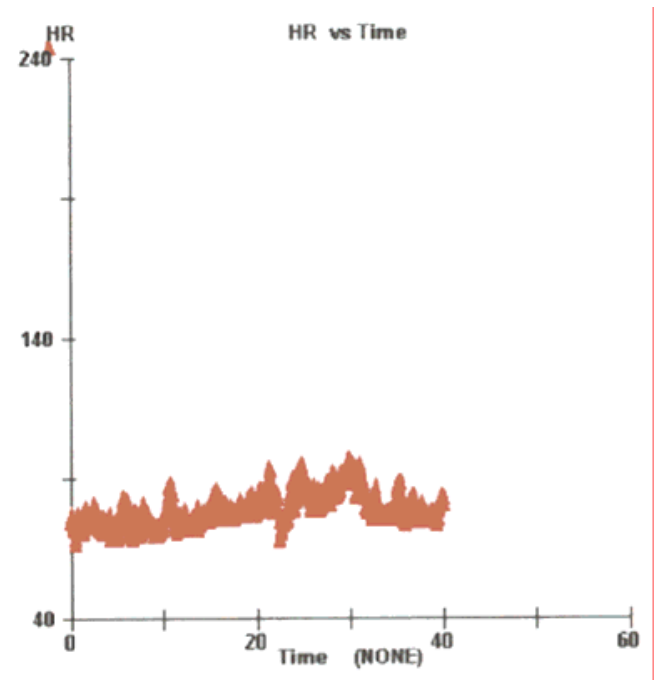

(c)

FIGURA 22: Respostas cardio-respiratórias durante a EENM do quadríceps: cinética dos gases (a); pressão parcial de $\mathrm{O}_{2}$ e $\mathrm{CO}_{2}$ (b); resposta da FC por ECG (c). 
Durante a postura ereta e marcha com EENM, o paciente se exercitou em altos níveis cardio-respiratórios, que podem estar relacionados com a mudança postural, esforço dos membros superiores, bem como, com a fase de flexão/extensão do joelho e reequilíbrio postural (CLIQUET, BAXENDALE \& ANDREWS, 1989); (NENE \& PATRICK, 1990). Estes dados são semelhantes aos encontrados por Jacobs e Mahoney (2002) durante os testes de esforço em marcha assistida por EENM e também com o uso do cicloergômetro de braço.

O paciente paraplégico ainda apresentava capacidade de realização de atividade motora mesmo se exercitando em altos níveis cardio-respiratórios, mas o teste foi cessado como o planejado.

Entretanto, em Abril de 2004, após 7 meses sem tomar o 4 AP, o paciente apresentou valores dos parâmetros cardio-respiratórios inferiores comparados aos das outras avaliações.

Em relação ao paciente 3, ele parou de tomar 4 AP em Setembro de 2002 e fez implante de células tronco em Abril de 2003. Os resultados das avaliações cardio-respiratórias mostram que as técnicas utilizadas não apresentaram efeitos benéficos ou maléficos sobre as variáveis cardio-respiratórias. A mudança na cinética dos gases (FIGURA 17-a e FIGURA 7-a), provavelmente é decorrente do período de 6 meses de treinamento com EENM, como o observado nos pacientes 4, 5, 6, 7 e 10 que não realizaram o implante de células tronco e não tomaram o 4 AP. 


\section{Apêndice C}

\section{RESULTADOS DO SUJEITO SAUDÁVEL}

O sujeito saudável, voluntário padrão, que realiza atividade física uma vez por semana, do sexo masculino, com 25 anos de idade, cujos valores de altura e massa corpórea são respectivamente, 179 cm e $84 \mathrm{Kg}$, realizou o mesmo protocolo que os pacientes, mas os movimentos de flexão e extensão dos joelhos foram realizados voluntariamente.

O protocolo do teste consistiu em 10 minutos de repouso, 20 minutos de flexão e extensão dos joelhos direito/esquerdo (contração isotônica concêntrica) e 10 minutos de recuperação em repouso.

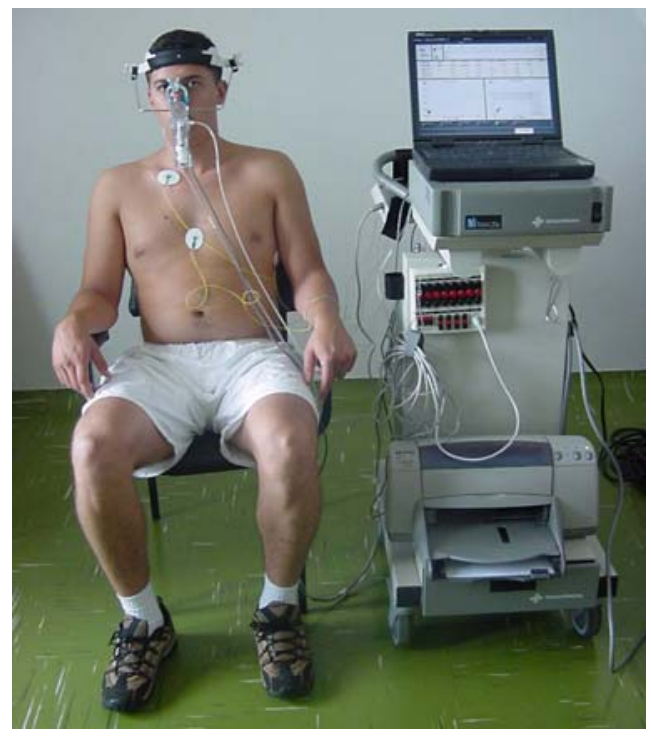

FIGURA 24 - Procedimento experimental com o sujeito saudável. 
O sujeito saudável, durante o repouso mostrou valores de $\mathrm{VO}_{2}(\mathrm{l} / \mathrm{min}): 0,37 \pm$ 0,04; $\mathrm{VCO}_{2}$ (l/min): 0,27 \pm 0,03; Ve (l/min): 10,83 \pm 1,52; FC (bpm): 78,10 \pm 5,54 e; Pa (mmHg): 120x80.

Durante a flexão e extensão voluntária dos joelhos, a cinética dos gases $\left[\mathrm{VO}_{2}\right.$ (l/min): 0,94 \pm 0,23; $\left.\operatorname{VCO}_{2}(\mathrm{l} / \mathrm{min}): 0,75 \pm 0,16 ; \mathrm{Ve}(\mathrm{l} / \mathrm{min}): 24,74 \pm 4,60\right]$ e a resposta da FC (103,47 \pm 4,60 bpm) mostraram que o regime permanente foi atingido rapidamente nos primeiros três minutos de exercício (FIGURA 24-a e 24-c). A Po apresentou valores inferiores e constantes, enquanto a $\mathrm{Pco}_{2}$ aumentou e também se manteve constante (FIGURA 24-b). Foi constatado o aumento da Pa sistólica e a redução da Pa diastólica (TABELA 9).

No início da recuperação o $\mathrm{VO}_{2}, \mathrm{VCO}_{2}$ e Ve atingiram o platô rapidamente com valores do período de repouso. Os valores de FC foram constantes e maiores comparados ao repouso, enquanto a Pa retornou aos valores de repouso.

Os valores de média e desvio padrão obtidos das variáveis cardiorespiratórias durante as fases de transição do teste são mostrados na Tabela 9.

TABELA 9 - Média e desvio padrão das variáveis cardio-respiratórias durante o repouso, exercício de flexão/extensão de joelhos e recuperação - sujeito saudável.

\begin{tabular}{clccc}
\hline $\begin{array}{c}\text { Sujeito } \\
\text { Padrão }\end{array}$ & \multicolumn{1}{c}{$\begin{array}{c}\text { Variáveis } \\
\text { Cardio-respiratórias }\end{array}$} & Repouso & Exercício & Recuperação \\
\hline & $\mathrm{VO}_{2}(\mathrm{l} / \mathrm{min})$ & $0,37 \pm 0,04$ & $0,94 \pm 0,23$ & $0,30 \pm 0,03$ \\
& $\mathrm{VCO}_{2}(\mathrm{l} / \mathrm{min})$ & $0,27 \pm 0,03$ & $0,75 \pm 0,16$ & $0,24 \pm 0,03$ \\
& $\mathrm{Ve}(\mathrm{l} / \mathrm{min}) \mathrm{BTPS}$ & $10,83 \pm 1,52$ & $26,74 \pm 4,60$ & $11,96 \pm 1,62$ \\
Saudável & $\mathrm{Po}_{2}(\mathrm{mmHg}) \mathrm{STPD}$ & $92,11 \pm 3,80$ & $91,14 \pm 3,31$ & $98,57 \pm 1,82$ \\
& $\mathrm{PcO}_{2}(\mathrm{mmHg}) \mathrm{STPD}$ & $38,91 \pm 1,78$ & $42,35 \pm 1,71$ & $37,31 \pm 0,75$ \\
& $\mathrm{FC}(\mathrm{bpm})$ & $78,10 \pm 5,54$ & $103,47 \pm 4,60$ & $81,87 \pm 4,60$ \\
& $\mathrm{~Pa}(\mathrm{mmHg})$ & $120 \times 80$ & $135 \times 75$ & $120 \times 80$ \\
\hline
\end{tabular}




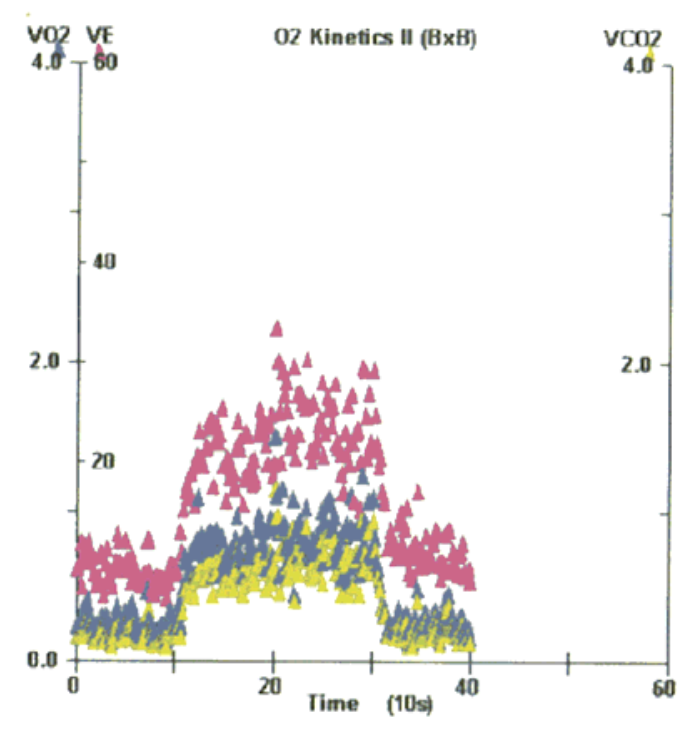

(a)

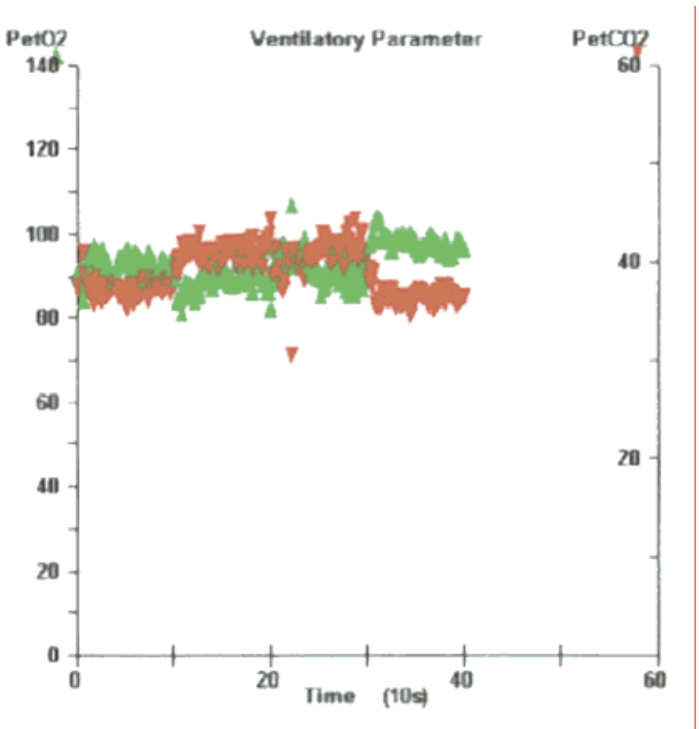

(b)

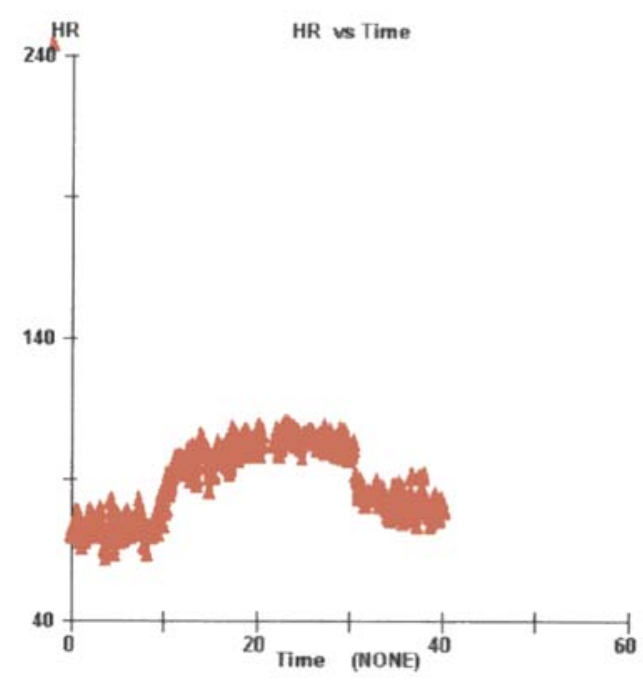

(c)

FIGURA 24 - Variáveis cardio-respiratórias do sujeito saudável durante o repouso, flexão e extensão do joelho e recuperação: cinética dos gases (a); $\mathrm{Po}_{2}$ e $\mathrm{Pco}_{2}$ (b); resposta da FC (c). 


\section{Apêndice D}

\section{REFLEXOS INTERMEMBROS EM TETRAPLEGIA}

Para verificar se houve a presença de reflexos intermembros (reflexo de interconexão entre os membros superiores e inferiores em tetraplégicos) foi utilizada a EENM dos nervos fibulares dos membros inferiores direito e esquerdo, alternadamente (durante 15 minutos) e obtida a atividade muscular dos membros superiores em repouso através de eletromiografia (EMG). Os sinais mioelétricos dos membros superiores (flexores do punho direito e esquerdo; extensores do punho direito e esquerdo; abdutor do polegar direito e esquerdo; adutor do dedo mínimo direito e esquerdo) foram captados por meio de eletrodos de superfície ativos diferenciais com ganho de 20 vezes (PA602 da empresa Linx Tecnologia Eletrônica LTDA), em seguida o sinal foi amplificado mais 50 vezes em uma placa condicionadora de sinais (MCS 1000-V2 da Linx) totalizando um ganho de 1000 vezes, nesta placa os sinais passaram ainda por filtros passa alta de $20 \mathrm{~Hz}$ e passa baixa de $500 \mathrm{~Hz}$. Este sinal foi então digitalizado por uma placa conversora analógico/digital de 12 bits (CAD 1256 também da Linx) a uma taxa de amostragem de $4000 \mathrm{~Hz}$. O software de aquisição de dados foi o AqDados versão 5.0 confeccionado pela mesma empresa. Foram obtidos sinais mioelétricos pelo período de um minuto antes de iniciar a EENM e durante a EENM (depois de transcorridos 5 minutos de estimulação). O procedimento experimental pode ser visualizado na Figura 25-a.

Alguns dos pacientes tetraplégicos que fazem parte do Programa de EENM apresentaram atividade mioelétrica dos membros superiores durante a EENM dos 
membros inferiores e pode ser exemplificada pela resposta do paciente 10 , como mostra a Figura 25-b.

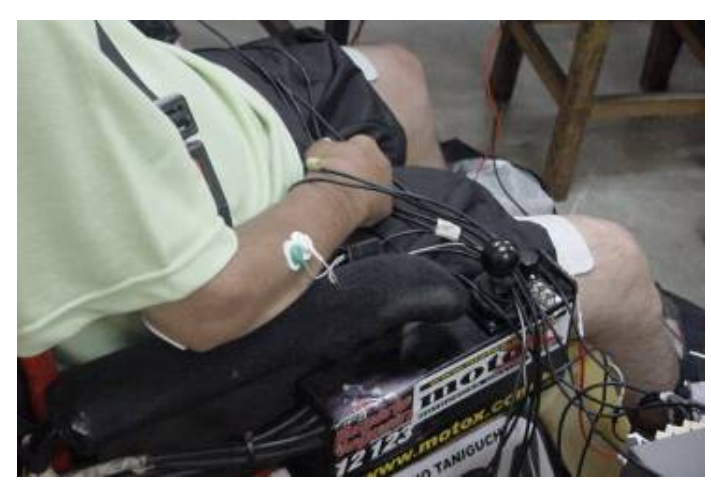

(a)
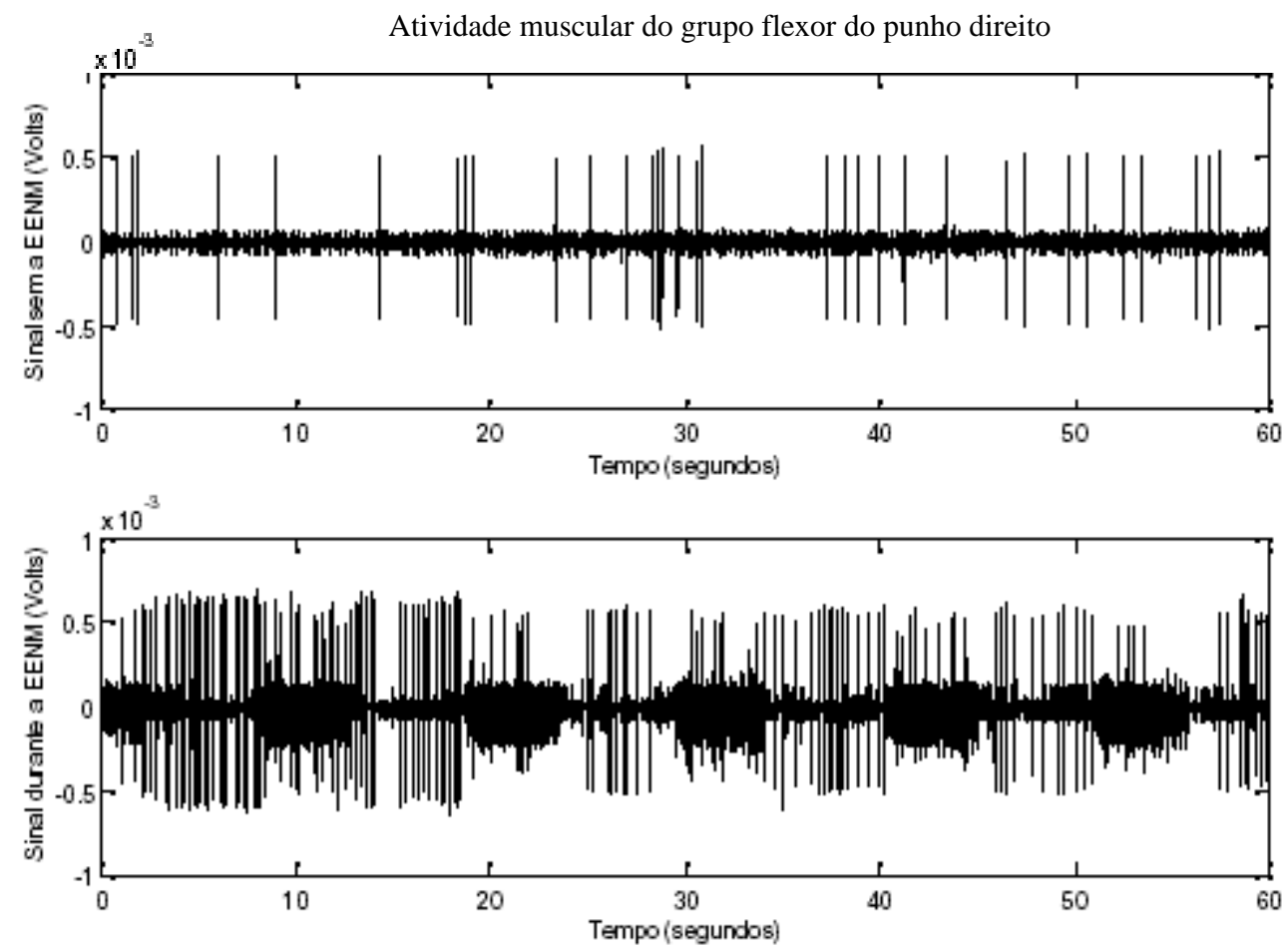

(b)

FIGURA 25: Procedimento experimental em neurofisiologia (a) e atividade muscular do grupo flexor do punho direito do paciente 10 sem e com a EENM (b). 
A atividade muscular nos membros superiores do paciente 10 indica possivelmente a presença de reflexos intermembros. Estes reflexos consistem em respostas motoras nos músculos distais dos membros superiores evocadas por estimulação de nervos periféricos mistos dos membros inferiores (CALANCIE 1991); (CALANCIE; LUTTON \& BROTON, 1996). Estas respostas evocadas podem ser ipslateral, contralateral ou ambos em cada paciente com lesão medular (CALANCIE, MOLANO \& BROTON, 2002); (ERTEKIN et al., 2002). A presença do reflexo intermembros pode ser decorrente de dois fatores:

1) os circuitos interneurais que são pré-existentes e inativos sob condições comuns (sinapses latentes) podem tornar-se funcionais após a lesão neural, ou

2) a presença de novas conexões sinápticas entre as fibras aferentes da extremidade inferior e os motoneurônios- $\alpha$ que inervam os músculos distais dos membros superiores.

Entretanto, os dados obtidos na literatura fundamentam a segunda hipótese, ou seja, ocorre uma reorganização medular caudal ao nível da lesão, com desenvolvimento de novas conexões sinápticas, sugerindo uma possível regeneração da medula (CALANCIE; LUTTON \& BROTON, 1996); (CALANCIE, MOLANO \& BROTON, 2002). Portanto, sugere-se que os resultados obtidos da atividade mioelétrica dos membros superiores deste tetraplégico - reflexo intermembros indicam reorganização dos reflexos, aumento da excitabilidade neural e possível recuperação da função medular, decorrentes dos efeitos terapêuticos do Programa de Estimulação Elétrica Neuromuscular. 
ANEXO A 


\section{Unidade de Reabilitação do Aparelho Locomotor \\ Programa de Estimulação Elétrica Neuromuscular \\ Departamento de Ortopedia e Traumatologia - FCM/UNICAMP}

\section{Termo de Consentimento Pós - Informação}

$\mathrm{Eu}$, portador do RG n ${ }^{\circ}$.

$\mathrm{HC} \mathrm{n}^{\circ}$ , residente à

$\mathrm{N}^{\circ}$. Bairro cidade de

Estado Telefone $\mathrm{n}^{\circ} .0 \mathrm{xx}$ ,nascido aos 1 ,declaro que contatei a Unidade de Reabilitação do Aparelho Locomotor com o intuito de solicitar minha participação no Programa de Estimulação Elétrica Neuromuscular. Nesta Unidade fui devidamente informado(a) sobre o seguinte:

$1^{\circ}$ ) que a estimulação elétrica neuromuscular é um procedimento não invasivo, realizado externamente na pele e, deste modo, não tem efeitos colaterais e não traz qualquer risco para integridade física do lesado medular;

$2^{\circ}$ ) que o objetivo geral do programa é a busca pela restauração dos movimentos dos membros paralisados e a prevenção e/ou redução da osteoporose;

$3^{\circ}$ ) que pesquisadores pós-graduandos desenvolvem projetos de pesquisa específicos dentro do Programa de Estimulação Elétrica Neuromuscular, coordenados pelo Prof. Dr. Alberto Cliquet Jr., e estou devidamente informado(a), segundo as normas e exigências do Comitê de Ética em pesquisa da FCM/UNICAMP que faço parte de um destes projetos;

$4^{\circ}$ ) que poderei, a qualquer momento, retirar-me do programa, sem que com isso venha a prejudicarme nos demais atendimentos do HC/UNICAMP.

Por fim, comprometo-me a informar a equipe sobre todo e qualquer tipo de procedimentos (e/ou tratamentos) externos, concomitantes à estimulação elétrica neuromuscular que são ou que venham a ser realizados no futuro. de de 200

Assinatura ou Impressão digital do paciente
Prof. Dr. Alberto Cliquet Jr.

(Coordenador do Programa)

Assinatura da Testemunha

RG: 
ANEXO B 


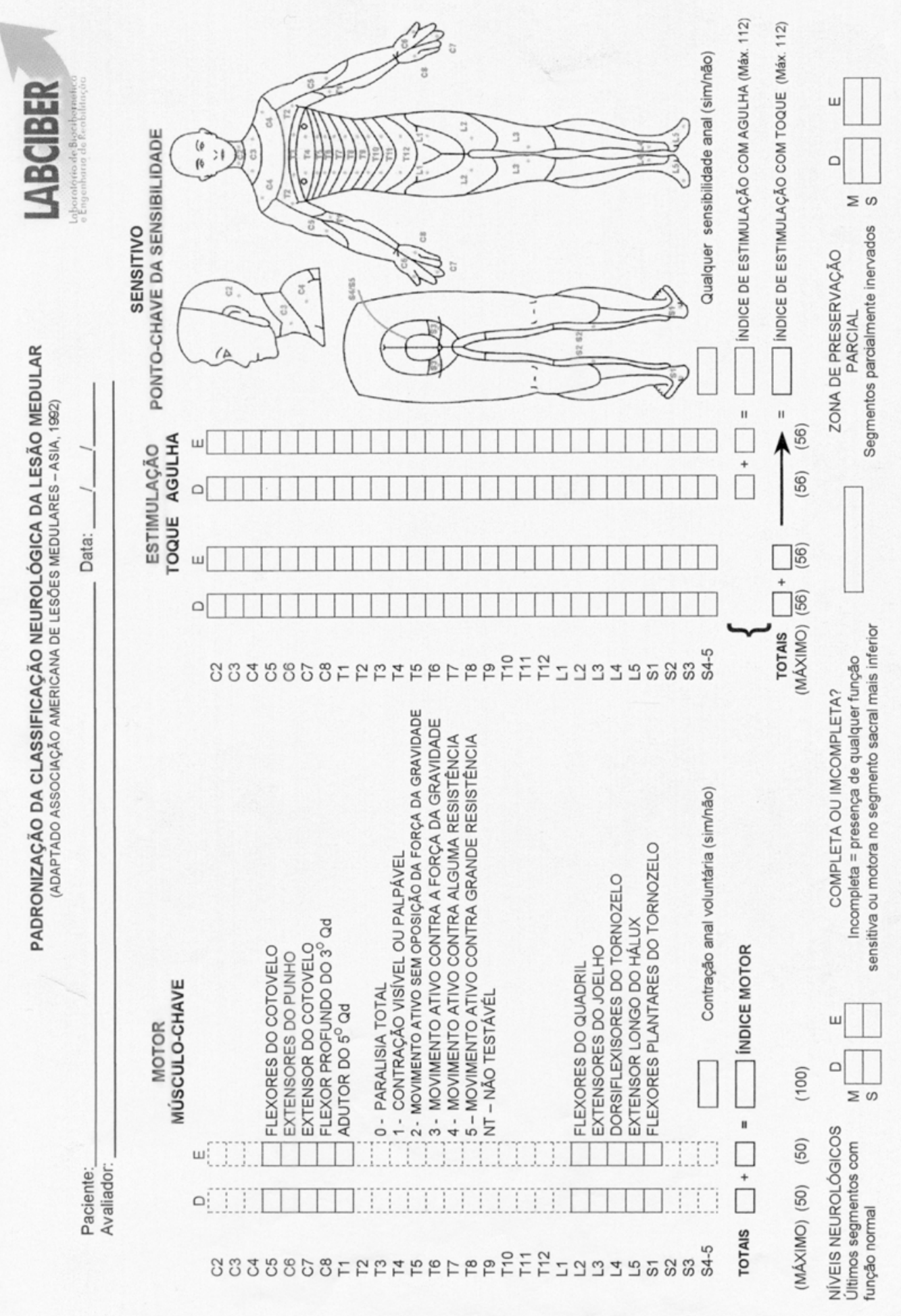




\section{PADRONIZAÇÃO DA CLASSIFICAÇÃO NEUROLÓGICA DA LESÃO MEDULAR \\ (Associação Americana de Lesões Medulares) \\ ÍNDICE DE INDEPENDÊNCIA FUNCIONAL}

Nome:

Data:

Examinador:

\section{CUIDADOS PESSOAIS}
a) alimentação:
b) cuidados com aparência:
c) banhos:
d) vestir parte superior do corpo:
e) vestir parte inferior do corpo:
f) asseio:

\section{CONTROLE DE ESFÍNCTERES}

g) controle vesical:

h) controle de esfíncter anal:

\section{MOBILIDADE/TRANSFERÊNCIA}

i) cama, cadeira, cadeira de rodas:

j) banheiro:

k) banheira, chuveiro:

\section{LOCOMOÇÃO}

l) caminhar, cadeira de rodas:

m) escada:

V. COMUNICAÇÃO

n) compreensão:

o) expressão:

\section{COGNIÇÃO SOCIAL}

p) interação social:

q) solução de problemas:

r) memória: 


\section{NÍVEIS}

\section{COM ASSISTÊNCIA}

\section{DEPENDÊNCIA COMPLETA}

1. Assistência total: indivíduo emprega nessa atividade de 0 a $25 \%$ do esforço necessário

2. Assistência máxima: indivíduo emprega nessa atividade de 25 a $50 \%$ do esforço necessário

\section{DEPENDÊNCIA MODIFICADA}

3. Assistência moderada: indivíduo requer mais que contato físico e emprega nessa atividade de 50 a 75\% do esforço necessário

4. Assistência mínima: com mínimo de contato: indivíduo não requer mais que contato físico e emprega nessa atividade $75 \%$ ou mais do esforço necessário

5. Supervisão: não requer assistência física, porém necessita de estímulos e disposição

\section{SEM ASSISTÊNCIA}

\section{INDEPENDÊNCIA}

6. Independência modificada (aparelhada): a atividade requer apoio assistencial e/ou não um tempo maior para sua execução e/ou se realiza de forma segura

7. Completa independência (imediata, com segurança): a atividade é feita de forma segura, sem modificação, sem órtese ou apoio assistencial e em tempo relativamente razoável 